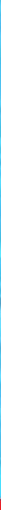

\title{
IntechOpen
}

\section{Perspectives in Water Pollution}

Edited by Imran Ahmad and Mithas Ahmad Dar
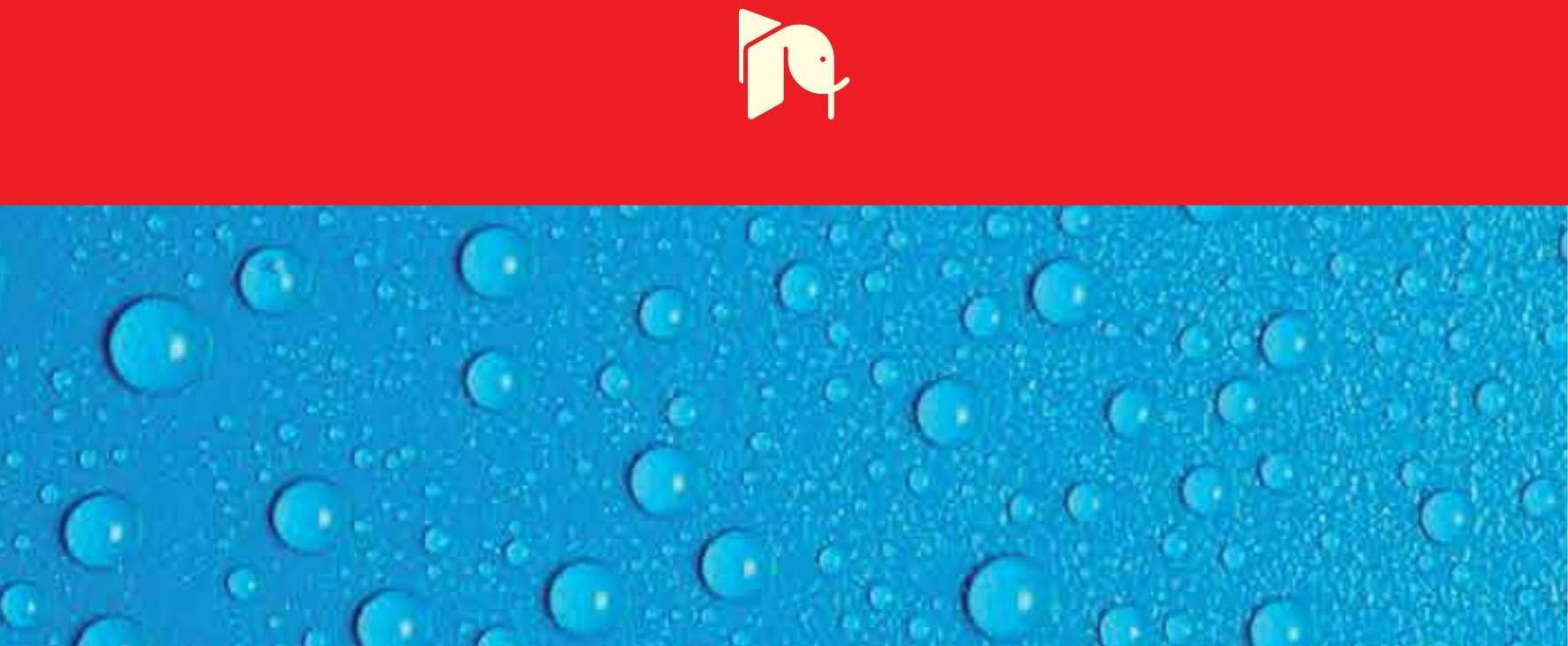



\section{PERSPECTIVES IN WATER POLLUTION}

Edited by Imran Ahmad Dar and Mithas Ahmad Dar 


\section{Perspectives in Water Pollution}

http://dx.doi.org/10.5772/50060

Edited by Imran Ahmad and Mithas Ahmad Dar

\section{Contributors}

Houma Bachari Fouzia, Bernard Thole, Felix Mtalo, Felipe Coutinho, Leonardo Henriques Pinto, Ricardo Vieira, Gigliola Rhayd Boechat Salloto, Orlando Martins, Deborah De Oliveira Santoro, Maysa Clementino, Alexander Cardoso, Usha Damodharan, Imran Ahmad Dar

\section{(c) The Editor(s) and the Author(s) 2013}

The moral rights of the and the author(s) have been asserted.

All rights to the book as a whole are reserved by INTECH. The book as a whole (compilation) cannot be reproduced, distributed or used for commercial or non-commercial purposes without INTECH's written permission. Enquiries concerning the use of the book should be directed to INTECH rights and permissions department (permissions@intechopen.com).

Violations are liable to prosecution under the governing Copyright Law.

\section{(cc) BY}

Individual chapters of this publication are distributed under the terms of the Creative Commons Attribution 3.0 Unported License which permits commercial use, distribution and reproduction of the individual chapters, provided the original author(s) and source publication are appropriately acknowledged. If so indicated, certain images may not be included under the Creative Commons license. In such cases users will need to obtain permission from the license holder to reproduce the material. More details and guidelines concerning content reuse and adaptation can be foundat http://www.intechopen.com/copyright-policy.html.

\section{Notice}

Statements and opinions expressed in the chapters are these of the individual contributors and not necessarily those of the editors or publisher. No responsibility is accepted for the accuracy of information contained in the published chapters. The publisher assumes no responsibility for any damage or injury to persons or property arising out of the use of any materials, instructions, methods or ideas contained in the book.

First published in Croatia, 2013 by INTECH d.o.o.

eBook (PDF) Published by IN TECH d.o.o.

Place and year of publication of eBook (PDF): Rijeka, 2019.

IntechOpen is the global imprint of IN TECH d.o.o.

Printed in Croatia

Legal deposit, Croatia: National and University Library in Zagreb

Additional hard and PDF copies can be obtained from orders@intechopen.com

Perspectives in Water Pollution

Edited by Imran Ahmad and Mithas Ahmad Dar

p. cm.

ISBN 978-953-51-1076-7

eBook (PDF) ISBN 978-953-51-6332-9 


\section{We are IntechOpen, \\ the world's leading publisher of Open Access books}

\section{Built by scientists, for scientists}

\section{$4,200+$}

Open access books available

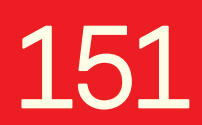

Countries delivered to

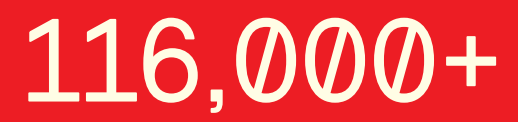

International authors and editors

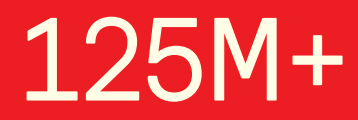

Downloads

Our authors are among the

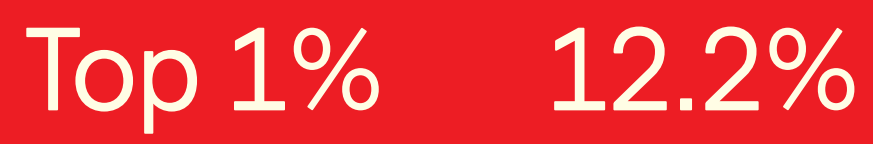

most cited scientists

Contributors from top 500 universities

\section{Interested in publishing with us? \\ Contact book.department@intechopen.com}

Numbers displayed above are based on latest data collected.

For more information visit www.intechopen.com 



\section{Meet the editors}

Imran Ahmad Dar, PhD, is a research scholar in the Dept. of Industries and Earth Sciences, Tamil university, India. He completed his B.Sc from the University of Kashmir, India in 2004, followed by an M.Sc Environmental Sciences from University of Kashmir, India in 2008. He is a researcher in the field of Earth and Environmental Sciences. He published his research work in various international journals such as Journal of Hydrology, Environmental Monitoring and Assessment, Environmental Quality Management etc. He is a member of Editorial Boards and a Scientific Reviewer of several international journals. He is listed in the Committee of IAMSET (International Association of Management Science and Engineering Technology, Hong Kong) and he is the Founding Editor of International Journal of Water Sciences, Intech.

Mithas Ahmad Dar completed a B.Sc from the University of Kashmir, India in 2003, followed by an M.Sc. in Environmental Sciences from University of Kashmir, India in 2005. He completed M.Tech Remote Sensing and GIS in 2008 from SRM University, Chennai, India. He received PhD in Earth Sciences in the Department of Earth Sciences, Ocean \& Atmospheric Science and Technology Cell, The Tamil University Thanjavur, Tamil $\mathrm{Nadu}$, India. He published more than 15 papers in various international journals, besides several Conferences and workshops. He acted/ is acting as a member of Editorial board or Scientific Reviewer of several international journals. Presently he is working as a Technical Expert in Rural Development Department, Civil Sectt. Jammu \& Kashmir, India. 



\section{Contents}

Preface XI

Chapter 1 Antibiotic Resistance in Aquatic Environments of Rio de Janeiro, Brazil 1

Felipe Hernandes Coutinho, Leonardo Henriques Pinto, Ricardo Pilz Vieira, Orlando Bonifacio Martins, Gigliola Rhayd Boechat Salloto, Deborah de Oliveira Santoro, Maysa Mandetta Clementino and Alexander Machado Cardoso

Chapter 2 Bioaccumulation of Heavy Metals in Contaminated River Water-Uppanar, Cuddalore, South East Coast of India 23 Usha Damodharan

Chapter 3 Contribution of Satellite Measurements to the Modeling and Monitoring of the Quality of Coastal Seawater 35

Houma Fouzia, Bachouche Samir, Bachari Nour El Islam and Belkessa Rabah

Chapter 4 Ground Water Contamination with Fluoride and Potential Fluoride Removal Technologies for East and Southern Africa 65

Bernard Thole

Chapter 5 Monitoring of Water Quality Parameters in Upper and Lower Reaches of Dudhganga Catchment, India 97

Mohd Iqbal, Haroon Sajjad, F.A. B hat and Imran Ahmad 



\section{Preface}

Water is an important natural resource which forms the core of the ecological system. $\mathrm{Hu}$ man use of water depends on ambient water quality and human alterations of the landuse have an extensive influence on water quality. Water is typically referred to as polluted when its quality is adversely affected by contaminants and undergoes a marked shift in its capability to support the biological communities.

The book is written for research scholars, hydrologists and environmentalists and especially students to serve as a valuable resource throughaut their scientific careers.

Many people have contributed to the development of this book. The editors are very much thankful to the participating authors and especially to Ms. Marija Radja, the publishing process manager, for her timely and kind communication with the editors during the entire process.

"Water is the elixir of life, don't pollute it".

Editor:

Imran Ahmad Dar

Research scholar, Department of Industries and Earth Sciences,

Tamil university, India

Co-editor:

Mithas Ahmad Dar

Technical Expert,

Rural Development Department, Civil Sectt. Jammu \& Kashmir, India 

Chapter 1

\title{
Antibiotic Resistance in \\ Aquatic Environments of Rio de Janeiro, Brazil
}

\author{
Felipe Hernandes Coutinho, \\ Leonardo Henriques Pinto, Ricardo Pilz Vieira, \\ Orlando Bonifacio Martins, \\ Gigliola Rhayd Boechat Salloto, \\ Deborah de Oliveira Santoro, \\ Maysa Mandetta Clementino and \\ Alexander Machado Cardoso
}

Additional information is available at the end of the chapter

http://dx.doi.org/10.5772/54638

\section{Introduction}

Aquatic environments possess ecological and economical relevance. Unfortunately, these sites are subjected to high levels of anthropogenic impact worldwide [1]. Urban, industrial and farming activities are responsible for the discharge of pollutants. Fertilizers, sludge, organic compounds, heavy metals and all sources of wastewater are released into water bodies often without appropriate treatment. A few possible outcomes from these contaminations are: eutrophication, hypoxia, toxicity, bioaccumulation, and dissemination of pathogens [2]. These pollutants can spread across long distances. Thus, sparsely populated areas where human activities are less intense are also affected by those disturbances [1].

Environmental contamination affects microbial communities in a myriad of ways. Source and amount of pollutants together with ecosystem dynamics modulate the responses of microorganisms to anthropogenic impacts [3]. Microbe communities react with drastic changes in ecosystem functioning, species composition and abundance [2,4]. Several consequences may arise from aquatic pollution. The connection between these impacts and potentially pathogenic bacteria is of particular relevance for human welfare [2]. 
High amounts of organic matter deposited in water bodies leads to nutrient enrichment. This promotes growth of heterotrophic bacteria, which include various opportunistic pathogens such as Shigella sp., Salmonella enterica and Vibrio cholerae. These are the etiological agents of waterborne diseases, like cholera and diarrhea, which affect millions of people worldwide. Those illnesses are most frequent in developing countries, where access to treated water and sanitation is limited [5]. Also, pathogenic bacteria originated from human feces are released directly into the environment through wastewater discharges, compromising water quality [2].

Since the discovery of inhibitory properties of antibiotics they have been widely used for treating bacterial infections. Approximately 250 of these molecules are currently in use [6]. These drugs are natural or synthetic substances capable of killing bacteria or retarding their growth. However, the effectiveness of treatments based on antibiotic therapy has been reduced over time, as a result of the spread of antibiotic resistant bacteria [7].

The selective pressure imposed by the use of antibiotics (ABs) results in death of susceptible bacteria while favors resistant strains. Bacteria may be inherently tolerant to these drugs or incorporate resistance genes by assimilating exogenous DNA. Extensive genetic exchange occurs in the environment, where opportunistic pathogens (commonly found in free-living communities) may become resistant upon acquiring resistance mechanisms.

The increasing spread of antibiotic resistance (AR) among environmental bacteria has led some authors to consider antibiotic resistant bacteria (ARB) and antibiotic resistance genes (ARG) as emerging pollutants $[6,8,9]$. These entities have a special property when compared to other contaminants: their ability to amplify and spread, persisting in the environment [9]. Since human populations are dependent on aquatic environments, the propagation of ARB and ARG within these sites represents a serious threat to public health [10].

However, antibiotic resistance is not just a medical issue but also an ecological matter. To understand the process by which resistance propagates, it is necessary to consider not only hospital settings, but also the ecology and evolution of resistant microorganisms [11]. In this chapter, we discuss how ARG and ARB arise and disseminate in aquatic environments, with special attention to how pollution affects this phenomenon. We describe the origins of antibiotic resistance genes and their interactions with environmental and pathogenic bacteria. In addition, we present 3 case studies regarding resistance in pristine and impacted aquatic environments from Rio de Janeiro. Finally, we describe prospects for reversing, or at least to mitigate the dissemination of antibiotic resistance among environmental bacteria. Through the text, the terms 'microbial communities', 'microbes' and 'microorganisms' are used to refer exclusively to members of the Bacteria domain.

\section{Antibiotics and resistant bacteria}

In the mid-1900s several new drugs originated from environmental microbes were discovered. During this time, most antibiotics currently in use were first characterized. This was started by the discovery of substances originated from free-living organisms that were able to inhibit 
microbial growth, such as penicillin [12]. Antibiotics belong to several classes of molecules that act impairing key microbiological processes like metabolic pathways and protein synthesis $[13,14]$ (Table 1). As a result, high enough levels of these drugs lead to death or inhibition of growth.

Antibiotics are mainly used for treating human infections. Although, the use of these drugs is not restricted to medical purposes. These substances are extensively applied in animal husbandry for veterinary objectives and also as growth promoters. ABs are also used in agriculture and aquaculture [23] for both prophylaxis and to fight bacterial contaminations [6]. World consumption of antibiotics has been estimated at up to 200.000 tons per year [24].

Although widely in use, the efficiency of antibiotics has decreased over time [5]. This is a result of the spreading of ARB; organisms capable of continuously growing in toxic concentrations of these drugs. Millions of individuals have their health compromised by infections caused by resistant microorganisms, making resistance a global concern [13]. The problem is so great that resistance now covers all known classes of antibiotics [25]. For some pathogens there is virtually no drug available for their treatment [14,26]. In addition, some bacterial diseases previously deemed treatable (e.g. gonorrhea and typhoid fever) or considered under control (e.g. tuberculosis) are once again a menace due to the emergence of resistant strains [5,9].

\begin{tabular}{|c|c|c|c|}
\hline Class & Antimicrobial agent & Mechanism of action & Resistance mechanism \\
\hline Aminoglycosides & $\begin{array}{l}\text { Gentamicin, Kanamycin, } \\
\text { Streptomycin }\end{array}$ & $\begin{array}{l}\text { Inhibition of protein } \\
\text { synthesis [15-17] }\end{array}$ & $\begin{array}{c}\text { Efflux, enzymatic inactivation, } \\
\text { mutated target }[15,17]\end{array}$ \\
\hline Amphenicols & Chloramphenicol & $\begin{array}{l}\text { Inhibition of protein } \\
\text { synthesis [14] }\end{array}$ & Efflux $[14,21]$ \\
\hline Macrolides & $\begin{array}{l}\text { Clarithromycin, } \\
\text { Erythromycin }\end{array}$ & $\begin{array}{l}\text { Inhibition of protein } \\
\text { synthesis }[14,18]\end{array}$ & Efflux, mutated target [18] \\
\hline Tetracyclines & Tetracycline, Doxycycline & $\begin{array}{l}\text { Inhibition of protein } \\
\text { synthesis }[15,18]\end{array}$ & Efflux $[15,18]$ \\
\hline Beta-Lactams* & $\begin{array}{l}\text { Penicillin, Aztreonam, } \\
\text { Cefotaxime }\end{array}$ & $\begin{array}{l}\text { Inhibition of cell-wall } \\
\text { synthesis }[15,18]\end{array}$ & $\begin{array}{c}\text { Enzymatic inactivation, mutatec } \\
\text { target }[15,18]\end{array}$ \\
\hline Glycopeptides & Vancomycin, Bleomycin & $\begin{array}{c}\text { Inhibition of cell-wall } \\
\text { synthesis }[15,18]\end{array}$ & $\begin{array}{l}\text { Cell wall modification, efflux } \\
\qquad[15,18]\end{array}$ \\
\hline Quinolones & $\begin{array}{l}\text { Nalidixic Acid, } \\
\text { Ciprofloxacin }\end{array}$ & $\begin{array}{l}\text { Inhibition of nucleic acids } \\
\text { synthesis }[15,18]\end{array}$ & Efflux, mutated target $[15,18]$ \\
\hline Sulfonamides & Sulfamethoxazole & $\begin{array}{l}\text { Inhibition of folate synthesis } \\
\text { pathway }[14,16]\end{array}$ & $\begin{array}{l}\text { Alternative enzymes, mutated } \\
\text { target }[14,16]\end{array}$ \\
\hline Lipopeptides & Daptomycin & $\begin{array}{c}\text { Cell membrane } \\
\text { depolarization }[14,19]\end{array}$ & $\begin{array}{c}\text { Cell membrane modification, } \\
\text { mutations }[17,19]\end{array}$ \\
\hline $\begin{array}{l}\text { Amino-acid } \\
\text { derivates }\end{array}$ & Polymyxin B & $\begin{array}{c}\text { Cell membrane } \\
\text { permeabilization }[14,20]\end{array}$ & $\begin{array}{l}\text { Cell membrane modification } \\
\qquad[20,22]\end{array}$ \\
\hline
\end{tabular}

Table 1. Antibiotic classes: action and resistance mechanisms 
Microorganisms resistant to at least three classes of ABs are considered multidrug-resistant. It is estimated that 400,000 cases of infections caused by multi-resistant bacteria occurred in Europe only during 2007, which can be connected to 25,000 deaths [27]. World Health Organization estimates that multidrug-resistant tuberculosis causes at least 150,000 deaths every year [28].

Multidrug-resistant pathogens are associated with increased morbidity and mortality, since they are much less susceptible to antibiotic therapy, our main weapon against bacterial infections [28]. Diseases caused by these microbes are more expensive to treat, because they usually require longer treatments, more clinical trials and a larger number of drugs. This is of special relevance in developing countries where little budget is directed for the acquisition of more efficient and expensive pharmaceuticals [5,13,26]

The concept of antibiotic susceptibility is dose dependent. At sufficiently high concentrations all organisms are likely to be susceptible. However, these doses are often so high that they are toxic to humans. While some strains tolerate concentrations barely above the clinical levels, others are able to survive at concentrations up to fifty times higher [29].

Several resistance mechanisms are well documented (Table 1). These adaptations may confer tolerance to a single drug or several of the same class. Common resistance strategies include: i) enzymatic inactivation, use of proteins capable of hampering antibiotic activity. ii) Mutations in target sites, expression of mutated proteins with reduced affinity for antibiotics. iii) Efflux pumps, inter-membrane proteins capable of removing antibiotics from cytoplasm. Intrinsic resistance occurs in the absence of target sites or due to inability of antibiotics to cross cell walls or membranes $[8,12,30]$.

\section{The resistome}

Antibiotic resistance is not restricted to pathogenic bacteria. Resistance is widespread among environmental microbes. Natural ecosystems are hotspots of resistance mechanisms, due to the large genetic diversity found among free-living microorganisms. The set of genes involved in microbial AR has been named the Resistome (Figure 1). This concept includes not only genes that encode real resistance determinants but also precursor genes that can evolve into such traits [12]. Soil and aquatic bacteria often present resistance determinants, even in pristine sites, like deep terrestrial subsurface and Antarctic waters [31,32]. Also, soil communities harbor bacteria capable of metabolizing antibiotics and subsisting on them as a sole carbon source [29].

Several microbes are known antibiotic producers. These organisms are sources of resistance genes. They control the toxic properties of these substances using self-preservation mechanisms. It is unlikely that these producers can generate inhibitory concentrations of antibiotics among free-living microbial communities [33]. Therefore, their use of ABs is probably distinct from its commonly known bactericidal purposes. In the environment, antibiotics play a different role. They function as signaling molecules used for inter-microbial communication, mediating community homeostasis [11,30,32]. At sub-inhibitory concentrations ABs are 
capable of inducing significant changes in gene expression patterns [33]. These substances can affect biofilm formation and cytotoxicity; therefore, at non-toxic levels, ABs act as signals with regulatory effects, in opposite to the bactericidal properties for which they are applied in medicine [34]

Antibiotics and resistance mechanisms were already present in Earth's microbiome long before humans started making use of these substances [31]. Environmental bacteria harboring resistance mechanisms against $\beta$-lactams, Vancomycin and Tetracycline may be more than 30.000 years old [35]. Evidence suggests that some natural ABs appeared on the planet over 100 million years ago. Beta-lactamases, enzymes that inactivate $\beta$-lactams are reportedly 2 billion years old [12].

ARG probably evolved from genetic units with physiological functions not related to resistance, such as detoxification, secretion and signaling pathways [36,37]. These genes encoded precursor proteins that, given the proper selective pressure can evolve into real AR features (Figure 1). Therefore, all bacterial genomes are likely to harbor resistome genes [12].

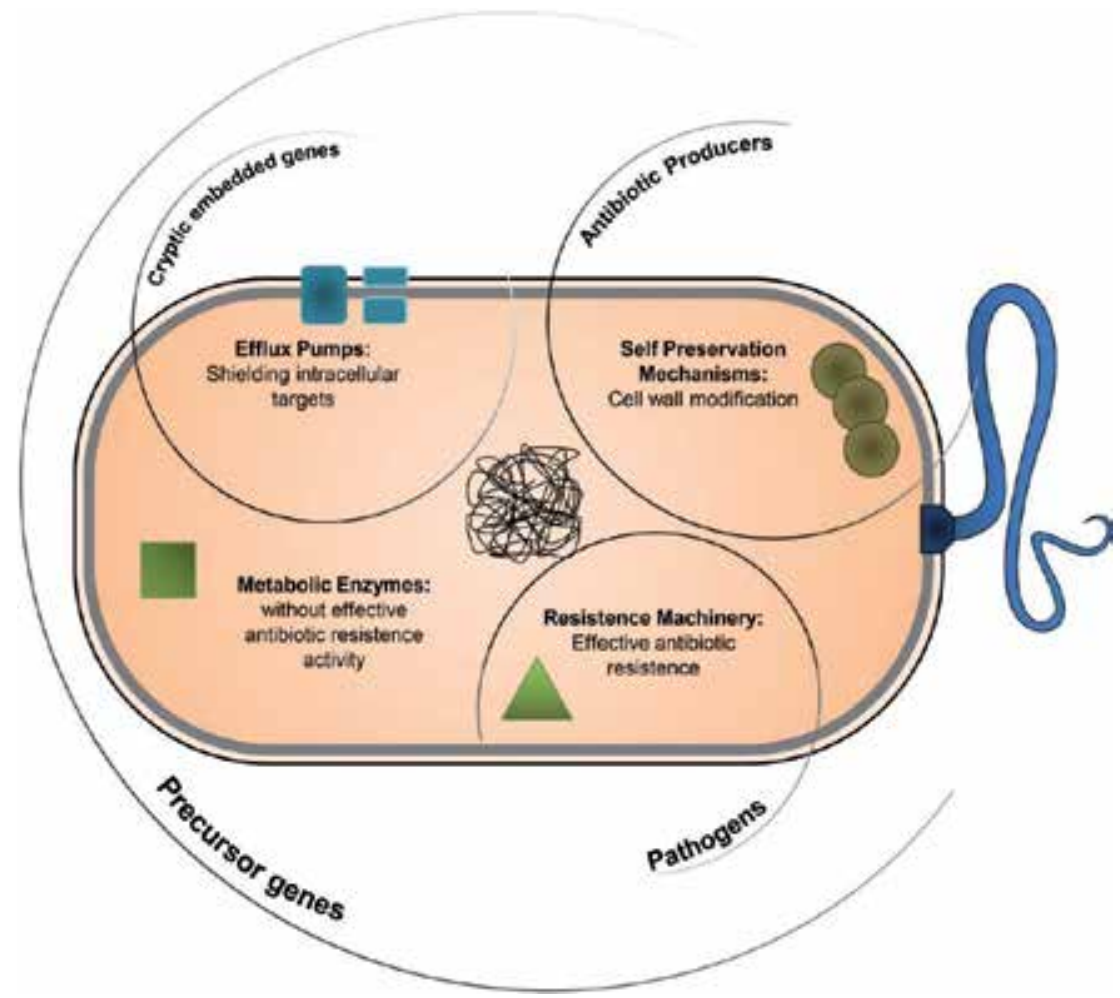

Figure 1. Functional mechanisms of the microbial resistome.

Resistance genes are plentiful and highly disseminated among environmental bacteria, which appear to be predominantly multi-resistant, often tolerating extremely high doses of ABs [25, 
$29,31]$. The complete genome of $E$. coli encodes nearly 600 proteins responsible for the outflow of small molecules, many of which can be associated with elimination of toxic compounds, which makes them possible mechanisms of innate resistance [12].

Studies have shed light on the evolution of ARB, suggesting that resistance traits can be associated with reduced fitness, which is a measure of how adapted an organism is to a particular environment. It is measured by comparing bacterial growth rates against control strains. Higher growth rates are interpreted as higher fitness and vice versa. Resistant bacteria have higher fitness than susceptible strains in the presence of antibiotics. By contrast, in the absence of such substances resistant bacteria tend to grow slower and are overcome by their susceptible counterparts. Therefore, when ABs are absent, resistance genes would be disadvantageous and tend to disappear from microbial populations.

Although, the lower relative fitness associated with AR is not absolute. Compensatory mutations are capable of reversing costs that arise from harboring resistance genes. Absence of fitness costs favors the persistence of $\mathrm{ARB}$ and $\mathrm{ARG}$ on microbial populations for extended periods after removal of antibiotics. In addition, AR traits may carry very little to no fitness costs, and in certain situations even increase it $[7,12,32]$.

\section{Evolution and dissemination of antibiotic resistance: The role of pollution}

Bacteria have very short life cycles compared to eukaryotes. This trait allows for the rapid emergence of new adaptations. In short periods of time, originally susceptible bacteria may become resistant through mutations or by acquiring resistance genes. When antibiotics are present, resistance traits tend to rapidly spread among microbial populations [38]. These characteristics of bacterial evolution contribute to a rapid development of multi-resistant pathogenic strains [10]. Consequently, once a new antibiotic is put into use, it does not take long until it is challenged by novel resistant microorganisms [25].

Dissemination of resistance is intensified as human populations grow and increase the use of antibiotics. The more these drugs are consumed, more intense is the selective pressure they impose on bacterial communities. As a result, resistance mutations are evolutionary successful and therefore tend to progressively increase their abundance among bacterial populations. This phenomenon takes place wherever bacterial communities are subjected to antibiotics as a relevant selective pressure, such as in hospitals.

When a multicellular organism is submitted to antibiotic therapy, drastic shifts occur in its symbiotic community. During this process, the richness and diversity of human-associated microbiota decreases [39]. Eventually, low abundance taxa may be eliminated [40]. Although, resilience of the overall community allows diversity to be restored over time [39]. Another consequence is the positive selection of $A R B$, which show higher abundance following antibiotic treatment [40]. ARG and ARB present in the human microbiota reach aquatic environments through wastewater discharges. Moreover, environmental bacteria are con- 
stantly inoculated into the human organism, through direct contact with these sites or indirectly through food and water.

Water bodies are sites of genetic exchange where environmental bacteria interact with microbes originated from humans and other animals, exchanging genes through horizontal gene transfer (HGT). Opportunistic pathogens often have large and versatile genomes, prone to sharing genetic material. This trait helps these organisms to colonize a more diverse set of environments. As consequence, aquatic ecosystems may become a threat to human wellbeing when they are affected by pollution carrying resistant bacteria [36].

Genetic transfer can be performed between pathogenic and environmental bacteria and even between very phylogenetically distant organisms such as species of Gram-positive and Gramnegative bacteria [41,42]. When ARG are not encoded in the bacterial chromosome but in mobile genetic elements (such as plasmids, transposons or integrons) the ability of these entities to be transferred is enhanced. $[37,43,44]$. As a result, antibiotic resistance may persist on environmental communities for long periods after the first contact with AR determinants [32] (Figure 2). Furthermore, phages are likely to play an important role in the spread of resistance. These viruses are abundant in aquatic ecosystems, and have been shown to carry ARG, both in pristine and polluted aquatic habitats [45].

Although environmental and pathogenic bacteria harbor ARG, the regulation of these genetic units is distinct between them. Pathogens usually carry these genes on mobile genetic elements and express them constitutively. Meanwhile, AR in free-living bacteria is usually chromosomally encoded and expression is initiated following exposure to antibiotics [12]. Since pathogenic organisms are much more likely to be subjected to toxic levels of ABs the continuous expression of ARG makes them permanently prepared to respond against these drugs. On the other hand, environmental bacteria are not constantly in contact with antibiotics; therefore repressing their resistance genes is probably advantageous.

The role of pollution in the rise and spread of resistant bacteria is not fully understood. Nevertheless, a growing body of evidence suggests that pollution promotes propagation of ARB within aquatic environments (Figure 2). In these sites, wastewater discharges from domestic sources affect the diversity of resistant bacteria [46-48]. Those impacts also shape the genetic pool of water bodies by increasing abundance of antibiotic resistance genes within these habitats [49]. As previously stated, in clinical situations, resistant microbes are the most successful and hence increase their numbers. Thus, hospital effluents have been shown to be rich in resistance genes [50] and resistant bacteria [51].

Farms make use of high doses of antibiotics as growth promoters. Animals submitted to these substances represent another source of resistant bacteria [9]. Multicellular organisms exchange members of their associated microbiota with other organisms and with their surroundings. Due to that, animals can spread ARB among other animals, humans and throughout the environment [30].

Antibiotic resistance is commonly encoded on the same mobile genetic elements that carry heavy metal resistance genes. Those genes are positively selected in presence of heavy metals. Along with them, ARG are co-selected. This occurs even in the absence of a selective pressure 


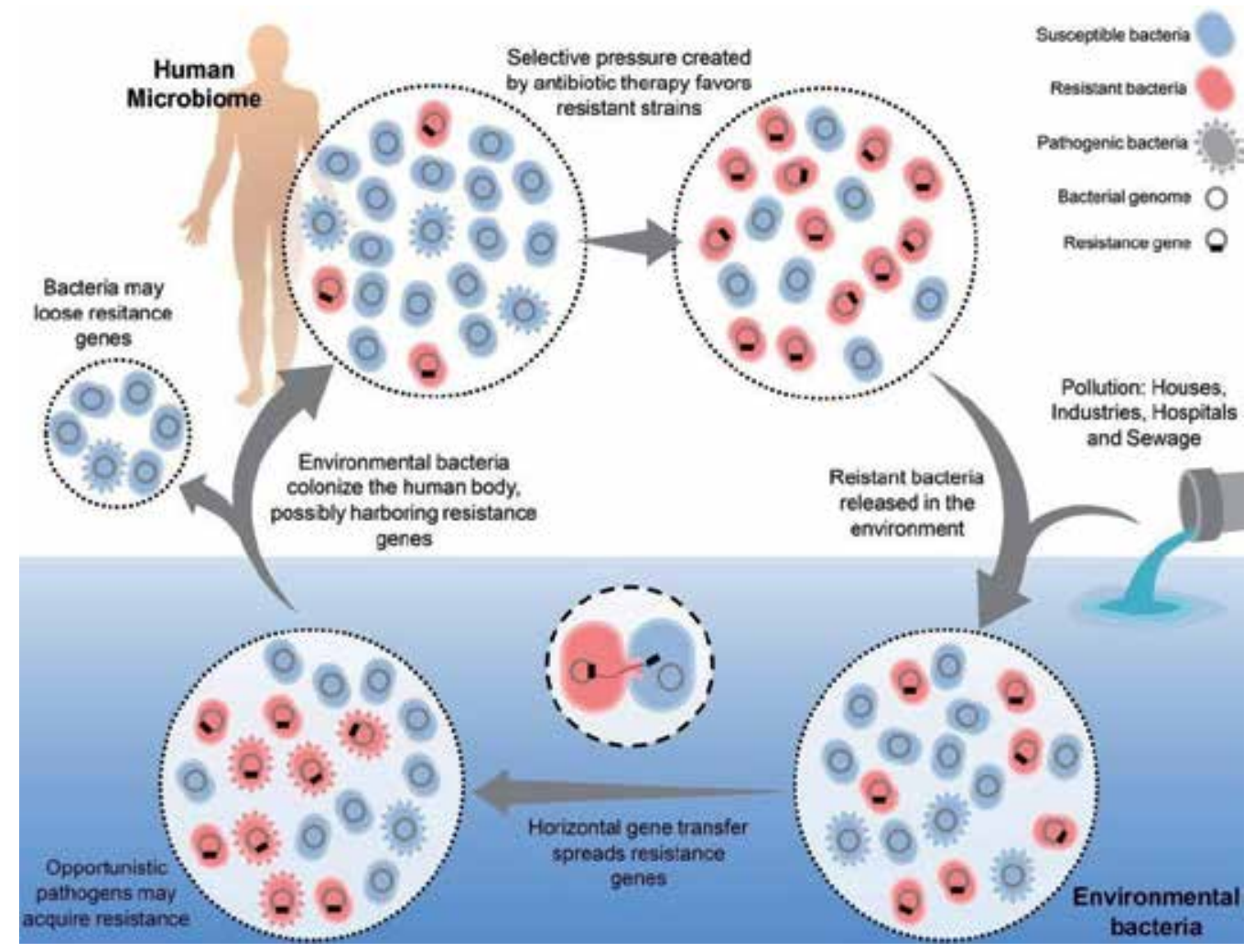

Figure 2. Schematic representation of the interactions between pollution, resistant bacteria and aquatic environments.

imposed by antibiotics [52,53]. Unlike organic matter, metals are not subjected to degradation. They persist in the environment for long periods, possibly promoting co-selection of antibiotic resistance genes [52-54].

Additionally, natural forces like wind and water disseminate microorganisms across long distances, along with AR determinants encoded in their genomes.

\section{Case studies: Interactions between water pollution and antibiotic resistant bacteria in Rio de Janeiro, Brazil}

\subsection{Diversity of antibiotic resistant bacteria in aquatic environments of Rio de Janeiro}

Rio de Janeiro city is situated around Guanabara Bay, a brackish environment submitted to intense pollution. Untreated sewage from domestic, clinical, industrial and agricultural origins is constantly released into the bay's waters [3]. Mixing of marine, freshwater and wastewater grants this habitat high microbial diversity [4]. Our group has investigated microbial ecology 
in the bay. We have worked to elucidate the impacts that anthropogenic activities exert on bacterial communities in this site.

Currently, we are exploring the connections between wastewater discharges and the diversity of ARB within the bay and nearby aquatic environments. For that purpose, we analyzed the diversity of cultivable bacteria resistant to ampicillin in water bodies situated in the state of Rio de Janeiro.

We assessed the diversity of ampicillin resistant bacteria from three impacted sites located in Rio de Janeiro city (BT, GB and CC). These communities were compared against bacterial diversity of three aquatic environments from Ilha Grande (PR, PB and MS), a pristine island located in a preserved area of the Atlantic rainforest (Figure 3). Ampicillin is a widely prescribed beta-Lactam antibiotic of the penicillins sub-class. This substance is also used in laboratory practices, in which bacteria receive ampicillin resistance genes through molecular cloning.

Inoculants for mixed bacterial cultures were obtained from each of the six sampling sites. Culturing was performed on four antibiotic concentrations. Bacteria were grown in clinical resistance and super-resistance (50 times higher [29]) concentrations of ampicillin. Superresistance cultures showing growth were inoculated on culture media supplemented with antibiotic concentrations 600 times higher than clinical levels. Bacteria were also cultivated on ampicillin-free media for control. All cultures were grown in Luria-Bertani liquid media for 24 hours at $37^{\circ} \mathrm{C}$ followed by DNA extraction for construction of $16 \mathrm{~S}$ rRNA gene libraries.

Communities from pristine environments of Ilha Grande only showed growth in antibioticfree cultures. Although, it is likely that ARB are present in these sites but could not be detected by our culturing methodology. All cultures from impacted environments of Rio de Janeiro city produced growth in all ampicillin concentrations. Vibrionales order was abundant in all gene libraries regardless of source of inoculants or antibiotic concentration. Diversity of resistant bacteria from impacted sites (BT, GB and CC) included members of orders Enterobacteriales, Firmicutes and Bacteroidales. These organisms are abundant in the intestinal tract of vertebrates, and their presence is an evidence of sewage contamination. Gene libraries analysis indicated that resistance is less disseminated among pristine and low impact environments (unpublished).

Bacteria from Guanabara Bay were isolated on solid agar plates containing ampicillin through functional selection. A total of nine isolates were obtained from these plates but only 5 could be identified by $16 \mathrm{~S}$ rRNA gene sequencing. Three isolates were classified as multi-resistant due to their tolerance to ampicillin, tetracycline and kanamycin. One of these isolates was identified as Acinetobacter calcoaceticus and the remaining two as Klebsiella pneumoniae. We obtained a high molecular weight plasmid from K. pneumoniae that granted ampicillin resistance upon electroporation into competent DH10B E. coli (unpublished).

Unpolluted sites (MS, PB and PR) showed lower diversity and relative abundance of resistant bacteria. Impacted sites (BT, GB and CC) were rich in ARB, many of which identified as fecal bacteria or as opportunistic pathogens. Potentially pathogenic bacteria showing ampicillin resistance were detected in gene libraries of all polluted environments. These results suggest that the degree of dissemination of AR depends on the levels of anthropogenic impact to which 


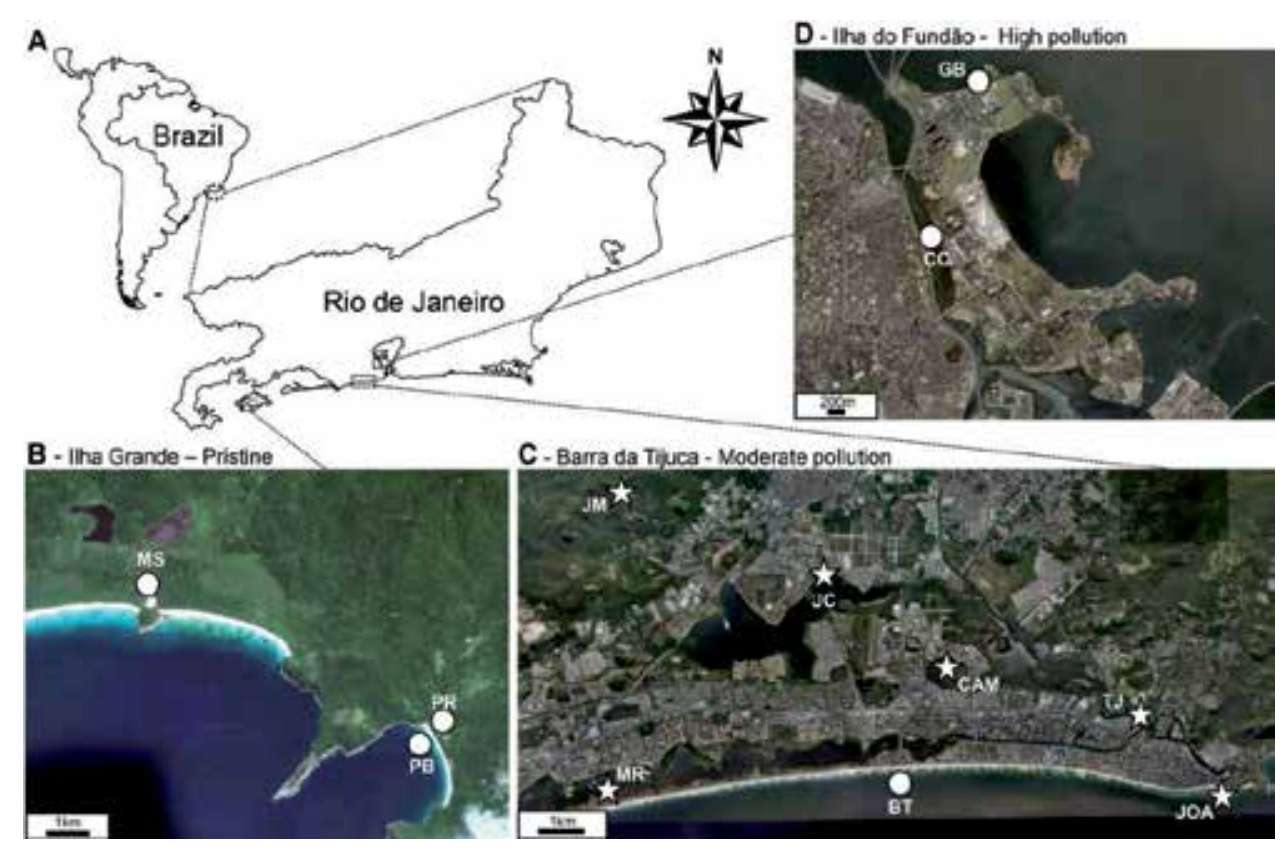

Figure 3. Map of the sampling sites located in the state of Rio de Janeiro. Case study 1 - Samples represented by circles: Mangrove system (MS), Paranaioca River (PR) and Parnaioca Beach (PB), Barra da Tijuca (BT), Guanabara Bay (GB) and Cunha Channel (CC). Case Study 2 - Samples represented by stars: Engenho Novo (JM), Jacarepaguá lagoon (JC), Camorim lagoon (CAM), Tijuca lagoon (TJ), Marapendi lagoon (MR) and Joá channel (JOA). Satellite images obtained from Google Maps.

each sampling site is submitted. Therefore, pollution and spread of antibiotic resistance within these environments are associated.

\subsection{Impacts on water resources in the Jacarepaguá lagoon system revealed by polyphasic approach}

Jacarepaguá lagoon system is located within the metropolitan area of Rio de Janeiro. Covering an area of $280 \mathrm{Km}^{2}$, the lagoon system consists of four major lakes: Jacarepaguá, Camorim, Tijuca and Marapendi. Several small rivers flow into those lakes, among which is the pristine stream of Engenho Novo (JM station). Joá Channel connects the Atlantic Ocean to the lagoon system, making the lakes brackish environments (Figure 3C). All lagoons are subjected to some degree of metropolitan pollution but Jacarepaguá (JC) and Camorim (CAM) are severely impacted. Mixing of sediments, seawater and continental freshwater make these ecosystem a dynamic habitat. Shifts in physical, chemical and microbiological properties of adjacent lakes and coastal marine environments occur over short periods of time, as a result of marine tides, raining water runoff and sewage flow. These alterations reflect on the local microbiome that responds to the most subtle changes.

For a more accurate picture of microbial diversity in environmental samples a polyphasic approach is recommended. Therefore, to investigate the lagoon system we performed a multi- 
step analysis that included construction of 16S rRNA gene libraries, of both free-living (metagenomic) and cultured (enrichment culture) bacterial communities. Additionally, we isolated bacteria from the lagoon system through selective agar plating. These isolates were submitted to antibiotic susceptibility tests through disc diffusion method. This technique consists in placing discs embedded with antibiotics on pure bacterial cultures streaked on agar. Antibiotics diffuse through the culturing medium unevenly, i.e. closer to the discs antibiotic concentrations are higher. By measuring the halo of inhibition around the discs, bacteria are classified as resistant or susceptible.

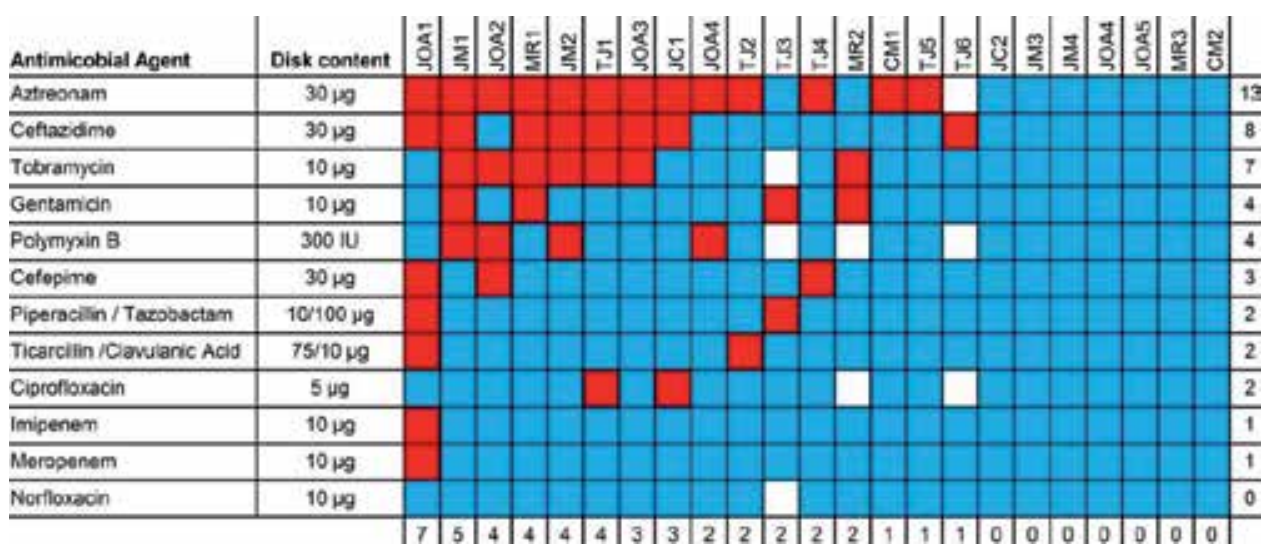

Figure 4. Antibiotic-susceptibility profiles of 23 isolates obtained from Jacarepaguá lagoon system determined by disc diffusion method. Red squares indicate resistance; blue squares indicate susceptibility and unavailable data is represented in white. Numbers in the right end of the table indicate how many isolates where resistant to the antibiotic of each line. Numbers in the bottom of the table indicate to how many antibiotics each isolate was considered resistant.

Through metagenomics, enrichment cultures and isolation, we evaluate three different portions of the bacterial diversity from the studied area, as evidenced by the very small number of operational taxonomic units found in common between the three datasets. Vibrio cholerae was detected in lakes by all methodological approaches. Phylogenetic analysis revealed great diversity of fecal bacteria and pathogens dwelling in the lagoons. ARB represented $50 \%$ of all isolates, which included species of known human pathogens such as Pseudomonas aeruginosa and Vibrio cholerae, as well as opportunistic pathogens like Enterococcus gallinarum and Vibrio fluvialis, all showing patterns of multi-resistance [55]. The resistance profile of 23 isolates obtained from the Jacarepaguá lagoon system is shown in Figure 4.

Our polyphasic experimental approach provided community-based indicators to assess health risks associated with aquatic environments in urban areas. Opportunistic pathogens are common in polluted lakes. Nevertheless, when these bacteria harbor resistance genes against conventional drugs, such environments pose a more serious risk to the well-being of local residents. Jacarepaguá lagoons are a source of food, water and leisure, despite the inadequacy of the lakes for human contact. In this study, we suggest complementary techniques for analyzing microbial diversity, aimed at evaluating water quality based on physical and chemical parameters; metagenomics and microbiological data. 


\subsection{Antibiotic resistance in Pseudomonas aeruginosa isolated from hospital wastewater treatment system}

P. aeruginosa is a highly adaptable opportunistic pathogen. The capacity of this bacterium to survive antimicrobial therapy represents a major challenge regarding treatment of infectious diseases [56]. Resistance in P. aeruginosa is attributed to chromosomal mutations or acquisition of ARG by genetic exchange mediated by plasmids, transposons or bacteriophages [57]. An increase in the incidence of multi-drug resistant hospital infections caused by this bacterium has been described [58-60].

Most reports surveying antimicrobial resistance have focused on clinical isolates but few studies assessed the antimicrobial resistance profiles of bacteria from hospital wastewater treatment plants [61-63].Such plants have been recognized as a reservoir of resistant organisms and resistance genes [30,53].

We evaluated the antimicrobial resistance patterns of $P$. aeruginosa isolated from a hospital situated in Rio de Janeiro city. These isolates were retrieved either from clinical samples or from the treatment plant that processes the hospital's wastewater discharges. The wastewater treatment system performs an extended aeration-activated sludge process followed by posttreatment (i.e. disinfection of final effluent by chlorination). The whole process includes five stages: wastewater arrival; aeration tank; settling tank; chlorination tank and output of chlorinated sewage (Figure 5). These stages are designed so that the majority of bacteria are eliminated during treatment. The process is considered adequate, unlike that of some hospitals around the globe, which release their effluents without any treatment.

With the exception of Polymyxin B, resistance was detected for all antibiotics tested. Resistance rates among clinical isolates were higher than those found in samples of the treatment system. By contrast, aztreonam resistance rates were higher among isolates from the treatment plant. A total of 21 resistance profiles were identified among our isolates. Of all clinical isolates, $89 \%$ were resistant to at least three classes of antibiotics, thus defined as multi-resistant. Only $18.5 \%$ of isolates from the wastewater treatment plant were classified as multi-resistant. The most surprising result obtained was the high resistance rates to aztreonam, in both clinical $(50 \%)$ and wastewater isolates (63\%) [51].

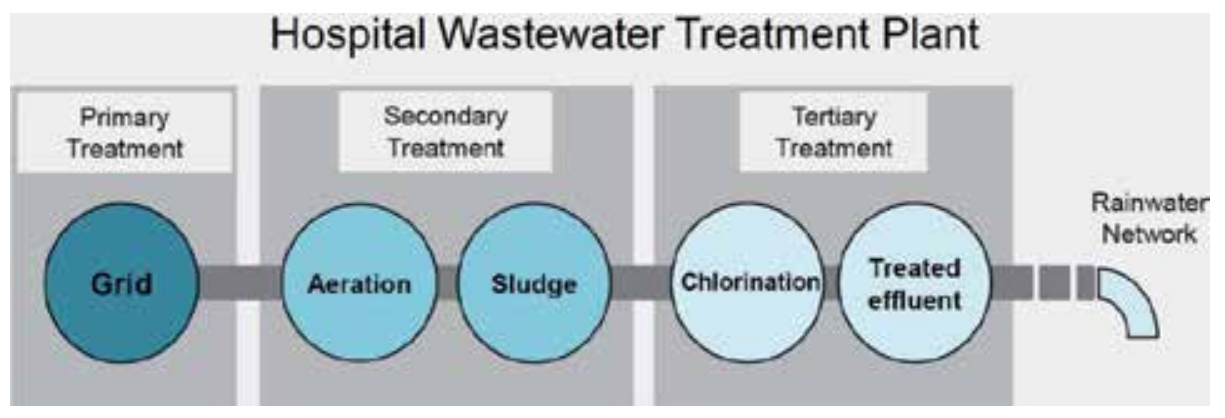

Figure 5. Schematic representation of the hospital's wastewater treatment plant. 
Several studies indicate that hospital wastewater treatment systems could work as disseminators of antibiotic resistant bacteria into the environment [61,62,64-67] Resistance levels detected among clinical and treatment system isolates suggests that these organisms are a significant source of ARG. Bacteria resistant to aztreonam were proportionally very abundant. This antibiotic is commonly used for the treatment of $P$. aeruginosa infections.

Exposure to antibiotics is recognized as the major factor promoting acquisition of fluoroquinolone and beta-lactam resistance [68-69]. Also, the up-regulation of efflux pumps is known to convey fluoroquinolone and aztreonam resistance [70]. Triclosan and quaternary ammonium compounds are widely used in clinical practices. These substances are released in hospital effluents along with cells of $P$. aeruginosa that must make use of these efflux pumps to tolerate their presence [71,72]. Use of quaternary ammonium compounds exerts a selective pressure that promotes the dissemination of qac genes, responsible for conferring resistance to these disinfectants. qacE genes are usually located in class 1 integrons, which are involved in the HGT of antibiotic resistance genes. Thus, these disinfectants can induce AR by co-selection. [73-75].

Our data indicates that the dissemination of aztreonam resistant bacteria in aquatic ecosystems may be compromising the effectiveness of that drug. Also, these results are further evidence that precarious conditions of basic sanitation and low efficacy of hospital effluent treatment plants can contribute to the spread of multi-resistant bacteria into aquatic ecosystems [76-78].

\section{Prospects for reversing resistance}

One of the most important actions needed to combat propagation of resistance is more research. Even though the sources ARG and ARB have been characterized, our understanding of the step-by-step process by which bacteria acquire and spread resistance is limited. Moreover, very little is known about the emergence of new resistance mechanisms. Advances in these fields are necessary for the development of comprehensive strategies to interfere with the dissemination of resistance traits $[30,79]$. These strategies should focus on both environmental and clinical perspectives of the problem to be successful.

It is important to determine which environments are potential sources of resistance traits that pose a threat to human health $[11,80]$. It is also relevant to elucidate how pollutants can work to enhance these risks. Among free-living communities, antibiotics are considered signaling molecules, but the mechanisms by which small substances act upon microbial communication are still poorly characterized. Efforts in this research field will yield valuable knowledge about the functioning of these drugs. This information will contribute to the development of new drugs and to optimize the use of antibiotics [33].

Ecosystems may be contaminated by ABs through wastewater discharges. Even so, it is unlikely that these substances reach inhibitory concentrations in aquatic environments. Moreover, these drugs are subjected to various degradation mechanisms such as photolysis, thermolysis, and enzymatic inactivation. Therefore, it is improbable that the presence of 
antibiotics in the environment causes bactericidal effects on microbial communities. Although it has been suggested otherwise, scientific evidence to support this statement is still missing. Nevertheless, sub-inhibitory concentrations of ABs can affect communities by modifying bacterial transcription patterns [81,82]. Resistant bacteria are able to multiply and spread resistance genes [42]. Therefore, the propagation of these organisms, instead of environmental contamination by antibiotics per se, is the most relevant factor contributing to the dissemination of resistance.

Providing adequate hygiene and sanitation conditions for human populations is essential, as untreated water can spread resistant pathogens [79]. Particular care should be taken regarding water treatment in hospital effluents, and any other places where antibiotics are widely consumed. Those are places where resistant strains are likely to be proportionally abundant. Therefore, effluents from those sites demand a more efficient method to eliminate bacteria prior to release [36].

Reduction of selective pressure by regulating the use of antibiotics is a key step to undermine the spread of resistance. This could be achieved by suspending the use of antibiotics when not strictly necessary (i.e., animal husbandry, agriculture and aquaculture), limiting the use of these drugs for medical and veterinary uses. Even for that, antibiotics should be controlled so that resistant strains are not favored [79]. In order to preserve the effectiveness of these molecules some countries have banned the use of antibiotics as growth promoters for animal raising. As previously stated, antibiotic resistance traits are often associated with lower relative fitness. Exploiting these fitness costs to favor susceptible strains is another possibility to reduce the number of bacteria capable of tolerating anti-microbials [83].

The enormous diversity within the resistome makes AR inevitable [12,25]. Maybe there are no effective methods to completely prevent the propagation of resistance. Therefore, the development of alternative treatments for bacterial infections may be required. Making use of new pharmacological compounds to which bacteria cannot resist or take longer to develop resistance could be the only alternative to antibiotic based treatments [79]. Also, phage therapy is a promising alternative to antibiotics.

\section{Conclusions}

Dissemination of antibiotic resistant bacteria has been investigated mainly due to its risks posed to public health. However, these investigations were focused on the medical perspectives of the problem and often ignored the role of ecosystems. It has been demonstrated that natural habitats are reservoirs of resistance traits, which drew attention to the importance of these sites for the evolution and ecology of antibiotic resistance [29,30]. Mankind has intensively impacted aquatic habitats, favoring the emergence of ARB [46-52].

The results from our analysis of aquatic environments from Rio de Janeiro are an example of how anthropogenic impacts can promote the spread of resistance in aquatic habitats. We could not detect resistant bacteria in pristine sites of Ilha Grande. Meanwhile, impacted environ- 
ments of the city had high diversity of ARB. Many resistant pathogens were detected in $16 \mathrm{~S}$ rRNA gene libraries and among isolated bacteria. The abundance of these organisms indicates an alarming phenomenon: pollution is promoting the spread of both pathogens and antibiotic resistance traits. In addition, even treated wastewater still harbors multi-resistant $P$. aerugino$s a$, suggesting that some of our efforts to mitigate the propagation of resistance are not completely efficient.

Unless preventive measures are taken to combat the spread of antibiotic resistance, by reducing pollution and making conscious use of these drugs, humanity may be faced with the end of the antibiotic era [5,15]. As previously mentioned, several approaches have been proposed to counteract the spread of AR, but very few of them have been implemented globally until 2012. Risks to human well-being brought by pollution of natural habitats are likely to be among the most convincing arguments for the preservation of Earth's ecosystems. Therefore it is important to raise awareness to those risks by disseminating this information among the members of our society. Also, antibiotic resistance should be taken into consideration in discussions of sustainable development like Rio+20, held in Rio de Janeiro city during 2012. These strategies can ensure the benefits brought by antibiotics, which significantly increased the welfare of humans and animals, certainly saving countless lives.

\section{Author details}

Felipe Hernandes Coutinho ${ }^{1 *}$, Leonardo Henriques Pinto ${ }^{1}$, Ricardo Pilz Vieira ${ }^{1}$, Orlando Bonifacio Martins ${ }^{1}$, Gigliola Rhayd Boechat Salloto ${ }^{2}$, Deborah de Oliveira Santoro², Maysa Mandetta Clementino ${ }^{2}$ and Alexander Machado Cardoso ${ }^{3}$

*Address all correspondence to: fhcoutinho@bioqmed.ufrj.br

1 Federal University of Rio de Janeiro - UFRJ, Rio de Janeiro, Brazil

2 Oswaldo Cruz Foundation - FIOCRUZ, Rio de Janeiro, Brazil

3 East Region Universitary Center -UEZO, Rio de Janeiro, Brazil

\section{References}

[1] Halpern, B. S, Walbridge, S, Selkoe, K. A, Kappel, C. V, Micheli, F, et al. A Global Map of Human Impact on Marine Ecosystems. Science (2008). , 2008(319), 5865-948.

[2] Nogales, B, Lanfranconi, M. P, Piña-villalonga, J. M, \& Bosch, R. Anthropogenic perturbations in marine microbial communities. FEMS Microbiology Reviews (2011). , 2011(35), 2-275. 
[3] Cardoso, A. M, Coutinho, F. H, Silveira, C. B, Ignacio, B. L, Vieira, R. P, et al. Metagenomics in polluted aquatic environments. In: Nuray Balkis (ed.) Water Pollution. Rijeka: InTech; Available from http://www.intechopen.com/books/water-pollution/ metagenomics-in-polluted-aquatic-environmentsAccessed 04 Septemer 2012), 89-104.

[4] Vieira, R. P, Gonzalez, A. M, Cardoso, A. M, Oliveira, D. N, Albano, R. M, et al. Relationships between bacterial diversity and environmental variables in a tropical marine environment, Rio de Janeiro. Environmental Microbiology (2008). , 10(1), 189-199.

[5] World Health Organization (WHO)WHO Annual Report on Infectious Disease: Overcoming Antimicrobial Resistance; World Health Organization: Geneva, Switzerland, (2000). http://www.who.int/infectious-disease-report/2000/.Accessed 5 September 2012

[6] Kümmerer, K. Antibiotics in the aquatic environment- A review- Part I. Chemosphere (2009). , 75(4), 417-434.

[7] Andersson, D. I, \& Levin, B. R. The biological cost of antibiotic resistance. Current Opinion in Microbiology (1999).

[8] Wright, G. D. Antibiotic resistance in the environment: a link to the clinic? Current Opinion in Microbiology (2010). , 13(5), 589-594.

[9] Pruden, A, Pei, R, Storteboom, H, \& Carlson, K. H. Antibiotic Resistance Genes as Emerging Contaminants: Studies in Northern Colorado. Environmental Science and Technology (2006). , 40(23), 7745-7750.

[10] Jalal KCAAkbar John B, Kamaruzzaman BY, Kathrisean K. Antibiotic Resistant Bacteria from Coastal Environment- A Review. In: Marina Pana (ed.) Antibiotic Resistant Bacteria- A Continuous Challenge in the New Millennium. Rijeka, InTech; (2012). Available from http://www.intechopen.com/books/antibiotic-resistant-bacteria-acontinuous-challenge-in-the-new-millennium/emergence-of-antibiotic-resistant-bacteria-from-coastal-environment-a-reviewaccessed 05 september 2012), 143-158.

[11] Martínez, J. L. Natural antibiotic resistance and contamination by antibiotic resistance determinants: the two ages in the evolution of resistance to antimicrobials. Frontiers in Microbiology. (2012). ar.1) doi:fmicb.2012.00001

[12] Wright, G. D. The antibiotic resistome: the nexus of chemical genetic diversity. Nature Reviews Microbiology (2007). , 5(3), 175-186.

[13] Levy, S. B, \& Marshall, B. Antibacterial resistance worldwide: causes, challenges and responses. Nature Medicine (2004). Suppl): S, 122-129.

[14] Tenover, F. C. (2006). Mechanisms of Antimicrobial Resistance in Bacteria. The American Journal of Medicine 119 (6 Suppl 1): SS10, 3.

[15] Ahmed, M. Antibiotic Resistance: An Emerging Global Headache In: Marina Pana (ed.) Antibiotic Resistant Bacteria- A Continuous Challenge in the New Millennium. 
Rijeka, InTech; (2012). Available from http://www.intechopen.com/books/antibioticresistant-bacteria-a-continuous-challenge-in-the-new-millennium/antibiotic-resistance-an-emerging-global-headacheaccessed 04 September 2012), 13-24.

[16] Skold, O. Sulfonamide resistance: mechanisms and trends. Drug Resistance Updates (2000). , 3(3), 155-160.

[17] Fischer, A, Yang, S, Bayer, A. S, Vaezzadeh, A. R, Herzig, S, et al. Daptomycin resistance mechanisms in clinically derived Staphylococcus aureus strains assessed by a combined transcriptomics and proteomics approach. Antimicrobial Chemotherapy (2011). , 66(8), 1696-1711.

[18] Walsh, C. Molecular mechanisms that confer antibacterial drug resistance. Nature (2000). , 406(6797), 775-781.

[19] Palmer, K. L, Daniel, A, Hardy, C, Silverman, J, \& Gilmore, M. S. Genetic Basis for Daptomycin Resistance in Enterococci. Antimicrobial Agents and Chemotherapy (2011). , 55(7), 3345-356.

[20] Moore, R. A, \& Hancock, R. E. Involvment of outer membrane of Pseudomonas cepacia in aminoglycoside and polymyxin resistance. Antimicrobial Agents Chemotherapy (1986). , 30(6), 923-926.

[21] Hancock REWResistance Mechanisms in Pseudomonas aeruginosa and Other Nonfermentative Gram-Negative Bacteria. Clinical Infectious Diseases (1998). Suppl1) SS99, 93.

[22] Fu, W, Yang, F, Khang, X, \& Zhang, X. Li Yet al. First structure of the polymyxin resistance proteins. Biochemical and Biophysical Research Communication (2011). , 361(4), 1033-1037.

[23] Buschmann, A. H, Tomova, A, López, A, Maldonado, M. A, Henríquez, L. A, et al. Salmon Aquaculture and Antimicrobial Resistance in the Marine Environment. PLoS ONE (2012). doi:10.1371/journal.pone.0042724

[24] Wise, R. Antimicrobial resistance: priorities for action. Journal of Antimicrobial Chemotherapy (2002). , 49(4), 585-586.

[25] Costa, D, Mcgrann, V. M, Hughes, K. M, \& Wright, D. W. GD. 2006. Sampling the Antibiotic Resistome. Science (2006). , 311(5759), 374-377.

[26] Mcgowan, J. E. Resistance in Nonfermenting Gram-Negative Bacteria: Multidrug Resistance to the Maximum. American Journal of Infection Control (2006). Suppl 1): SS36, 29.

[27] European Centre for Disease Prevention and Control (ECDC) \& European Medicines Agency (EMEA)Joint technical report: the bacterial challenge. Time to React: http:// www.ecdc.europa.eu/en/publications/Publications/0909_TER_The_Bacterial_Challenge_Time_to_React.pdfaccessed 04 September (2012). 
[28] World Health Organization(2012). Fact sheet $N^{\circ} 194$ : Antimicrobial resistance. http:// www.who.int/mediacentre/factsheets/fs194/en/index.html.Accessed 5 September 2012

[29] Dantas, G. Sommer MOA, Oluwasegun RD, Church GM. Bacteria Subsisting on Antibiotics. Science (2008). , 320(5872), 100-103.

[30] Allen, H. K, Donato, J, Wang, H. H, Cloud-hansen, K. A, Davies, J, et al. Call of the wild: antibiotic resistance genes in natural environments. Nature Reviews Microbiology (2010). , 8(4), 251-259.

[31] Bhullar, K, Waglechner, N, Pawlowski, A, Koteva, K, Banks, E. D, et al. Antibiotic Resistance Is Prevalent in an Isolated Cave Microbiome. PLoS ONE (2012). doi:10.1371/ journal.pone.003495

[32] Martínez, J. L. Environmental pollution by antibiotics and antibiotic resistance determinants. Environmental Pollution (2009). , 157(11), 2893-2902.

[33] Davies, J. Are antibiotics naturally antibiotics? Journal of Industrial Microbiology and Biotechnology (2006).

[34] Linares, J. F, Gustafsson, I, Baquero, F, \& Martínez, J. L. Antibiotics as intermicrobial signaling molecules instead of weapons. Proceedings of the National Academy of Sciences (2006). , 103(51), 19484-19489.

[35] Costa, D, King, V. M, Kalan, C. E, Morar, L, \& Sung, M. WWL et al. Antibiotic resistance is ancient. Nature (2011). , 477(7365), 457-461.

[36] Baquero, F, Martínez, J. L, \& Cantón, R. Antibiotic and antibiotic resistance in water environments. Current Opinion in Biotechnology (2008). , 19(3), 260-265.

[37] Martínez, J. L. Antibiotics and Antibiotic Resistance Genes in Natural Environments. Science (2008). , 321(5887), 365-367.

[38] Zhang, Q, Lambert, G, Liao, D, Kim, H, Robin, K, et al. Acceleration of Emergence of Bacterial Antibiotic Resistance in Connected Microenvironments. Science (2011). , 333(6050), 1764-1767.

[39] Dethlefsen, L, Huse, S, Sogin, M. L, \& Relman, D. A. The Pervasive Effects of an Antibiotic on the Human Gut Microbiota, as Revealed by Deep 16S rRNA sequencing. PLoS Biology (2008). doi:10.1371/journal.pbio.0060280

[40] Jernberg, C, Löfmark, S, Edlund, C, \& Jansson, J. K. Long-term ecological impacts of antibiotic administration on the human intestinal microbiota. ISME Journal (2007). , $1(1), 56-66$.

[41] Courvalin, P. Transfer of Antibiotic Resistance Genes between Gram-Positive and Gram-Negative Bacteria. Antimicrobial Agents and Chemotherapy (1994). , 1994(38), 7-1447. 
[42] Kruse, H, \& Sørum, H. Transfer of multiple drug resistance plasmids between bacteria of diverse origins in natural microenvironments. Applied and Environmental Microbiology (1994). , 60(11), 4015-4021.

[43] Sommer MOADantas G. Antibiotics and the resistant microbiome. Current Opinion in Microbiology (2011). , 14(5), 556-563.

[44] Livermore, D. M, \& Hawkey, P. M. CTX-M: changing the face of ESBLs in the UK. Journal of Antimicrobial Chemotherapy (2005). , 56(3), 451-454.

[45] Colomer-lluch, M, Jofre, J, \& Muniesa, M. Antibiotic Resistance Genes in the Bacteriophage DNA Fraction of Environmental Samples. PLoS ONE (2011). doi:10.1371/ journal.pone.0017549

[46] Czekalski, N, Berthold, T, Caucci, S, Egli, A, \& Bürgmann, H. Increased levels of multiresistant bacteria and resistance genes after wastewater treatment and their dissemination into Lake Geneva, Switzerland. Frontiers in Microbiology (2012). doi:fmicb. 2012.00106 .

[47] Thevenon, F, Adatte, T, Wildi, W, \& Poté, J. Antibiotic resistant bacteria/genes dissemination in lacustrine sediments highly increased following cultural eutrophication of Lake Geneva (Switzerland). Chemosphere (2012). , 86(5), 468-476.

[48] Vignesh, S, \& Muthukumar, K. Arthur James R. Antibiotic resistant pathogens versus human impacts: A study from three eco-regions of the Chennai coast, southern India. Marine Pollution Bulletin (2012). , 64(4), 790-800.

[49] Tacão, M, Correia, A, \& Henriques, I. Resistance to broad-spectrum antibiotics in aquatic systems: Anthropogenic activities modulate the dissemination of blaCTX-Mlike genes. Applied and Environmental Microbiology (2012). , 2012(78), $12-4134$.

[50] Schwartz, T, Kohnen, W, Jansen, B, \& Obst, U. Detection of antibiotic-resistant bacteria and their resistance genes in wastewater, surface water and drinking water biofilms. FEMS Microbiology Ecology (2003). , 43(3), 325-335.

[51] Santoro, D. O. Romão CMCA, Clementino MM. Decreased aztreonam susceptibility among Pseudomonas aeruginosa isolates from hospital effluent treatment system and clinical samples. International Journal of Environmental Health Research (2012). doi:10.1080/09603123.2012.678000

[52] Mcarthur, J. V, \& Tuckfield, R. C. Spatial Patterns in Antibiotic Resistance among Stream Bacteria: Effects of Industrial Pollution. Applied Environmental Microbiology (2000). , 6(9), 3722-3726.

[53] Martínez, JL, Farjado, A, Garmendia, L, Hernandez, A, \& Linares, . FEMS Microbiology Reviews 2009; 33(1): 44-65.

[54] Baker-austin, C, Wright, M. S, Stepanauskas, R, \& Mcarthur, J. V. Co-selection of antibiotic and metal resistance. TRENDS in Microbiology (2006). , 14(4), 176-182. 
[55] Salloto GRBCardoso AM, Pinto LH, Coutinho FH, Vieira RP et al. Submitted for publication on 18 June (2012). Impacts on water resources in the Rio+20 meeting place revealed by polyphasic approach.

[56] Labaer, J, Qiu, Q, Anumanthan, A, Mar, W, Zuo, D, et al. The Pseudomonas aeruginosa PA01 gene collection. Genome Research (2004). b): , 2190-2200.

[57] Poole, K. (2011). Pseudomonas aeruginosa: resistance to the max. Frontiers in Microbiology 2(65): doi:fmicb.2011.00065

[58] Pellegrino FLPCTeixeira LM, Carvalho MGS, Nouér SA, de Oliveira MP et al. (2002). Occurrence of a multidrug-resistant Pseudomonas aeruginosa clone in different hospitals in Rio de Janeiro, Brazil. Journal of Clinical Microbiology. 2002; , 40(7), 2420-2424.

[59] Navon-venezia, S, Ben-ami, R, \& Carmeli, Y. Update on Pseudomonas aeruginosa and Acinetobacter baumannii infections in the healthcare setting. Current Opinion in Infectious Diseases (2005). , 18(4), 306-313.

[60] Romão, C, Miranda, C. A, Silva, J, Clementino, M. M, De Filippis, I, et al. Presence of qacE $\Delta 1$ gene and susceptibility to a hospital biocide in clinical isolates of Pseudomonas aeruginosa resistant to antibiotics. Current Microbiology (2011). , 63(6), 16-21.

[61] Chitnis, V, Chitis, S, Vaidya, K, Ravikant, S, Patil, S, et al. Bacterial population changes in hospital effluent treatment plant in central India. Water Research (2004). , 38(2), 441-447.

[62] Prado, T, Pereira, W. C, Silva, D. M, Seki, L. M, et al. Detection of extended-spectrum b-lactamase-producing Klebsiella pneumoniae in effluents and sludge of a hospital sewage treatment plant. Letters in Applied Microbiology (2008). , 46(1), 136-141.

[63] Chagas, T. P, Seki, L. M, Cury, J. C, Oliveira, J. A, Dávila, A. M, et al. Multiresistance, beta-lactamase-encoding genes and bacterial diversity in hospital wastewater in Rio de Janeiro, Brazil. Journal of Applied Microbiology (2011). , 111(3), 572-581.

[64] Sayah, R. S, Kaneene, J. B, Johnson, Y, \& Miller, R. Patterns of antimicrobial resistance observed in Escherichia coli isolates obtained from domestic- and wild-animal fecal samples, human septage, and surface water. Applied Environmental Microbiology (2005). , 71(3), 1394-1404.

[65] Kim, S, \& Aga, D. S. Potential ecological and human health impacts of antibiotics and antibiotic-resistant bacteria from wastewater treatment plants. Journal of Toxicology and Environmental Health (2007). , 10(8), 559-573.

[66] Fasih, N, Zafar, A, Khan, E, Jabeen, K, \& Hasan, R. Clonal dissemination of vanA positive Enterococcus species in tertiary care hospitals in Karachi, Pakistan. Journal Pakistan Medical Association (2010). , 60(10), 805-809.

[67] Robledo, I. E, Aquino, E. E, \& Vásquez, G. J. Detection of the KPC gene in Escherichia coli, Klebsiella pneumoniae, Pseudomonas aeruginosa and Acinetobacter baumannii 
during a PCR-based nosocomial surveillance study in Puerto Rico. Antimicrobial Agents and Chemotherapy. (2011). , 55(6), 2968-2970.

[68] Carmeli, Y, Troillet, N, Eliopoulos, G. M, \& Samore, M. H. Emergence of antibioticresistant Pseudomonas aeruginosa: comparison of risks associated with different antipseudomonal agents. Antimicrobial Agents and Chemotherapy (1999). , 43(6), 1379-1382.

[69] Harris, A, Torres-viera, C, Venkataraman, L, Degirolami, P, Samore, M, \& Carmeli, Y. Epidemiology and clinical outcomes of patients with multiresistant Pseudomonas aeruginosa. Clinical Infectious Diseases (1999). , 28(5), 1128-1133.

[70] Livermore, D. M. Multiple mechanisms of antimicrobial resistance in Pseudomonas aeruginosa: our worst nightmare? Clinical Infectious Diseases (2002). , 34(5), 634-640.

[71] Chuanchuen, R, Narasaki, C. T, \& Schweizen, H. The MexJK efflux pump of Pseudomonas aeruginosa requires OprM for antibiotic efflux but not for efflux of Triclosan. Journal of Bacteriology (2002). , 184(18), 5036-5044.

[72] Tuméo, E, Gbaguidi-haore, H, Patry, I, Bertrand, X, Thouverez, M, et al. Are antibiotic-resistant Pseudomonas aeruginosa isolated from hospitalized patients recovered in the hospital effluents? International Journal of Hygiene and Environmental Health (2008).

[73] Gaze, W. H, Abdouslam, N, \& Hawkey, P. M. Wellington EMH. 2005. Incidence of class 1 integrons in a quaternary ammonium compound-polluted environment. Antimicrobial Agents and Chemotherapy (2005). , 49(5), 1802-1807.

[74] Maillard, J-Y. Bacterial resistance to biocides in the healthcare environment: should it be of genuine concern? Journal of Hospital Infectections, (2007). S2): 60-72.

[75] Hegstad, K, Langsrud, S, Lunestad, B. T, Scheie, A. A, Sunde, M, et al. Does the wide use of quaternary ammonium compounds enhance the selection and spread of antimicrobial resistance and thus threaten our health? Microbial Drug Resistance (2010). , 16(2), 91-104.

[76] Muela, A, Pocino, I, Arana, J, Justo, J. I, Iriberri, J, et al. Effects of growth phase and parental cell survival in river water on plasmid transfer between Escherichia coli strains. Applied Environmental Microbiology (1994).

[77] Guardabassi, L. Lo Fo Wong DMA, Dalsgaard A. The effects of tertiary wastewater treatment on the prevalence of antimicrobial resistant bacteria. Water Research (2002). , 36(8), 1955-1964.

[78] Baquero, F. From pieces to patterns: evolutionary engineering in bacterial pathogens. Nat Rev Microbiol (2004). , 2(6), 510-518.

[79] Bush, K, Courvalin, P, Dantas, G, Davies, J, Eisenstein, B, et al. Tackling antibiotic resistance. Nature Reviews Microbiology (2011). , 9(12), 894-896. 
[80] Martínez, J. L, Baquero, F, \& Andersson, D. I. Predicting antibiotic resistance. Nature Reviews Microbiology (2007). , 5(12), 958-965.

[81] Yim, G, Wang, H. H, \& Davies, J. The truth about antibiotics. International Journal of Medical Microbiology (2006).

[82] Goh, E, Yim, G, Tsui, W, Mcclure, J, Surette, M. G, et al. (2002). Transcriptional modulation of bacterial gene expression by subinhibitory concentrations of antibiotics. PNAS, 99(26), 17025-17030.

[83] Andersson, D. I, \& Hughes, D. Antibiotic resistance and its cost: is it possible to reverse resistance? Nature Reviews Microbiology (2010). , 8(4), 260-271. 
Chapter 2

\title{
Bioaccumulation of Heavy Metals in Contaminated River Water-Uppanar, Cuddalore, South East Coast of India
}

\author{
Usha Damodharan
}

Additional information is available at the end of the chapter

http://dx.doi.org/10.5772/53374

\section{Introduction}

Industrialization and human activities have partially or totally turned our environment into dumping sites for waste materials. As a result, many water resources have been rendered polluted and hazardous to man and other living systems [1]. The toxic substances discharged into water bodies are not only accumulated through the food chain [2], but may also either limit the number of species or produce dense populations of microorganisms [3]. Aquatic ecosystems are affected by several stresses that significantly weaken biodiversity. River pollution is an environmental problem in the world. They are subjected to various natural processes such as the hydrological cycle occurring in the environment, Because of unprecedented development, human beings are responsible for choking several aquatic ecosystems to death. Storm water runoff and carry out of sewage into rivers are two common ways that various nutrients and other pollutants enter the aquatic ecosystems resulting in pollution [4, 5]. Heavy metal contamination particularly the non-essential elements may have distressing effects on the ecological balance of the recipient aquatic environment with a diverse of organisms including fish. It has particular significance in ecotoxicology, since the heavy metals are highly persistent and have the potential to bio accumulate and bio magnify in food chain, and become toxic to living organisms at higher trophic levels in nature.

Uppanar River is considered to be one of the highly polluted rivers in south east coast of India due to industrialization. SIPCOT (Small Industrial Promotion Corporation of Tamil Nadu, covering an area of about 520 acres with 52 industries) is located on the bank of the Uppanar River at Cuddalore. It was established for chemical, petrochemical, pharmaceutical, biocides, fertilizer, fungicides, chlor-alkai and metal processing industries etc. Many 
possible environmental contaminants could be discussed in a review of toxic substances from industrial sources. The combined effect of all these might be the reason of frequent fish death and depletion of aquatic ecosystems in this area. Indiscriminate discharge of partially treated effluents from SIPCOT industrial complex into coastal environment affects both biotic and abiotic system and finally causes some ill effects to human beings through food chain. A detailed study was made on the bio accumulation of heavy metals in the food chain and the spectrum of issues and consequences were discussed in the present study.

The specific objectives of this study are:

i. The interpretation of the impact of pharmaceutical industrial effluent on surface water quality of Uppanar River in Cuddalore.

ii. $\quad$ Find out the suitability of river water for fisheries.

iii. To evaluate the health risk of fish consumption by human beings collected from the river.

\subsection{Study area}

Uppanar River is a stream in Cuddalore (Lat.11/43'N, Long. 79/46' E) (Fig. 1). It flows between Cuddalore and Chidambaram Taluks and joins with the Bay of Bengal by the mouth of Gadilam River. It runs behind the SIPCOT (State Industrial Promotion Corporation of Tamil Nadu Limited) industrial complex which consists of Pharmaceutical industries, fertilizers, dyes, chemicals, mineral processing plants and metal based industries. The river receives the partially treated and untreated effluents of these industries through small channels and pipeline. The water at lower reaches is polluted more when compared to the upper reaches. In addition to the industrial wastes, the river also receives the municipal wastes and domestic sewage from the Cuddalore old town. As the river receives the treated and partially treated effluents from nearly 55 industries, it is said to be highly polluted. Pharmaceutical industrial effluent before and after treatment and four stations in the Uppanar River, the river (Outfall), Upstream (uncontaminated -Semmankuppam) and Downstream (Contaminated-Kudikadu) were selected for the heavy metal $(\mathrm{Cu}, \mathrm{Cd}, \mathrm{Mn}, \mathrm{Zn}$ and $\mathrm{Pb}$ ) analyses and seasonal variations were reported. A study on the transfer of $\mathrm{Cd}, \mathrm{Pb}, \mathrm{Cu}$, $\mathrm{mn}$ and $\mathrm{Zn}$ through the food chain of the river Uppanar proved the existence of bioaccumulation in fish.

\subsection{Sampling methods and sample preparation}

Water samples were collected with $1 \mathrm{~L}$ polyethylene bottles which were previously cleaned by washing with non-ionic detergent, rinsed with tap water and later soaked in $10 \% \mathrm{HNO}_{3}$ for 24 hours and finally rinsed with deionized water prior to use. During sampling, sample bottles were rinsed with sampled water three times and then filled to the brim at a depth of one meter below the wastewater from each of the four designated sampling points. Temperature and $\mathrm{pH}$ measured immediately after collection. The waste water and river water samples were digested and heavy metals were determined 
using Atomic Absorption Spectrophotometer (AAS) as described in the APHA standard methods (1992).
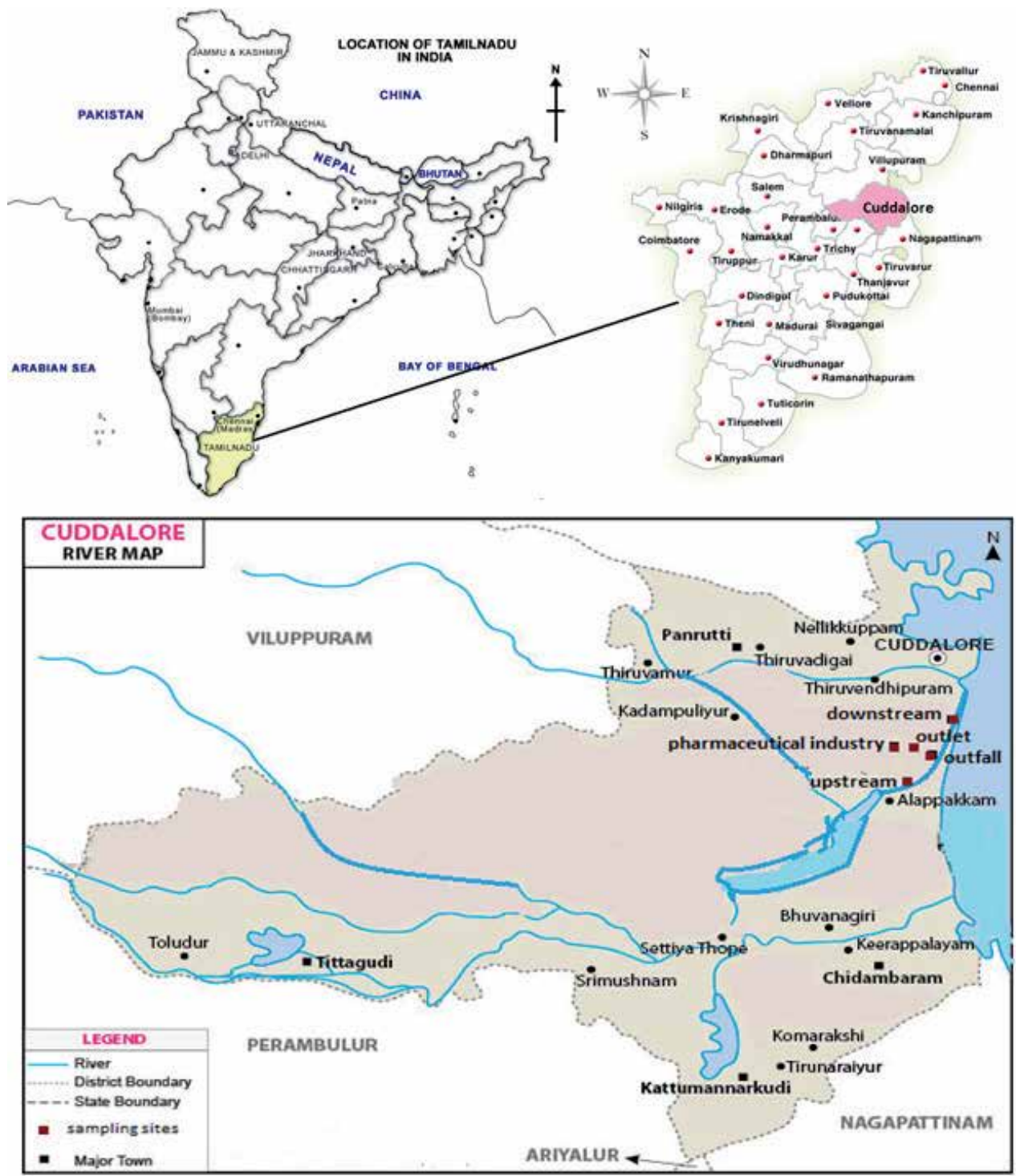

Figure 1. The map of Cuddalore and Uppanar River sampling sites

Dried samples of muscle tissues from each fish were digested using microwave digestion system. After digestion, the residues were diluted to $25 \mathrm{ml}$ with $2.5 \%$ of $\mathrm{HNO}_{3}$. The Instrument (Atomic Absorption Spectrophotometer - AAS) was calibrated with standard solutions and prepared from commercial materials. The water used was deionized and distilled. 
The metal analysis of the tissue and water samples $(\mathrm{Cd}, \mathrm{Cu}, \mathrm{Mn}, \mathrm{Zn}, \mathrm{Pb})$ were carried out by using Atomic Absorption Spectrophotometer (AAS).

\subsection{Result and discussion}

The spatial variation of the heavy metals, $\mathrm{Cd}, \mathrm{Cu}, \mathrm{Pb}, \mathrm{Zn}$ and $\mathrm{Mn}$ ) along the six sampling locations of all the four seasons was shown in Fig 2. The average mean concentrations of $\mathrm{Cd}$, $\mathrm{Cu}, \mathrm{Pb}, \mathrm{Zn}$ and $\mathrm{Mn}$ were higher in the untreated effluents than the treated effluents.

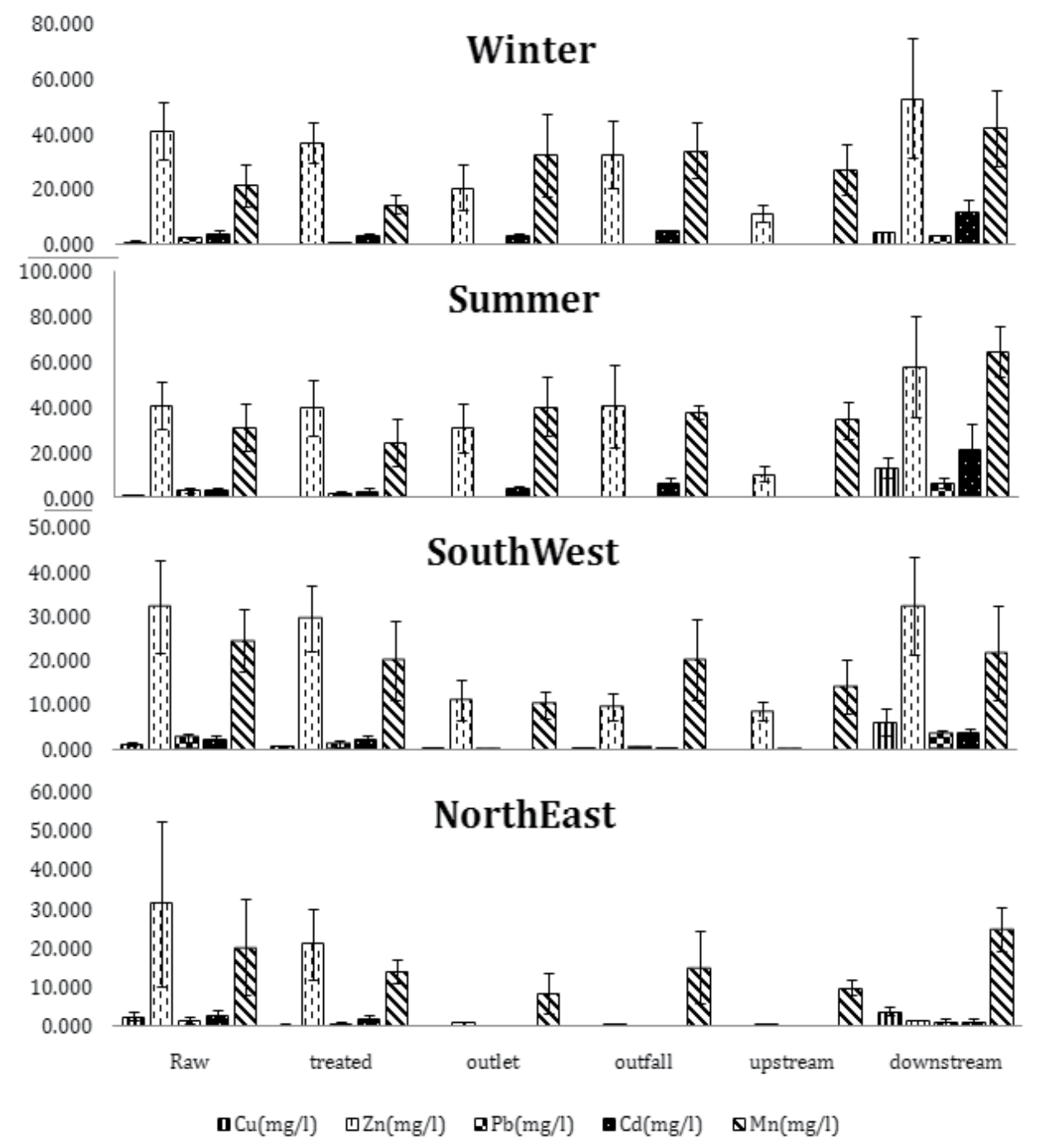

Figure 2. Mean and S.D of heavy metal ( $\mathrm{Cu}, \mathrm{Pb}, \mathrm{Cd}, \mathrm{Mn}$ and $\mathrm{Zn})$ concentrations in pharmaceutical industry effluents(Raw \& Treated) and Uppanar River water at four sampling sites 


\subsection{Cadmium}

Cadmium concentrations in unpolluted natural waters are usually below $1 \mu \mathrm{g} / \mathrm{l}$. Contamination of drinking-water may occur as a result of the presence of cadmium as an impurity in the zinc of galvanized pipes or cadmium-containing solders in fittings, water heaters, water coolers and taps. Drinking-water from shallow wells of areas in Sweden where the soil had been acidified contained concentrations of cadmium approaching $5 \mu \mathrm{g} / \mathrm{l}$. In Saudi Arabia, mean concentrations of $1-26 \mu \mathrm{g} / 1$ were found in samples of potable water, some of which were taken from private wells or cold corroded pipes (Mustafa et al., 1988). Levels of cadmium could be higher in areas supplied with soft water of low $\mathrm{pH}$, as this would tend to be more corrosive in plumbing systems containing cadmium. In the Netherlands, in a survey of 256 drinking-water plants in 1982, cadmium $(0.1-0.2 \mu \mathrm{g} / \mathrm{l})$ was detected in only $1 \%$ of the drinking-water samples. Cadmium has been shown to induce carcinogenesis by both the inhalation and parental routes of exposure. The variations in the heavy metal concentration of both the untreated and treated effluents were due to the heavy metal decreasing efficiency of primary and secondary treatment of the Effluent Treatment Plant (ETP). The average mean concentration of $\mathrm{Cd}$ at the river water ranged from $(0.011-21.213 \mathrm{ppm})$ during all the four seasons. There was a higher fluctuation in the various sampling sites of river, which was attributed to the reason of the other industrial and anthropogenic sources. Upstream $\mathrm{Cd}$ concentration during all the four seasons were several times lesser than the Cd concentration of raw effluent, which indicated the dilution effect of the river weather and also it showed that this site is free from anthropogenic inputs, and only the natural effects are the predominant factors in this particular site.

\subsubsection{Copper}

Copper is a natural element which is widely distributed in soils, rocks and in rivers and the sea. The $\mathrm{Cu}$ is widely used in society and yet is potentially quite toxic to life in rivers. The present result of average mean concentration of $\mathrm{Cu}$ at the various sampling stations of river water ranged from $0.230-13.313 \mathrm{mg} / \mathrm{l}$ during all the four seasons. The $\mathrm{Cu}$ concentration at outfall increased two folds compared to the outlet that could be attributed to the reason of anthropogenic activities, agriculture runoff, sludge from publicly-owned treatment works (POTWs) and municipal and industrial solid waste dumped into the river water. Copper is released in to water as a result of natural weathering of soil and discharges from industries and sewage treatment plants $[7,8]$. The $\mathrm{Cu}$ concentration in downstream were several folds higher than the raw effluent $\mathrm{Cu}$ concentration. It may be attributed to domestic sewage and run-off from extensive farmed areas [9]. Copper compounds which are used in electroplating industries such as cupric sulphate and cupric acetate and in fertilizers such as copper naphthenate and paint industries such as cuprous oxide, Ceramics and glass industries such as cupric acetate, cuprous and cupric oxides used as pigments and for making glazes were discharged through the treated industrial effluents. Other than this copper released through the domestic activities such as human wastes flushed through the toilets, washing and bathing water etc. Copper occurs naturally in all foods and water and, in small concentrations, plays an essential role in the human diet. Copper in the dissolved form is potentially very 
toxic to aquatic animals and plants, especially to young life-stages such as fish larvae. The toxicity of copper is however greatly reduced when it is bound to particulate matter in the river water and when the water is hard. The industries and public should recognize the need to monitor the concentrations in discharges and in rivers closely, to ensure that Water Quality Objectives are not exceeded.

\subsubsection{Lead}

Exposure to lead causes a variety of health effects, and affects children in particular. Water is rarely an important source of lead exposure except where lead pipes, for instance in old buildings, are common. Removal of old pipes is costly but the most effective measure to reduce lead exposure from water. The higher concentration of $\mathrm{Pb}$ at various sampling sites of river water could be attributed to the reason of less soluble of $\mathrm{Pb}$ containing minerals in natural water and its concentration diluted through the dilution effect of the water $[10,11]$. The $\mathrm{Pb}$ concentration in downstream of all the four seasons was several folds higher than the raw effluents. The profile of the $\mathrm{Pb}$ showed that it did not have only one source; furthermore higher concentration of $\mathrm{Pb}$ in the downstream indicated the presence of contamination through various industrial effluents of SIPCOT area and local anthropogenic inputs. Lead is rarely found in source water, but enters tap water through corrosion of plumbing materials. The most common problem is with brass or chrome-plated brass faucets and fixtures which can leach significant amounts of lead into the water, especially hot water. Most industrially processed lead is applied for fabricating computer and TV screens. The lead compound tetra-ethyl lead is applied as an additive in fuels. This organic lead compounds is quickly converted to inorganic lead, and ends up in water, sometimes even in drinking water. Fortunately, this form of release of lead is less and less abundant. Lead accumulates in leg tissue. The most severe type of lead poisoning causes encephalopathy. Lead toxicity is induced by lead ions reacting with free sulfydryl groups of proteins, such as enzymes. These are deactivated. Furthermore, lead may interact with other metal ions.

\subsubsection{Zinc}

Zinc can be introduced into water naturally by erosion of minerals from rocks and soil; however since zinc ores are only slightly soluble in water. Values of 5-22 mg have been reported in studies on the average daily intake of zinc in different areas. The zinc content of typical mixed diets of North American adults varies between 10 and $15 \mathrm{mg} /$ day. Drinking-water usually makes a negligible contribution to zinc intake unless high concentrations of zinc occur as a result of corrosion of piping and fittings. Under certain circumstances, tap water can provide up to $10 \%$ of the daily intake (WHO). High natural levels of zinc in water are usually associated with higher concentrations of other metals such as lead and cadmium. Mostly, the zinc is introduced into water by artificial pathways such as by-products of steel production or coal-fired power stations, or from the burning of waste materials. Zinc is also used in some fertilizers that may leach into groundwater. Older galvanized metal pipes and well cribbings were coated with zinc that may be dissolved by soft, acidic waters. Zinc is an essential nutrient for body growth and development; however drinking water containing high 
levels of zinc can lead to stomach cramps, nausea and vomiting. Although the $\mathrm{Zn}$ is normally found little amount in nature, It is also emitted through effluents of many commercial industries during mining and smelting (metal processing) activities. In the present study upstream $\mathrm{Zn}$ concentration during all the four seasons was several times lesser than the $\mathrm{Zn}$ concentration of raw effluent, which showed that there was no adverse effect of effluent on the upstream. The $\mathrm{Zn}$ concentration in downstream ranged from $1.130-58.046 \mathrm{mg} / \mathrm{L}$ of all the four seasons which was attributed to the greatest frequency of near source areas like hazardous waste sites and the release of industrial effluents through the transmission of iron pipes. Urban runoff, mine drainage, and municipal sewages are the more concentrated sources of zinc in water.

\subsubsection{Manganese}

The element manganese is present in over 100 common salts and mineral complexes that are widely distributed in rocks, in soils and on the floors of lakes and oceans. Industrial emissions containing manganese oxides are the principal source of manganese in the atmosphere. The total atmospheric emission of manganese from anthropogenic sources in India was estimated to be $1225 \mathrm{t}$ in 1984; 78.5\% of this originated from industrial processes, mainly related to metal alloy production. Emissions stemming from gasoline-powered motor vehicles accounted for a further $17.2 \%$, whereas the remaining $4.3 \%$ of atmospheric manganese emissions were due to the burning of coal for power generation, solid waste incineration and pesticide application. In the present study the Mn concentration in downstream ranged from $21.736-64.837 \mathrm{mg} / \mathrm{L}$ of all the four seasons and it was several folds higher than the raw effluent, which could be attributed to the reason of its usage in the cleaning, bleaching, manufacturing of iron, steel alloys, batteries, glass and fireworks industries and improper discharge of the effluents from these industries [12,13]. Manganese is an essential element in humans and animals, functioning both as an enzyme co-factor and as a constituent of metalloenzymes. Gross deficiencies of manganese have never been observed in the general population, but a recent experimental study involving human subjects fed a manganese-deficient diet $(0.11 \mathrm{mg} / \mathrm{d})$ resulted in the development of dermatitis and hypocholesterolaemia and elevated concentrations of serum calcium and phosphorus. A statistical analysis of the metabolic studies showed that a daily manganese intake of approximately $5 \mathrm{mg}$ is required to consistently maintain a positive balance.

The present results showed that the metal concentration decreased in the ranking order of $\mathrm{Zn}>\mathrm{Mn}>\mathrm{Cu}>\mathrm{Cd}>\mathrm{Pb}$ during all the four seasons. According to the seasons, it was in the following ranking pattern summer $>$ winter $>$ Southwest $>$ Northeast.

Most of the dissolved heavy metals showed high concentrations during the summer period than that of the other seasons. ANOVA of the results showed that the metal concentrations were significantly different between sampling stations and the four seasons. The highest flows occurred during the northeast monsoon from October to December. It was also observed that for all (five) metals studied; there was a trend of increasing concentrations from the upstream stations to the downstream stations. 


\section{Bio concentration factor}

A study on the transfer of $\mathrm{Cd}, \mathrm{Pb}, \mathrm{Cu}, \mathrm{Mn}$ and $\mathrm{Zn}$ through the food chain of the river Uppanar proved the existence of bioaccumulation in fish. The Bio- concentration factor of the heavy metals in muscle tissues of fish from the river water are presented in Table 1 . The BCF of $\mathrm{Cu}$ ranged from 0.001 to 0.009 , that of $\mathrm{Pb}$ ranged from 0.061-0.100, $\mathrm{Cd}$ from 0.003-0.004, $\mathrm{Zn}$ from 0.031-0.083, and Mn 0.408-0.922.The BCF value of $\mathrm{Cu}$ was found highest (0.009) in L. calcarifer and it was low in A. thalassinus (0.001), while the BCF value for $\mathrm{Pb}$ was highest (0.100) in M. cephalus and was lowest in L. calcarifer (0.061). The BCF value of Cd was highest (0.004) in T. mossambica and M. cephalus (0.004) and it was low 0.003 in A. thalassinus and $L$. calcarifer. The BCF value of $\mathrm{Zn}$ was highest (0.083) in A. thalassinus and was lower (0.031) in L. calcarifer. The BCF value of Mn was highest (0.922) in T. mossambica was highest and was lower (0.408) in L. calcarifer. The trends of BCF for heavy metals in four species of fish were in the ranking order of $\mathrm{Mn}>\mathrm{Pb}>\mathrm{Zn}>\mathrm{Cu}>\mathrm{Cd}$.

\begin{tabular}{ccccc}
\hline BCF & L.alcarifer & M.cephalus & A.thalasinuss & T.mossambica \\
\hline Cu muscles/Cu water & 0.009 & 0.002 & 0.001 & 0.002 \\
\hline Pb muscles/Pb water & 0.061 & 0.100 & 0.063 & 0.074 \\
\hline Cd muscles/Cd water & 0.003 & 0.004 & 0.003 & 0.004 \\
\hline Zn muscles/Zn water & 0.031 & 0.041 & 0.083 & 0.073 \\
\hline Mn muscles/Mn water & 0.408 & 0.798 & 0.707 & 0.922 \\
\hline
\end{tabular}

$\mathrm{BCF}=$ Conc. in muscle tissues of fish (dry weight basis) / Conc. in water of the river

Table 1. Bio concentration factor of heavy metals in muscle tissues of fish from the river water

Due to the improper discharge of partially treated industrial waste water and domestic sewage water into the Uppanar river, the level of heavy metals recorded in water of the downstream and the heavy metals other than $\mathrm{Zn}$ and $\mathrm{Mn}$ in the water of upstream were generally high and their values exceeded the maximum permissible limit when compared with the

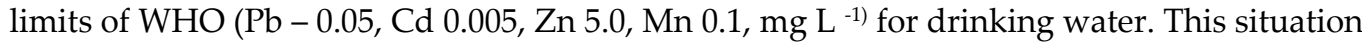
has arisen as a result of the rapid expansion of industrial activities, followed by increased urbanization and growth of population with exploitation of natural resources, extension of modern agricultural practices as well as the lack of environmental regulations [14]. The present finding showed significant co-relationships between heavy metal concentrations of water and that of the fish tissue, which may indicate that the fish bio-accumulated these elements from the water of Uppanar River. Further, these present result showed that metal concentrations in muscle tissue were below the allowable concentration and consumption safety tolerance in fish set by countries elsewhere, and suggested by WHO. The maximum levels permitted for fishes are - $\mathrm{Zn} \mathrm{100,} \mathrm{Cu} 30, \mathrm{Mn} \mathrm{1.0,} \mathrm{and} \mathrm{Pb} 2.0, \mu \mathrm{g} \mathrm{g}{ }^{-1}$ as per $\mathrm{WHO}$ and permitted level $\mathrm{Cd}$ is $0.05-0.1 \mu \mathrm{g} \mathrm{g}^{-1}$ [14], None of the metals in the present results were above the prescribed limits; thus have, little threat to public health. The present study indi- 
cates that, consumption of these species is safe. However, it is quite evident that there was bioaccumulation of heavy metals in fish tissues and condition may get worse. Therefore, a regular monitoring of heavy metal levels in fishes is necessary.

\section{Heavy metal concentration of Indian rivers}

The comparison of dissolved metal concentration of River Uppanar with other Indian rivers showed that the $\mathrm{Cd}, \mathrm{Cu}$ and $\mathrm{Pb}$ concentration was several times higher than the Achankoil, Ganga, Brahmani and Mahanadi River (Table 2). The comparative results showed Uppanar River is highly contaminated with industrial effluents discharge, which are the important point sources of toxic heavy metals like $\mathrm{Cd}, \mathrm{Cu}$ and $\mathrm{Pb}$. The concentration of $\mathrm{Zn}$ and $\mathrm{Mn}$ at Uppanar River was higher when compared to Mahanadi, Ganga and Brahmani, while it was several hundred times higher than Achankoil River [15, 16, 17, 18 and 19]. The present study revealed that pollutants found in river water are also present in pharmaceutical industrial effluents at higher frequencies of occurrence and concentration. Therefore, pharmaceutical industrial ETPs are clearly a significant point source for organic pollutants in surface waters.

\begin{tabular}{lllllll}
\hline Rivers & Cd & Cu & Pb & Zn & Mn & References \\
\hline Mahanadi River & - & 5.9 & 2.68 & 11.0 & 96.9 & Kanhauser et al., (1997) \\
\hline Achankovil River & 6.0 & 224 & 72 & 415 & 699 & Prasad et al., (2006) \\
\hline Ganga River & 5 & 10 & 120 & 60 & 260 & Aktar et al., (2010) \\
\hline Damodhar River & 300 & 3950 & - & - & - & Chatterjee et al., (2010) \\
\hline Brahmani River & 4.0 & 4.7 & 27 & 80.1 & 102 & Reza et al., (2010) \\
\hline Uppanar River & 36.08 & 191.5 & 98.5 & 201.38 & 273.93 & Present Study \\
\hline
\end{tabular}

Table 2. Comparison of dissolved metal concentration with other Indian River ( $\mu \mathrm{g} / \mathrm{L})$

\section{Conclusion}

As heavy metals are not decomposed biologically, level of these metals, beyond recommended limit, may exist in the river for quite a long distance and it may lead to the long term health-related problems to the people and communities using the water, particularly as a domestic supply source. The result of this work revealed that the mean level of heavy metals discharged into the river has exceeded the maximum permissible limit set by Indian Standards for Drinking Water. The resulting effect is the increase in background level of all the pollutants along the river. It is also observed that level of pollutants in the river during summer season is relatively higher when compared to the other seasons. When the quality of the river is compared with the Indian Standards recommended limits for source of water supply, the river was found to contain some heavy metals above the recommended limits, 
indicating pollution. Land-use changes in recent years have resulted in a significant deterioration of the water quality of the Uppanar River. Considering the fact that this area is highly populated with many industries and the final drainage of this river ends into the sea, the water quality and pollution status of this river system is of great concern. Therefore, in this study water samples that were taken during four consecutive seasons confirmed that the river has seriously been polluted with $\mathrm{Cu}, \mathrm{Pb}, \mathrm{Mn}, \mathrm{Zn}$ and $\mathrm{Cd}$. The result demonstrated that trace elements have originated from various pollutant sources; however, the main anthropogenic sources were industrial wastes, municipal wastes and run-off from agricultural fields.. Heavy metal concentration found in the edible part of fish species are within the WHO permissible limits for human consumption. Thus, there appears to be no immediate threat to the fisheries of the river due to heavy metal contamination. Though, the results indicate that the heavy metal contamination of the river affects the aquatic life including the fish, a scientific method of detoxification of the river water is essential to improve the health of these fish and in turn, the human beings consuming the fishes of the river. Despite mounting urban sprawl of Cuddalore old town in the past decade increased industrialization consequently followed by releasing of untreated industrial effluents into the river played a significant role in polluting the Uppanar River.

\section{Author details}

\section{Usha Damodharan}

Address all correspondence to: ushadamodhar@gmail.com

Department of Ecology and Environmental Sciences, Pondicherry Central University, Pondicherry, India

\section{References}

[1] Bakare AA, Lateef A, Amuda OS, Afolabi RO. The Aquatic toxicity and characterization of chemical and microbiological constituents of water samples from Oba River, Odo-oba, Nigeria. Asian Journal of Microbiology, Biotechnology and Environmental Sciences 2003; 5, 11-17.

[2] Odiete WO. Environmental physiology of animals and pollution 1999; 261. Lagos: Diversified Resources Ltd.

[3] Okafor N. Aquatic and waste Microbiology 1985; 1st edn. pp. 1-14. Enugu: Fourth Dimension Publishing Company Ltd.

[4] Sudhira HS, Kumar VS. Monitoring of lake water quality in Mysore City. In: International Symposium on Restoration of Lakes and Wetlands: Proceedings of Lake 2000. 
[5] Adeyemo OK. Consequences of pollution and degradation of Nigerian aquatic environment on fisheries resources 2003; The Environmentalist, 23(4), 297-306.

[6] APHA. 1992. American Public Health Association. Standard methods for the examination of water and wastewater. 18th Ed. Washington, D.C.

[7] Hutchinson T H. Reproductive and developmental effects of endocrine disruptors in invertebrates: in vitro and in vivo approaches. Toxicology Letters 2002; 131: 75-81.

[8] Romo-Kroger C M, Kiley JR, Dinator MI, Llona F. Heavy metals in the atmosphere coming from a copper smelter in Chile, Atmospheric Environment 1994; 28, 705-711.

[9] Wu YF, Liu CQ, Tu CL. Atmospheric deposition of metals in TSP of guiyang, PR China. Bulletin of Environmental Contamination and Toxicology 2008; 80 (5), 465-468.

[10] Venugopal T, Giridharan L, Jayaprakash M. Characterization and risk assessment studies of bed sediments of River Adyar-An application of speciation study. International Journal of Environmental Research 2009a; 3 (4), 581-598.

[11] Venugopal T, Giridharan L, Jayaprakash M, Velmurugan PM. A comprehensive geochemical evaluation of the water quality of River Adyar, India. Bulletin of Environmental Contamination and Toxicology 2009b; 82 (2), 211-217.

[12] IPCS Principles and methods for the assessment of risk from essential trace elements 2002. Geneva, World Health Organization, International Programme on Chemical Safety (Environmental Health Criteria 228).

[13] Agency for Toxic substances and Diseases Registry (2000). Toxic Profile for Chromium. Geneva, World Health Organization, International Programme on Chemical Safety (Environmental Health Criteria 228).

[14] Joint FAO/WHO Expert Committee on Food Additives. Evaluation of certain food additives and contaminants. Cambridge, Cambridge University Press, 1982 (WHO Food Additives Series, No. 17).

[15] Konhauser KO, Powell MA, Fyfe WS, Longstaffe F J, Tripathy S. Trace element chemistry of major rivers in Orissa State, India. Environmental Geology 1997; 29 (1- 2), 132-141.

[16] Aktar G, Williams C, David D. The accumulation in soil of cadmium residues from phosphate fertilizers and their effect on the cadmium content of plants. Soil Science 2010; 121, 86-93.

[17] Chatterjee SK, Bhattacharjee I, Chandra G. Water quality assessment near an industrial site of Damodar River, India. Environmental monitoring and Assessment 2010; 161 (1-4), 177-189.

[18] Prasad AL, Iverson A, Liaw. Newer Classification and Regression Tree Techniques: Bagging and Random Forests for Ecological Prediction. Ecosystems 2006; 9:181-199. 
[19] Reza R, Singh G, Heavy metal contamination and its indexing approach for river water. International Journal of Environment Science and Technology 2010; Vol. 7, No. 4, 2010, pp. 785-792 
Chapter 3

\title{
Contribution of Satellite Measurements to the Modeling and Monitoring of the Quality of Coastal Seawater
}

\author{
Houma Fouzia, Bachouche Samir, \\ Bachari Nour El Islam and Belkessa Rabah \\ Additional information is available at the end of the chapter \\ http://dx.doi.org/10.5772/53375
}

\section{Introduction}

The highly demographic increase in the developing countries led to a rapid expansion of the primary urban areas. Solid and liquid rejects coming from domestic consumption and industrial activities are spilled out on potential water sources such as seas, lakes and other natural areas. In order to protect the natural medium and to control the pollution caused by such rejects. It is necessary to achieve a continuous survey of the reject zones. Satellite imagery can be used to estimate, with a reasonable accuracy, the factors affecting the water quality. It has a great importance to achieve the necessary continuous monitoring of the relevant area with an overall analysis of its pollution. (Houma F and al, 2004)

Waste disposal in water affects and alters the chemical and physical characteristics of the water in question, consequently its light reflectance properties which can be detected by satellite imagery. These changes cause, in turn, an alteration of the water appearance. It is, therefore, reasonable to estimate the relations linking the variation of the chemical and physical properties to the variation of the spectral properties of water, or more precisely, to its reflecting power.

Water was sampled from sites of Oran and Algeria's bay, port, sea, as well as from the urban sewage and industrial refuse. Temperature $(\mathrm{T})$, acidity $(\mathrm{pH})$, turbidity $(\mathrm{TU})$, suspended material (SM), dissolved oxygen (DO), electrical conductivity $C$, chemical oxygen demand $(\mathrm{COD})$, biological oxygen demand at the fifth day $\left(\mathrm{BOD}_{5}\right)$ and reflectance of water from satellite SPOT were determined.

The reflectance coefficient of water at each of the studied areas has calculated using SPOT image at three bands: XSI $(0.5-0.59 \mu \mathrm{m}), \mathrm{XS} 2(0.6-0.69 \mu \mathrm{m})$ and XS3 $(0.7-0.79 \mu \mathrm{m})$. The aim 
of this study is to find the regression line (equation) and the correlation between the reflectance coefficient, calculated from satellite image, and each physical and chemical parameter.

The sea water pollution by hydrocarbons became alarming, considering the harmful effects caused on the environment. Pollution by hydrocarbons is the technological risk the most threatening in the area of Algiers due to the existence of a particularly polluting industrial zone at the origin of which a great sea traffic.

The satellite images however are the most used by the researchers to determine these pollutants, considering the width of the field of sight and the radiometric range of the satellites which extends from the visible to the infra-red and until the radar image.

In this work, we were interested to combine the information required by various satellites to characterize the sea water pollution by hydrocarbons. The optical images used are collected by the satellites Landsat MSS, TM and SPOT. The detection and the possible determination of the zones contaminated by hydrocarbons using the space techniques constitute an effective means to intervene in order to ensure the monitoring of the Algerian coasts.

A correlative analysis between the hydrocarbon contents and the reflectance calculated by the satellite images allow us to transform rough images into images treated and combined using a software of satellite image processing PCSATWIN. These images delimit and characterize the zones polluted by hydrocarbons.

Indeed, our objective consists of the development of a methodology based on the satellite data for the localization and the monitoring of the evolution of pollution by polyaromatic and total hydrocarbons. The analysis shows us that each sensor offers useful information and that the combination between these various informations makes it possible to propose a procedure of maps establishment that can be interpreted as aquatic pollution maps. (Spitzer \& Dirks, 1985 ; Baban ,1993 and Houma et al., 2010).

\section{Analysis on the ground and water sampling}

Knowledge of the water quality is an essential component in integrated coastal management. Direct supervision increased, coupled with the reflectance of the sea calculated from satellite sensors is necessary to determine the status of coastal waters.

We present the methodology used for modeling of chlorophyll and the phytoplankton that have an effect on the color and quality of marine waters. The use of satellite imagery has allowed mapping of parameters indicative of water pollution and photosynthetic organisms on the surface and at depth. The objective of the work is twofold:

- Get models between the spectral response of seawater with the physical properties of optical pollution parameters using ground measurements.

- Perform inversion models in order to achieve a mapping of the spatial and temporal variability of parameters in surface water and into the depths of coastal areas. 
The coastal zone water is the most significant part of the sea from nutritive resources point of view but also most subjected to the aggressions of pollution of various natures. The Algiers littoral is practically touched by various types of pollution. We note a significant urban density on the coast which pours its discharges in marine water and of the factories which reject their industrial waste and contribute to pollute the environment under the effect of the toxic and corrosive substances in addition to the very significant sea traffic present in the area.

The use of the remote sensing can advantageously replace the long, expensive and tiresome traditional methods for the monitoring of the quality of water.

The taking of images has encouraged the scientists to its use in various applications in marine sciences. The techniques used rest on a simple and effective concept which is to correlate the satellite data with in situ measurements. (Houma F and al, 2010)

The Algiers bay is located in the central part of the Algerian coast. It is characterized by its semicircular shape of an approximate surface of about $180 \mathrm{~km}^{2}$. It is limited to the East by Bordj El- Bahri (Cape Matifou) and to the West by Rais Hamidou (the Pescade headland). This area is very urbanized and the majority of the units are concentrated in the industrial zones of Oued Smar, El Harrach, Algiers seaport, Rouiba and Réghaia. The city is located on the Mediterranean coast, in the North of Africa with a latitude of $36^{\circ} 49^{\prime} 35^{\prime \prime}-36^{\circ} 49^{\prime} 50^{\prime \prime}$ and longitude of $03^{\circ} 14^{\prime} 50^{\prime \prime}-03^{\circ} 00^{\prime} 40^{\prime \prime}$ East. The zone of study is mainly contaminated by various sources of pollution and is subjected to several types of urban, industrial and oil wastes.

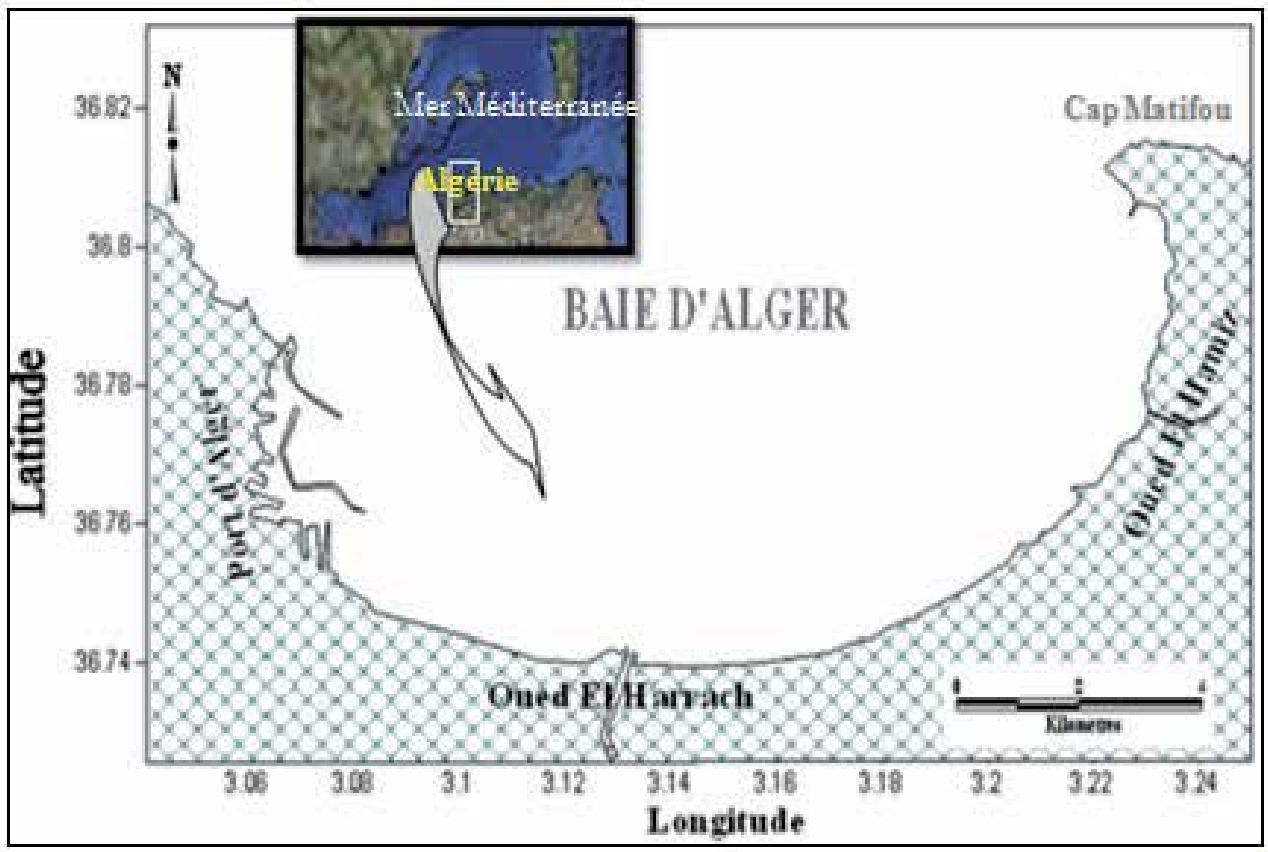

Figure 1. Location of the Bay of Algiers 
Within the evaluation framework of the coastal site contamination degree of Algiers bay by hydrocarbons. The analyses are carried out at the laboratory by applying the method "ultraviolet Spectrofluorimetry" for the polyaromatic ones and "the infra-red" for total hydrocarbons.

The choice of the site is not fortuitous; indeed studies on Algiers bay show clearly that all the coast is polluted by hydrocarbons.

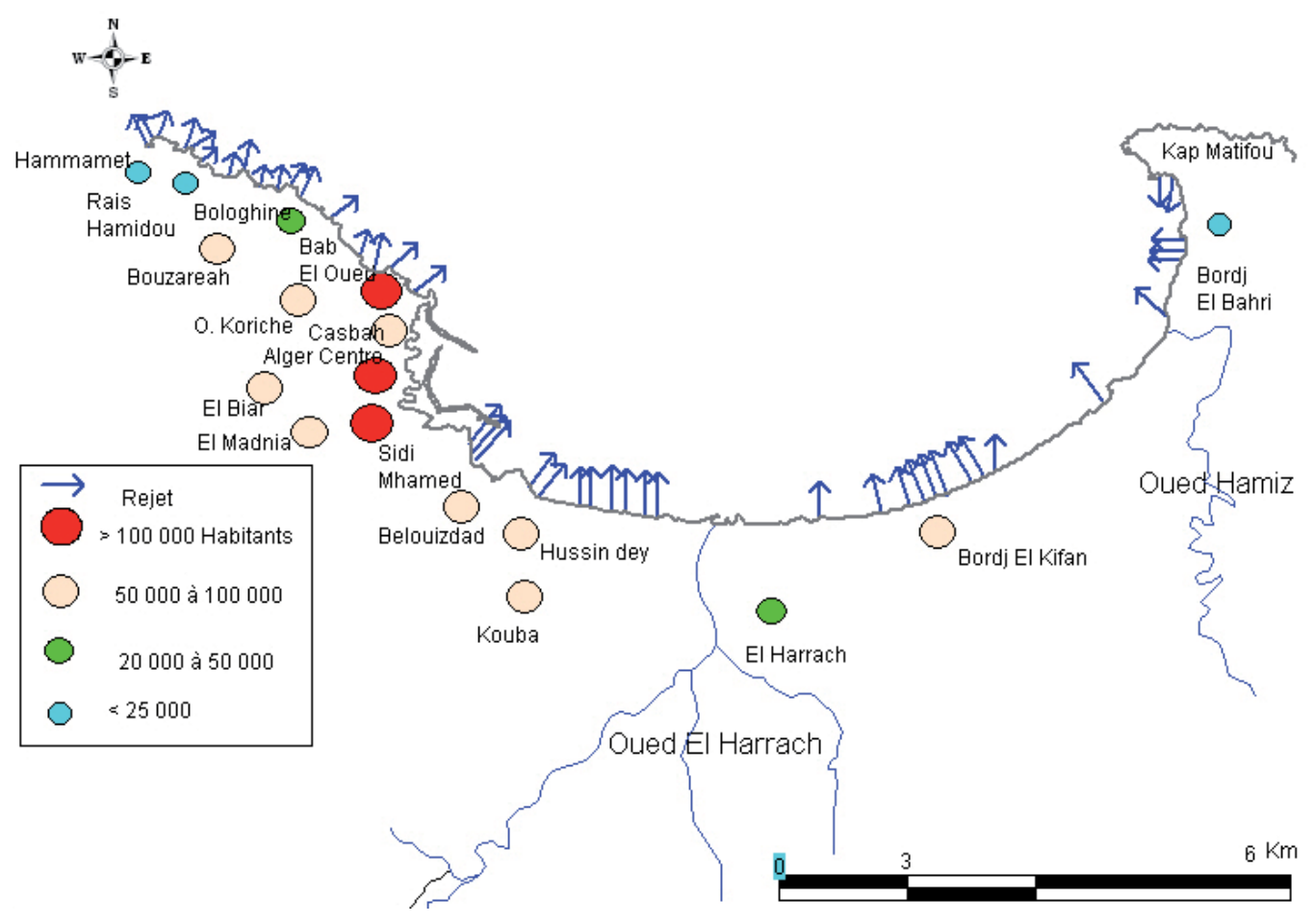

Figure 2. The main sewage discharges in the Bay of Algiers.

Since the first inhabited flights, studies on the quality of littoral water were identified according to their turbidity, in particular on the basis of the images acquired by the Gemini capsules correlated with in situ measurements. Since 1970, several scientists observed a positive correlation between the signal received by the sensor and the suspended matter content. The turbidity cartography of the surface and the estimate of the matters suspended based upon reflectance were carried out by Spitzer et Baban. These works rest on the strong correlation observed between the images and the content of these measured concentrations in situ. A significant correlation between the numerical account of the first channel of the satellite Landsat TM and the suspended matter concentration was carried out. 

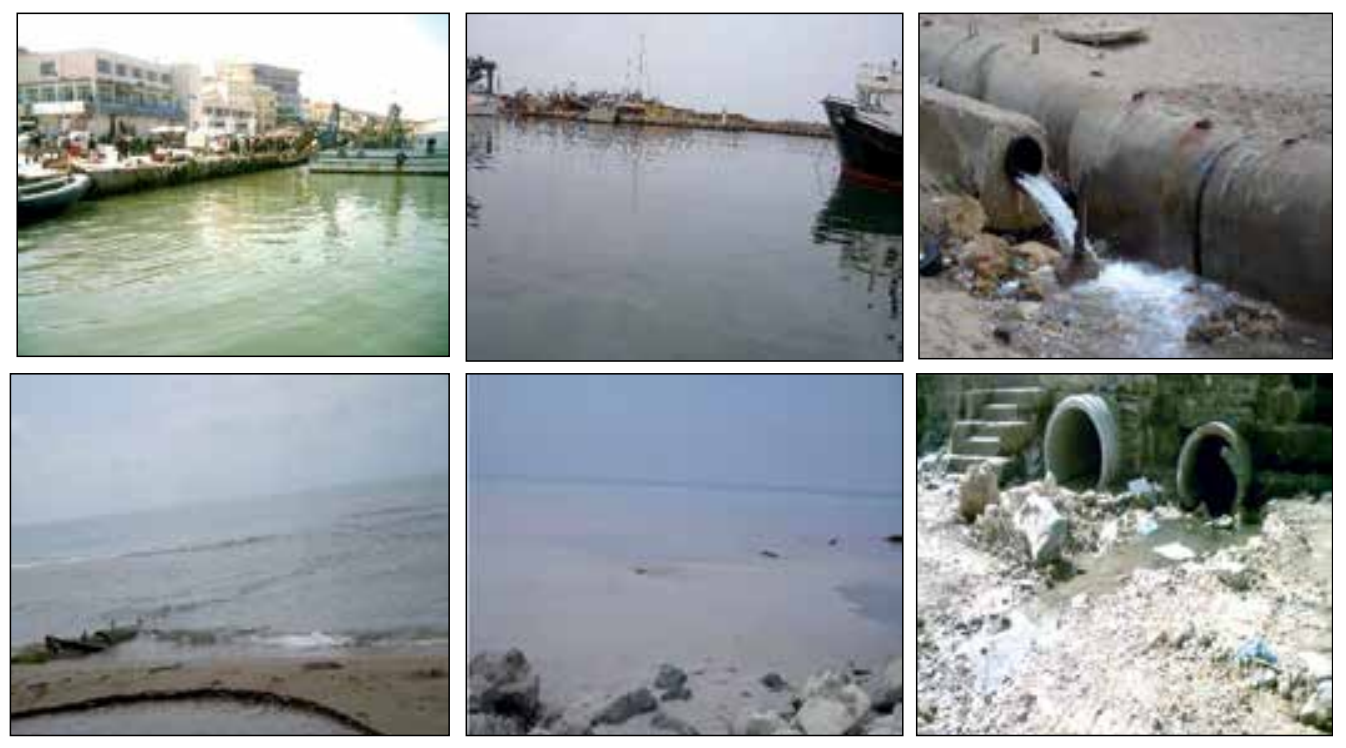

Figure 3. Oil pollution, industrial and urban discharges the level of the Bay of Algiers

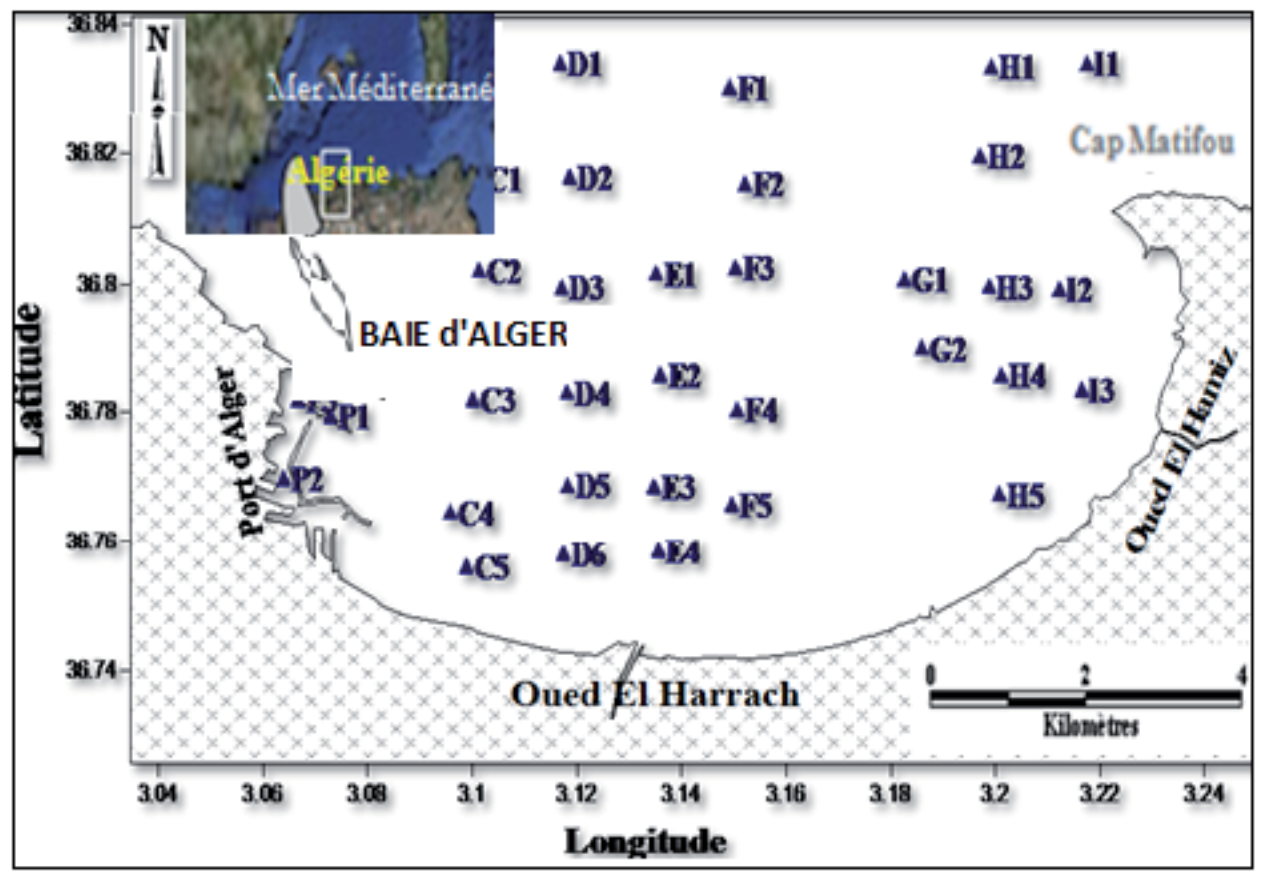

Figure 4. Location of sampling stations during of the oceanographic cruise 2009 


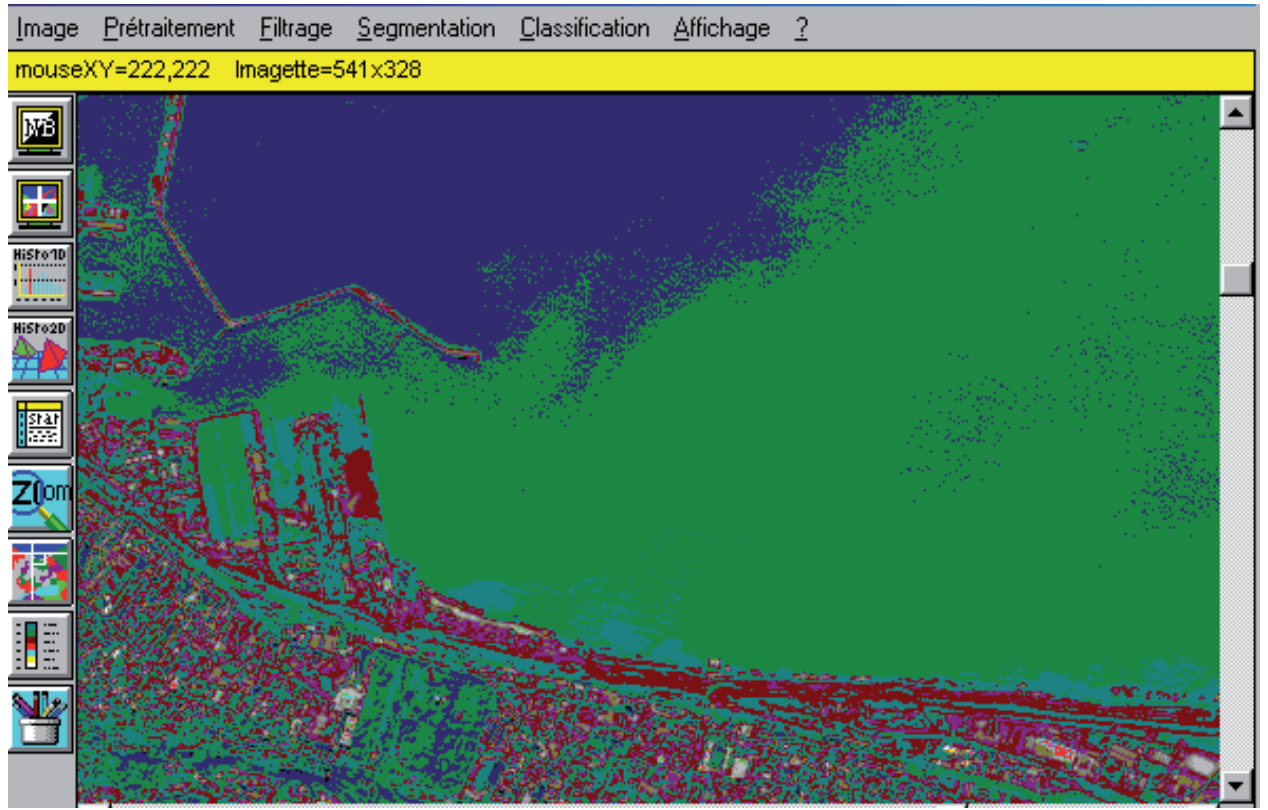

Figure 5. Rough image of bay of Algiers taken by the satellite SPOT.
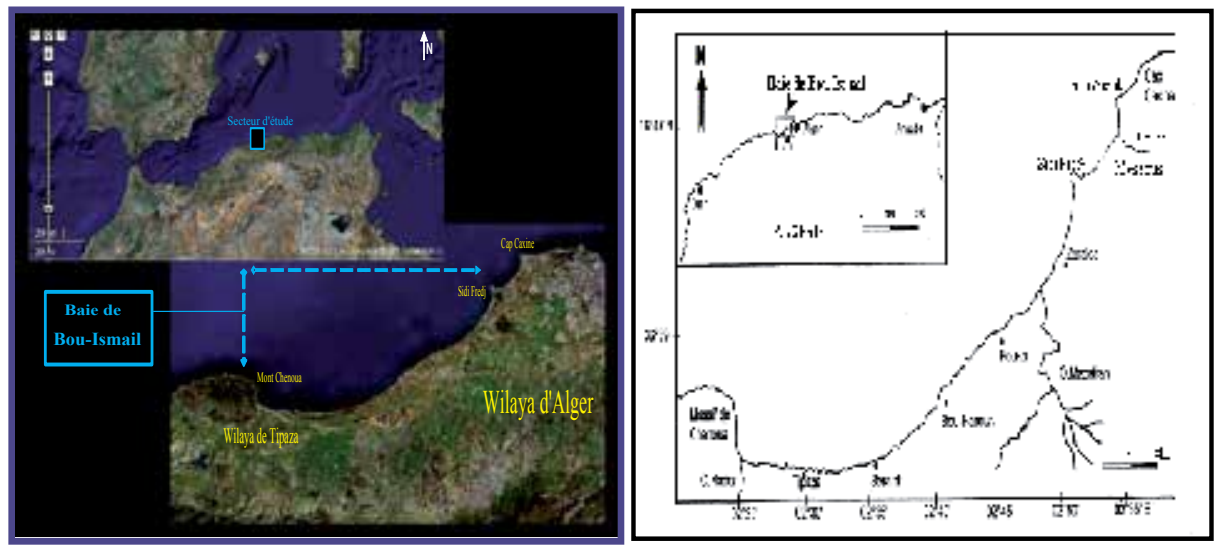

Figure 6. Geographical location of the Bay of Bousmail 

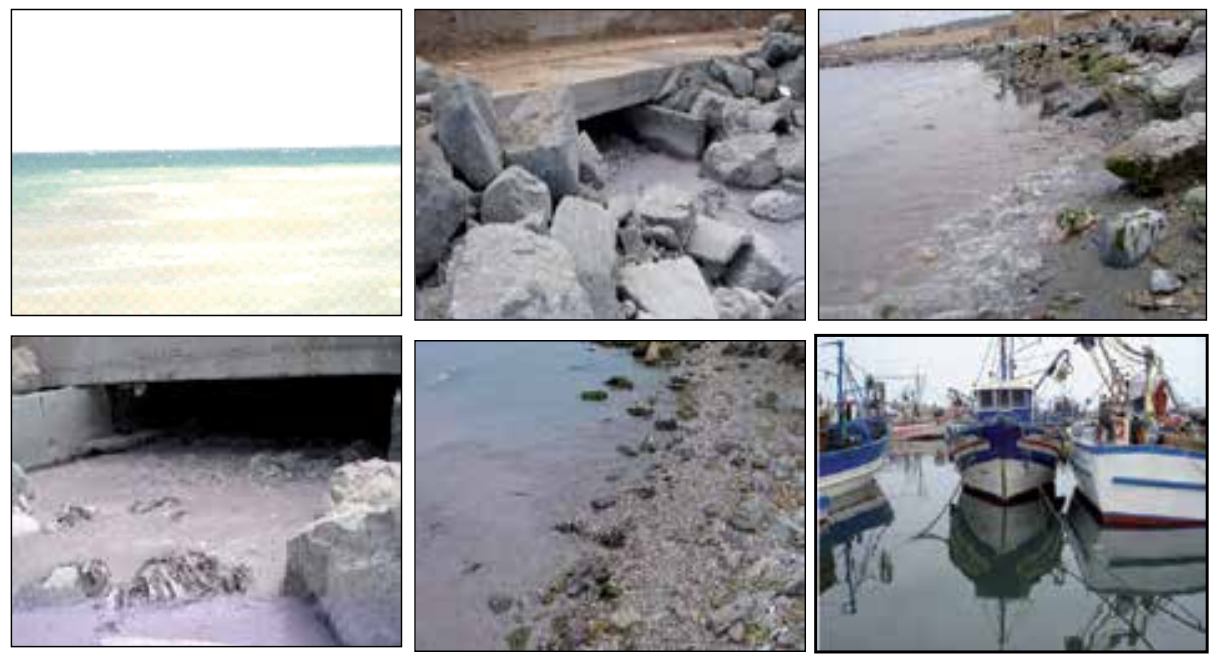

Figure 7. The main sewage discharges in the Bay of Bousmail

The spectral bands Thematic Mapper were used more to correlate with the spectral properties of water and its content in organic matter or for the characterization of the colour, salinity and the sea water chlorophyll concentration.

While taking as a starting point the various developed approaches and the characteristics of the satellites SPOT and Landsat, we have tried to highlight the use of the teledetection in order to find relations between the optical parameters and the hydrocarbon concentration present in water.

A model of interaction of the solar spectrum with the system ground-atmosphere-sensor is thus developed in order to transform the rough images into reflectance images.

The results of reflectance obtained from the numerical data SPOT and Landsat are correlated with the results expressing the content of polyaromatic and total hydrocarbons. The relations of the correlative analysis are given in each spectral band of the satellites to distinguish the best coefficients of correlation and then to apply the best adjustment in order to transform a rough image into indicating image of pollution.

\section{Determination of water reflectance by SPOT imagery}

Radiation reaching the satellite is made up of the global spectral radiation reflected by the ground while passing again through the atmosphere $\mathrm{R}_{\text {ground - atm }}$ and part of diffused radiation by the Earth's atmosphere towards the satellite $\mathrm{R}_{\text {atm-sat }}$ the radiation which reaches the sensor is: 


$$
\begin{array}{ll}
\mathrm{R}_{\text {sensor }}=\mathrm{R}_{\text {ground-atm }}+\mathrm{R}_{\text {atm-sat }} & \mathrm{a} \\
\mathrm{R}_{\text {sensor }}(\lambda)=\mathrm{R}_{\text {atm- sat }}(\lambda)+\mathrm{G}_{\lambda}\left(\theta_{\mathrm{S}}\right) \mathrm{T}_{\lambda}\left(\theta_{\mathrm{v}}\right) \rho_{\mathrm{l}} & \mathrm{b}
\end{array}
$$

With:

$$
\begin{array}{ll}
R_{\text {ground-atm }}=G_{\lambda}\left(\theta_{S}\right) T_{\lambda}\left(\theta_{v}\right) \rho_{\lambda} /\left(1 \rho_{\lambda} \omega\right) & a \\
R_{\text {sat }_{l}}=E_{\text {atmo }_{l}}+G\left(\theta_{s}\right) T_{\lambda}\left(\theta_{v}\right) \rho_{\lambda} & b
\end{array}
$$

$Q_{\lambda}$ is the coefficient of reflectance, $G_{\lambda}$ is the total radiation which reaches the ground, it represents the sum of a direct radiation and a radiation diffused by the air molecules and the aerosols towards the ground; $\mathrm{T}_{\lambda}\left(\theta_{\mathrm{v}}\right)$ is the function of the radiation transmission into upper atmosphere; $\omega$ is the spherical albedo for the atmosphere which explains the multiple reflexions between the surface of the ground and the atmosphere; $\theta_{\mathrm{S}}$ is the solar angle of zenith in degrees and $\theta_{v}$ is the angle of sight of the sensor at the time of while taking the images. (Houma and Bachari, 2012)

Since the reflectivity of water is low, the equation (1) can be roughly linear as in equation (1b):

The radiance of measured by a satellite sensor results from the solar radiation affected by several process: absorption and diffusion on both downward and upward path by the atmospheric components, reflection at the ground surface.

where: $E_{a t m o}$ is just the radiance of the atmosphere if the ground was nonreflecting $\left(Q_{\lambda}=0\right)$; $G_{\lambda}$ is a global radiation include a direct radiation and a diffuse radiation.; $T_{\lambda}\left(\theta_{v}\right)$ is a transmission function from the ground to the top of the atmosphere for the radiance; $\mathrm{Q}_{\lambda}$ is the hemispherical reflectance of the ground, $\mathrm{A}$ is the spherical albedo for the atmosphere which account for multiple scattering and reflections between the ground surface and the atmosphere $; \theta_{\mathrm{s}}$ solar zenith angle in degrees and $\theta_{\mathrm{v}}$ viewer angle in degree

When the soil reflectance is a weak the equation (1) can be approximately in linear form as in equation $(2 b)$ :

The SPOT satellite observes the earth, in three spectral channels XS1 $(0.5$ - $0.59 \mu \mathrm{m})$, XS2 $(0.6$ $0.69 \mu \mathrm{m}), \mathrm{XS} 3(0.7-0.79 \mu \mathrm{m})$ with a spatial resolution of $20 \mathrm{~m}$ and with a panchromatic channel $(0.6-0.81 \mu \mathrm{m})$ with a spatial resolution $10 \mathrm{~m}$. In these SPOT spectral windows, only ozone absorption, molecular and aerosol diffusion, affect radiation in its double way sun-ground and ground-captor (Bachari.N et al, 1997).

In the first part of our work we simulate the measurement achieved by the captor for pure water (from the sea far from any pollution).

$$
\begin{aligned}
& B_{\text {simulated }}=\frac{\int_{\Delta \lambda} R_{\text {sat } \lambda} S_{\lambda} d \lambda}{\int_{\Delta \lambda} E_{0 \lambda}(1+f) \cos (\theta) S_{\lambda} d \lambda} \quad a \\
& B_{\text {simulated }}=C_{J} \cdot B_{\text {image }} \quad \mathrm{b}
\end{aligned}
$$


where $\mathrm{E}_{0 \lambda}$ is a mean solar exo-atmospheric irradiances in $\mathrm{w} \mathrm{cm}^{-2} \mu \mathrm{m}^{-1} ;(1+\mathrm{f})$ is an earth-sun distance in astronomical units. The " $\mathrm{f}$ " for a specific day can be approximated by the relation of Gurney and Hall,1983; $f=0.0167 \sin (2 \pi(j-93.5)) / 365)$ where $j$ is day number of the year, $S_{\lambda}$ : is a sensitivity of record and $\Delta \lambda$ is a band of record.

In second part we using the imagery treatment (N.Bachari et al, 1994), we determine the real value evaluated by the satellite for a deep sea water $\left(B_{\text {real }}\right)$. We use a both the simulated value $\left(B_{\text {simulated }}\right)$ and the real value to calculated the calibration $C_{j}$ factor for each channel :

$$
\mathrm{C}_{\mathrm{i}}=\left(\mathrm{B}_{\text {simulated }} / \mathrm{B}_{\text {real }}\right)_{\mathrm{i}}
$$

We take the image and we transform the digital account into radiance by the linear relation :

$$
\mathrm{E}=\pi \cdot \mathrm{C}_{\mathrm{j}} \cdot \mathrm{B}
$$

for each channel $\mathrm{j}$ We use the reverse model to calculate the reflectance Ref $_{\mathrm{j}}$ for each pixel from the following relation:

$$
\begin{array}{ll}
\operatorname{Re} f_{j}=\frac{\pi C_{J} B-\int_{\Delta \lambda} R_{a t m o} S_{\lambda} d \lambda}{\int_{\lambda} G_{\lambda} T_{\lambda}\left(\theta_{v}\right) S_{\lambda} d \lambda} & \mathrm{a} \\
E=\pi L=A+K<\rho> & \mathrm{b} \\
\Pi L=R_{\text {atm-sat }}+R_{\text {sol-atm }} & \mathrm{c} \\
\Pi L=A+K<\rho> & \mathrm{d}
\end{array}
$$

The brightness simulated in the general case is given by:

$$
B_{\text {simulated }}=\frac{\int_{\Delta \lambda} R_{\text {sensor }(\lambda) \cdot} S(\lambda) \cdot d \lambda}{\int_{\Delta \lambda} S(\lambda) d \lambda}
$$

$S(\lambda)$ represents the spectral band.

If the real brightness of a given image is $B_{\text {image, }}$ we must have a first order relation of approximation such as in equation $(3 b)$

$$
\begin{aligned}
& A=\frac{\int_{\lambda_{1}}^{\lambda_{2}} R_{\text {capteur }} S(\lambda) d \lambda}{\int_{\lambda_{1}}^{\lambda_{2}} S(\lambda) d \lambda}, \text { and : } \quad K=\frac{\int_{\lambda_{1}}^{\lambda_{2}} G_{\lambda} T_{\lambda} S(\lambda) d \lambda}{\int_{\lambda_{1}}^{\lambda_{2}} S(\lambda) d \lambda} \\
& B_{\text {image }}=\frac{\int_{\Delta \lambda} R_{\text {sensor }}(\lambda) \cdot S(\lambda) d \lambda}{\int_{\Delta \lambda} E_{0}(\lambda)(1+f) \cos (\theta) S(\lambda) d \lambda}
\end{aligned}
$$


$C_{\mathrm{J}}$ is the factor of calibration of the sensor; $E_{0}(\lambda)(1+f)$ is the average radiance outside the solar atmosphere expressed in unit $\mathrm{W} \mathrm{cm}^{-2} \mu \mathrm{m}^{-1} ;(1+\mathrm{f})$ is the distance earth-sun in astronomic units; $\mathrm{f}$ is the coefficient given by the relation of "Gurney and Hall, (1983)" such as for one day specific: $\mathrm{F}=0.0167 \sin (2 \pi(\mathrm{J} 93.5)) / 365)$ where $\mathrm{J}$ is the number of days of the year.

\subsection{Rough satellite data conversion into reflectance}

The calibration of the numerical accounts in reflectance of the set ground and atmosphere is carried out according to the method suggested by the users guide Spot. It is obtained by a linear transformation of numerical accounts into brightness:

\section{$\mathrm{L}=\mathrm{CN} / \mathrm{G}$}

Where: $\mathrm{L}$ : is brightness in $\mathrm{W} / \mathrm{m}^{2} / \mathrm{Sr}$; $\mathrm{N}$ : the numerical account

G: the gain of the sensor absolute calibration

For an application in images, it is thus necessary to be able to transform values of brightness into numerical account then in reflectance values and that by taking into account a considerable zone representing the sea in a given scene. Knowing the values of brightness for a given channel and each type of sensor, the data is expressed in milliwatts per centimetre square per steradian by micrometer $\left(\mathrm{W} / \mathrm{m}^{2} / \mathrm{Sr}\right)$.

The passage to reflectance values is done in two stages:

- Brightness conversion $\mathrm{L}_{\lambda}$ into numerical account $\mathrm{CN}$.

- Conversion into reflectance Ref on the level of each pixel.

The relation between the numerical account of a pixel $\mathrm{CN}$ and its brightness on the level of the sensor is linear. We can write the relation in the form:

$$
\mathrm{L}_{\lambda}=\mathrm{a} \cdot \mathrm{CN}+\mathrm{a}_{\mathrm{o}}
$$

$\mathrm{a}$ and $\mathrm{a}_{\mathrm{o}}$ are called coefficients of calibration.

By making an approximation to this function which represents a whole of numerical data by an analytical function we could have the following relation:

$\mathrm{CN}_{\mathrm{XS} 1}=1,23 \cdot \mathrm{L}_{\mathrm{XS} 1}-0,22$

For the same conditions of simulation, the constants are calculated by using the spectral signatures of sea water for the data of the channels. For HRV SPOT, the results are reproduced in the following table: 


\begin{tabular}{lll}
\hline Channel & $\mathbf{a}$ & $\mathbf{a}_{\mathbf{o}}$ \\
\hline XS1 & 1,23 & 0,22 \\
\hline XS2 & 1,24 & $-0,08$ \\
\hline XS3 & 1,32 & $-0,59$ \\
\hline
\end{tabular}

Table 1. Coefficients of calibration for HRV SPOT.

Combining between the equations which express spectral brightness and reflectance on the level of the ground, we find also a linear relation between the numerical account and the reflectance Ref which can be written in the form:

$$
\operatorname{Ref}=\mathrm{b} . \mathrm{CN}+\mathrm{b}_{\mathrm{O}}
$$

In this case term Ref contains all the informations on the optical properties and the terrestrial scene observed. The parameters $b$ and $b_{o}$ depend on the atmospheric and astronomical conditions.

We present the graph determining the linear relation of calibration between the reflectance and the numerical account for the channels of SPOT XS1, XS2 and XS3.

Application:

\begin{tabular}{cccc}
\hline & L(w.m $\left.{ }^{-2}\right)$ & CN & Ref. \\
\hline Channel XS1 & 53.935 & 66.560 & 03215 \\
\hline Channel XS2 & 17.734 & 21.910 & 0.2606 \\
\hline Channel XS3 & 6.0591 & 7.408 & 0.2101 \\
\hline
\end{tabular}

\begin{tabular}{llll}
\hline \multicolumn{2}{l}{ Paramètres atmosphériques } & \multicolumn{2}{l}{ Paramètres astronomiques } \\
\hline Ozone $\mathrm{Cm}$ & 0.30 & Jour & 344 \\
\hline Humidité relative $\%$ & 80 & Heure & 11.26 .00 \\
\hline Température K & $\mathrm{T}^{\circ} \mathrm{C}+273$ & Latitude & $36^{\circ} 38^{\prime} 58.67^{\prime \prime} \mathrm{N}$ \\
\hline Visibilité Km & 20 & Longitude & $2^{\circ} 24^{\prime} 2.45^{\prime \prime} \mathrm{E}$ \\
\hline Altitude de l'ozone & 200 & $\beta 0$ & 0 \\
\hline Alpha (a) & 1.5 & $\theta \mathrm{v}$ & $10^{\circ}$ \\
\hline Fc & 0.9 & $\varphi$ & $45^{\circ}$ \\
\hline$\omega 0$ & 0.9 & $\psi$ & $60^{\circ}$ \\
\hline
\end{tabular}

- The reflectance of water is strong in the first channel compared to the second channel where it is also more significant as that calculated in the channel three.

- The reflectance of the zones loaded with sediments and that of the polluted zones is stronger compared to the reflectance of the water zones not loaded.

Table 2. The input parameters for the SDDS 


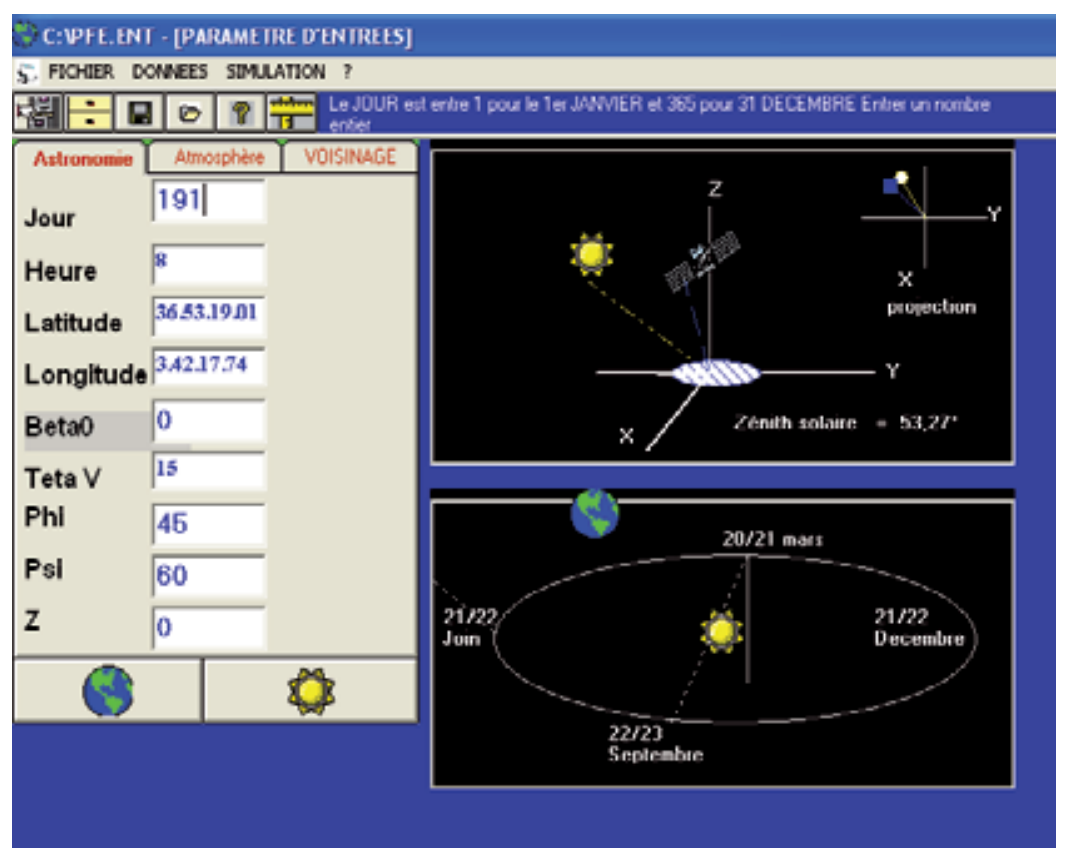

Figure 8. Atmospheric and astronomical data by SDDS software

\begin{tabular}{|c|c|c|c|c|c|c|c|}
\hline Téta V & & 10 & & & 20 & & \\
\hline Stations & Prof & SPOT 1 & SPOT 2 & SPOT3 & SPOT 1 & SPOT 2 & SPOT 3 \\
\hline 1 & 1 & 49,463 & 23,237 & 5,2607 & 49,401 & 23,536 & 5,3053 \\
\hline 2 & 1,5 & 48,476 & 21,265 & 5,0766 & 48,435 & 21,544 & 5,0993 \\
\hline 3 & 1,5 & 48.451 & 21.692 & 5.2331 & 48.412 & 21.975 & 5.2583 \\
\hline 4 & 1,5 & 48.451 & 21.692 & 5.2331 & 48.412 & 21.975 & 5.2583 \\
\hline 5 & 1,5 & 48,996 & 21,938 & 5,2943 & 48,957 & 22,224 & 5,3198 \\
\hline 6 & 2 & 47,567 & 19,736 & 4,9991 & 47,545 & 19,990 & 5,0104 \\
\hline 7 & 2 & 47,567 & 19,737 & 5,0061 & 47,545 & 19,991 & 5,0174 \\
\hline 8 & 2 & 35,627 & 15,095 & 3,8516 & 35,612 & 15,289 & 3,8612 \\
\hline 9 & 4 & 44.602 & 16.728 & 5.0852 & 44.668 & 16.884 & 5.0860 \\
\hline 10 & 4,5 & 43,973 & 16,279 & 5,0888 & 44,020 & 16,414 & 5,0892 \\
\hline 11 & 4,5 & 43.965 & 16.271 & 5.0829 & 44.012 & 16.406 & 5.0832 \\
\hline 12 & 4,5 & 43.985 & 16.291 & 5.0971 & 44.032 & 16.427 & 5.0974 \\
\hline 13 & 5 & 32.129 & 10.226 & 2.3493 & 32.093 & 10.306 & 2.3495 \\
\hline 14 & 5 & 32,303 & 10,156 & 2,3292 & 32,266 & 10,235 & 2,3293 \\
\hline 15 & 5 & 32,129 & 10,226 & 2,3493 & 32,093 & 10,306 & 2,3495 \\
\hline 16 & 5 & 32,481 & 11,916 & 3,8032 & 32,524 & 12,002 & 3,8034 \\
\hline 17 & 5,5 & 31,71 & 10,014 & 2,3491 & 31,684 & 10,083 & 2,3492 \\
\hline 18 & 6 & 31,313 & 9,8473 & 2,3490 & 31,295 & 9,9059 & 2,3491 \\
\hline 19 & 8 & 29,908 & 9,4613 & 2,3490 & 29,917 & 9,4914 & 2,3490 \\
\hline 20 & 8,5 & 29,912 & 11,107 & 3,8071 & 29,992 & 11,134 & 3,8071 \\
\hline
\end{tabular}

Table 3. Luminances $L\left(w \cdot m^{-2}\right)$ on the three channels SPOT HRV 


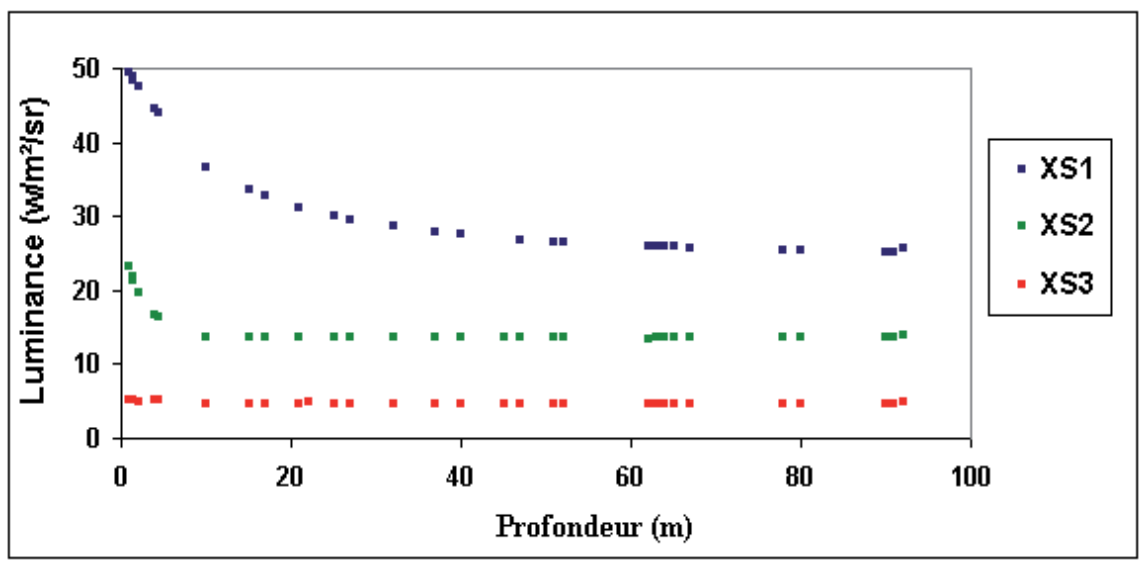

Figure 9. The reflectance in the the water column on the channels (SPOTXS). (Houma et al,2010)

\section{Determination of water reflectance by SPOT imagery}

The radiance of measured by a satellite sensor results from the solar radiation affected by several process: absorption and diffusion on both downward and upward path by the atmospheric components, reflection at the ground surface. The SPOT satellite observes the earth, in three spectral channels XS1 $(0.5-0.59 \mu \mathrm{m}), \mathrm{XS} 2(0.6-0.69 \mu \mathrm{m}), \mathrm{XS} 3(0.7-0.79 \mu \mathrm{m})$ with a spatial resolution of $20 \mathrm{~m}$ and with a panchromatic channel $(0.6-0.81 \mu \mathrm{m})$ with a spatial resolution $10 \mathrm{~m}$. In these SPOT spectral windows, only ozone absorption, molecular and aerosol diffusion, that affects radiation in its double way sun-ground and ground-captor (Bachari.N et al, 1996).

The SPOT satellite observes the earth, in three spectral channels with a spatial resolution of $20 \mathrm{~m}$ and with a panchromatic channel $(0.6-0.81 \mu \mathrm{m})$ with a spatial resolution $10 \mathrm{~m}$. In these SPOT spectral windows, only ozone absorption, molecular and aerosol diffusion, affect radiation in its double way sun-ground and ground-captor (Bachari.N et al, 1996).

In the first part of, we simulate the measurement achieved by the captor for a pure water (from the sea far from any pollution).

Turbidity and suspended solids have one comment effect in reducing light penetration thereby suppressing primary production in the form of algae and macrophates. This, in turn affects the available dissolved oxygen.

The oxygen needed for chemical oxidation of organic matter and the accompanied minerals is expressed as COD. Therefore, higher values of this parameter means more organic pollution. $\mathrm{BOD}_{5}$ estimates the oxygen needed for biological oxidation of organic and inorganic matters by organisms which are actually present in the polluted water. So, the ratio COD/ $\mathrm{BOD}_{5}$ refers to the capacity of organisms found in the water to oxidise the organic matter found in the medium. For easier monitoring water quality we could use the satellite imagery to expect, by 
excellent validity, the capability of the water to reduce the organic pollution resulted from urban discharge. Saprobity is a biocenotial expression of $\mathrm{BOD}_{5}$. Many investigators (Zelinka and Marvan, 1957; Rothshein, 1977 and Sladecek, 1973) showed the relation of saprobic zones to the $\mathrm{BOD}_{5}$ especially within the limosaprobity Sladecek and Tucek (1975) modified this relation and showed the abundant organisms at different saprobic index. They reported that their diagram is valid in $90-95 \%$ of cases. According to Sladecek (1969 and 1973 ), our BOD values ( 50 - 500) represent saprobic index between 3.5 to 6.5 which have saprobity degrees of polysaprobity ( sea in this work), isosaprobity ( port, zone3 and P-lac1), and metasaprobity ( outlet1, outlet2 and Plac2). According to Graham category (1965) our areas are seriously (sea, port, zone 3, and P.lac1) and grossly (outlet 1,outlet2 and P.lac2) polluted.

At such saprobic index the self purification and decay is going under anaerobic condition.

The substances which determine the optical properties of water surfaces, and then influence their reflectivity, may be classified in three categories : i) the alive phytoplankton and the detritus which come with it ;ii) the suspended particles; iii) the dissolved organic matter.The phytoplankton and the biogenic detritus which are associated with it have generally the same colour. In most oceanic waters and in some coastal waters where terrigenous supplies are little, the influence of the phytoplankton is dominant.In natural conditions; it is very difficult to dissociate the effects of the phytoplankton and those of the biogenic detritus on the coefficient of absorption for which only global estimations are made. The phytoplankton cells and the particles correspond to the biogenic detritus causing a Mie diffusion of the light which does not much depended on the wavelength. Therefore, the colour of water gradually takes a green shade with the increase of the phytoplankton concentration. As it was expected, our results show that for polluted waters.

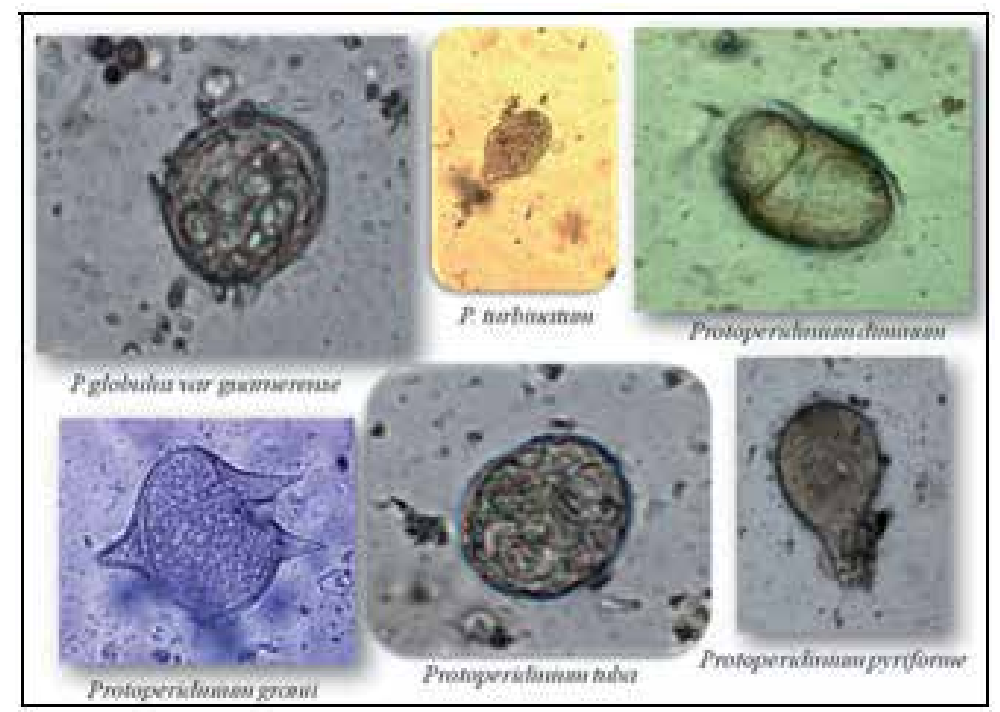

Figure 10. Phytoplankton species of genera (Protoperidinium et Ceratium) identifed using an inverted microscope (Gx40). 
A high correlation $(r=0.65)$ between turbidity and suspended material was found. Turbidity and suspended solids have one comment effect in reducing light penetration thereby suppressing primary production in the form of algae and macrophates. (Ferrari, 1992). This, in turn affects the available dissolved oxygen. Our results confirmed this situation which showed a high negative correlation between turbidity and dissolved oxygen $(r=0.87)$. The following regression equation regression is derived.

$$
\mathrm{DO}=-0.0252 \mathrm{Tu}+2.54552
$$

The oxygen needed for chemical oxidation of organic matter and the accompanied minerals is expressed as COD. Therefore a higher value of this parameter means more organic pollution. $\mathrm{BOD}_{5}$ estimates the oxygen needed for biological oxidation of organic and inorganic matters by organisms which are actually present in the polluted water. So, the ratio $\mathrm{COD} / \mathrm{BOD}_{5}$ refers to the capacity of organisms found in the water to oxidize the organic matter found in the medium. The results showed that this ratio increased with pollution degree and with reflectance $(r=0.9)$ at the different reflectance channels. For easier monitoring water quality we could use the satellite imagery to expect, by excellent validity, the capability of the water to reduce the organic pollution resulted from urban discharge. Moreover, the biological parameters could be calculated from each other since they are highly correlated $\left(r^{2}=0.68-0.96\right)$.

Saprobity is a biocenotial expression of $\mathrm{BOD}_{5}$. Many investigators (Zelinka and Marvan, 1957; Rothshein, 1977 and Sladecek, 1973) showed the relation of saprobic zones to the $\mathrm{BOD}_{5}$ especially within the limosaprobity. Sladecek (1975) modified this relation and showed the abundant organisms at different saprobic index. They reported that their diagram is valid in $90-95 \%$ of cases.

However, our results showed that the concentration of the dissolved oxygen in sea and port is moderate which means that the regression succession of saprobic cycle is continued under aerobic condition which may shorten this process toward less saprobity. It seems that the main sewage sites have reached the progressive direction of saprobity. It is now in the regressive succession of the saprobity and this process is more progressed in sea and port where more dissolved oxygen than in other areas where less dissolved oxygen. Outlet1,2 and Plac2 are suffering of the bad effect of both low dissolved oxygen and high turbidity.

The sites should be examined to determine the saprobity degree by biological indicators in order to know how the ecological system is developed.

According to a program developed by Bachari and Beabadji (1994), we used the equation

$$
\text { Ref2 }=0.0192 \mathrm{COD} / \mathrm{BOD}_{5}-0.0202 \quad\left(\mathrm{r}^{2}=0.92\right)
$$

to compose the figures 3 and 4 which clearly showed different distinct colour subareas in each of the studied area. Each colour indicates a different degree of water quality or pollution. By this technique it is possible to construct a very beautiful and global picture for degree of 
unknown pollution spread over a wide water surface with relatively less expanses and rapid evaluation.

Correlation coefficient were very low $(\mathrm{r}<0.15)$ between reflectance and some water physical parameters ( $\mathrm{T}, \mathrm{pH}$ and $\mathrm{C})$.

However, reflectance was highly correlated $(r=0.83-0.85)$ with the rest of physical (TU, SM) and biological (DO, COD, $\left.\mathrm{BOD}_{5}\right)$ parameters $(\mathrm{r}=0.67-0.92)$.

\begin{tabular}{|c|c|c|}
\hline Fonctions & Conversions radiométriques & $\mathbf{R}$ \\
\hline Turbidité (NTU) = f( Ref TM1) & Turbidité $\left(\right.$ NTU) $=215,5 \operatorname{Ref}^{2}+231,6 \operatorname{Ref}+5,183$ & $+0,90211$ \\
\hline Turbidité (NTU) = f (Ref XS1) & Turbidité = 315,9 Ref (XS1) - 1,670 & $+0,88567$ \\
\hline $\operatorname{MES}(\mathrm{mg} / \mathrm{l})=\mathrm{f}(\operatorname{Ref} X \mathrm{~S} 1)$ & $\operatorname{MES}(\mathrm{mg} / \mathrm{l})=439,1 \operatorname{Ref}(\mathrm{XS} 1)-3,611$ & $-0,87023$ \\
\hline Turbidité (NTU) = f (Ref TM2) & Turbidité = 131,1 Ref (TM2) - 1,059 & $+0,84108$ \\
\hline $\operatorname{Ref}(X S 1)=f($ Chlr) & $\operatorname{Ref}(\mathrm{XS1})=0,17 \cdot \operatorname{Ln}(\mathrm{Ch} \mid \mathrm{r})+0,692$ & $+0,89532$ \\
\hline $\operatorname{Ref}(T M 1)=f(C h l r)$ & $\operatorname{Ref}(\mathrm{TM} 1)=-1,224{ }^{*} \mathrm{Ch}\left|\mathrm{r}^{2}+1,224 * \mathrm{Ch}\right| \mathrm{r}+0,134$ & $+0,81403$ \\
\hline $\operatorname{Ref}(T M 2)=f(C h l r)$ & $\operatorname{Ref}(\mathrm{TM} 2)=0,523^{*} \mathrm{Chlr}+0,168$ & $+0,76400$ \\
\hline
\end{tabular}

- Concentrations of chlorophyll a and suspended matter are specified in units mg/l.

Table 4. Correlations of reflectances and indicators for pollution of seawater obtained from the visible channels (SPOTXS) in the Algiers Bay. Database (Oceanographic Campaigns 2009)

\section{Pollution map}

By using software PCSATWIN we have transformed the reflectance image into an image which makes it possible to estimate a certain extent the pollution of the environments. Indeed, there is a strong relation between the reflectances and these components content. Actually, the colour of sea water which is one of the obvious organoleptic descriptors, remains always a significant factor of differentiation which informs about the gleam of water, about its quality and which can be useful like an indicator of its transparency.

However, it seems that the correlation is better for XS1 than XS2, and XS2 than XS3 on the satellite SPOT HRV. Landsat TM gives a strong connection on the first two channels while sensor MSS4 presents only the channel interesting for our application.

Spectral bands XS1, TM1, TM2 and MSS4 give the best coefficients of correlation with corresponding reflectances Ref (XS1), Ref (TM1), Ref (TM2) and Ref (MSS4). They are thus best adapted for the follow-up of the quality of water. The lowest values are observed on channels XS3, TM5, TM6, MSS6 and MSS7 what is entirely logical since the absorption of water becomes very significant in this infra-red band, on the other hand the diffusion of the radiation becomes very weak and almost negligible what decreases the information acquired by the sensors. 


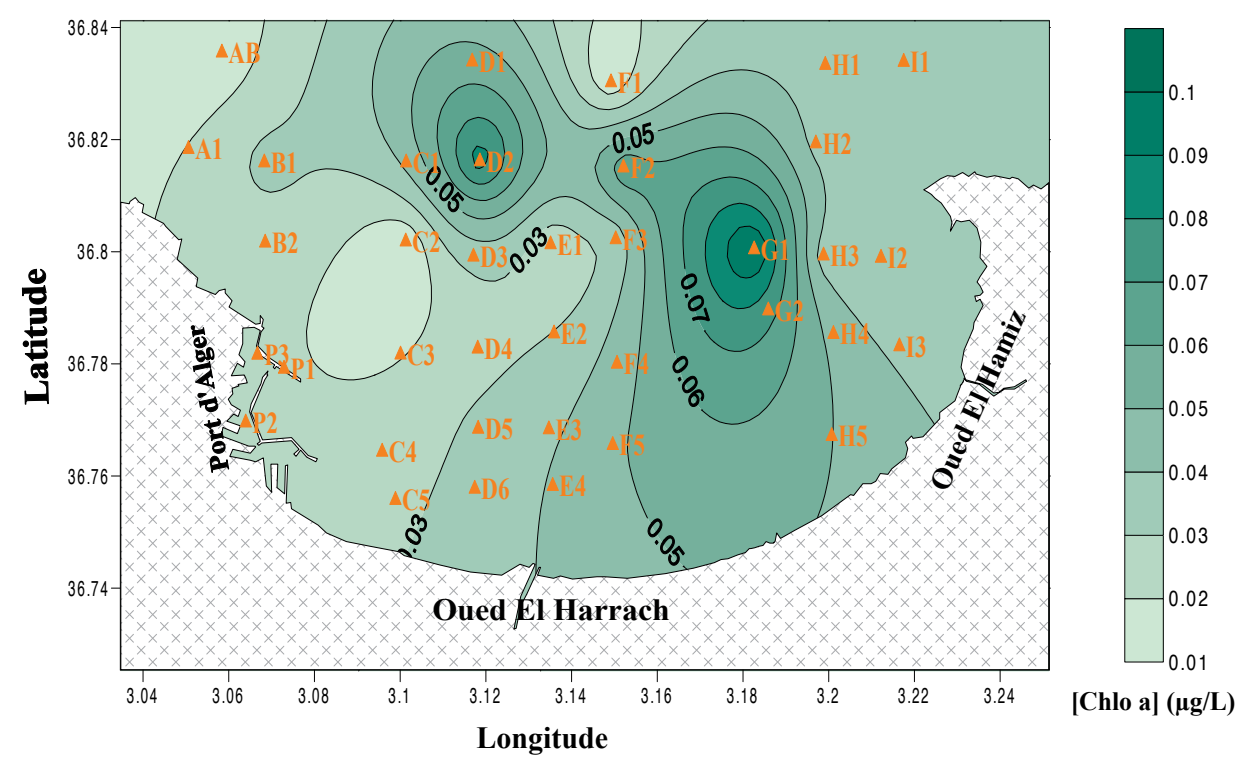

Figure 11. Spatial distribution of chlorophyll at 25 meters of depth in the bay of Algiers. (April,2009)

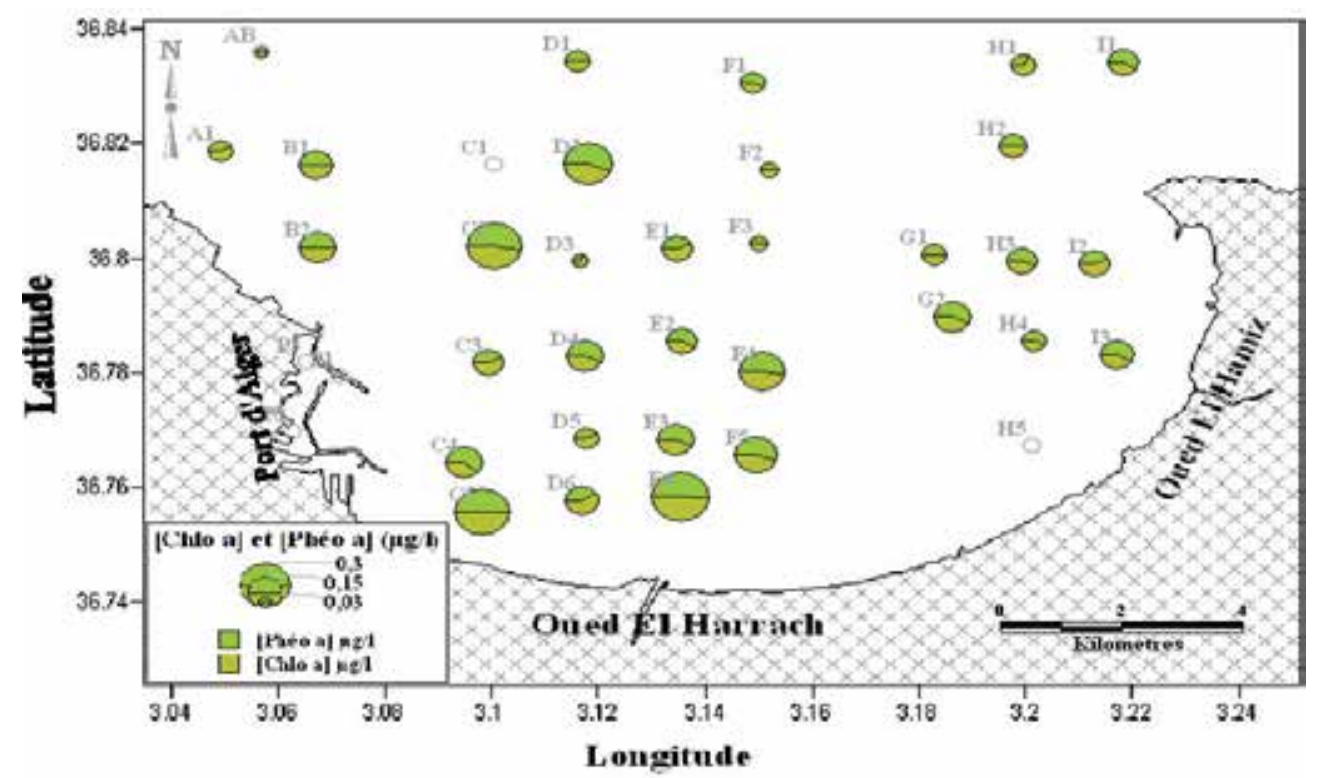

Figure 12. Distribution of chlorophyll a and pheopigments in surface waters of the Algiers Bay. (Oceanographic campaign in May 2009) 


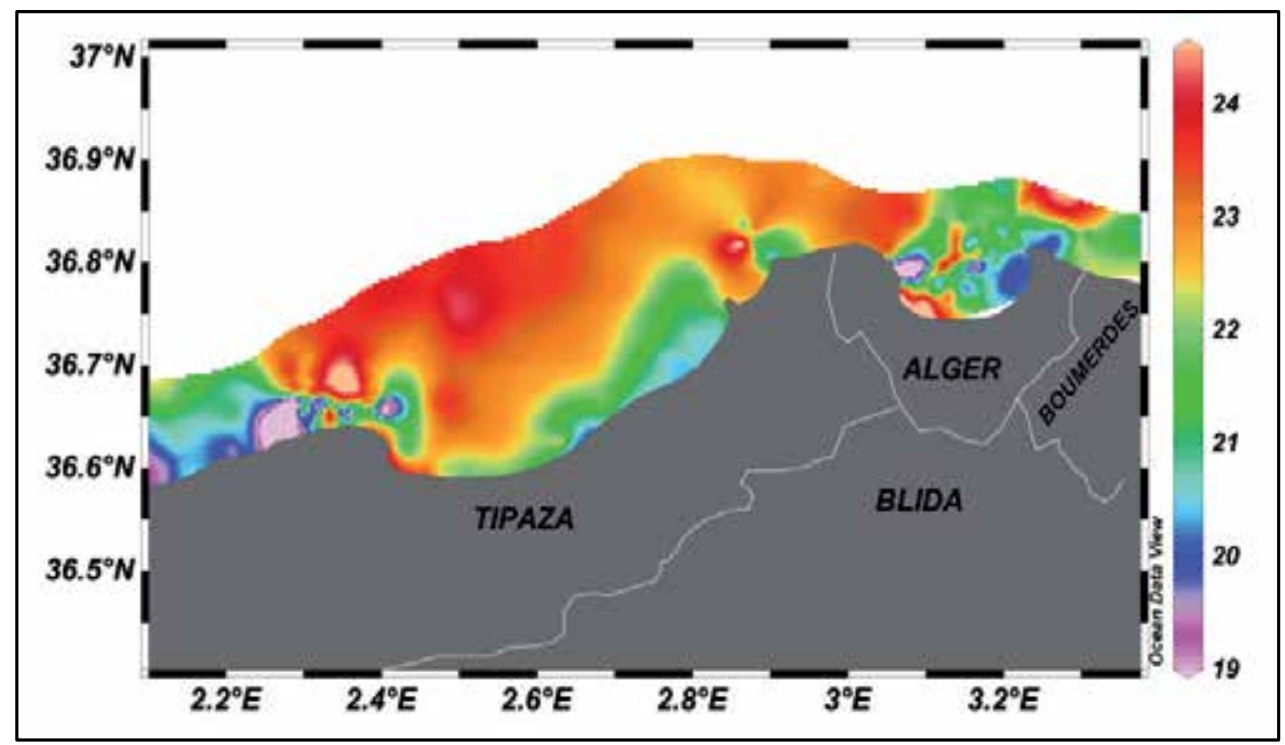

Figure 13. Variation of the temperature of the surface in the region Algiers.

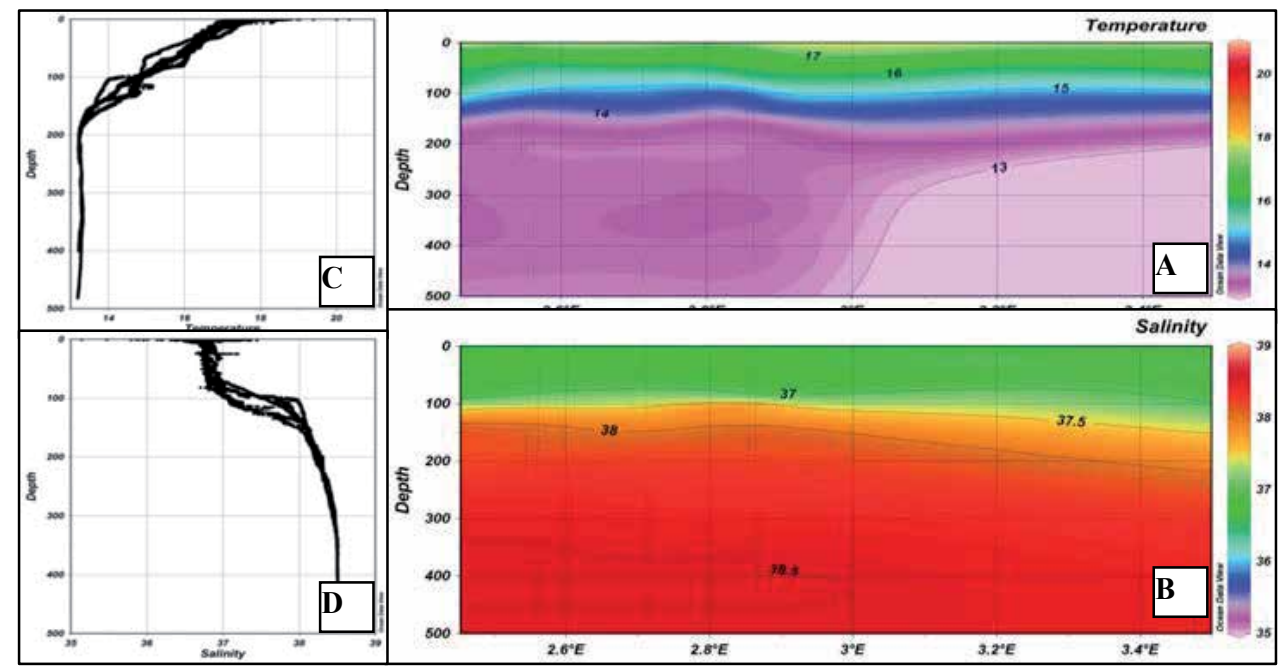

Figure 14. Temperature and salinity along the coast of the central region, profile of the temperature and salinity according to the depth. 


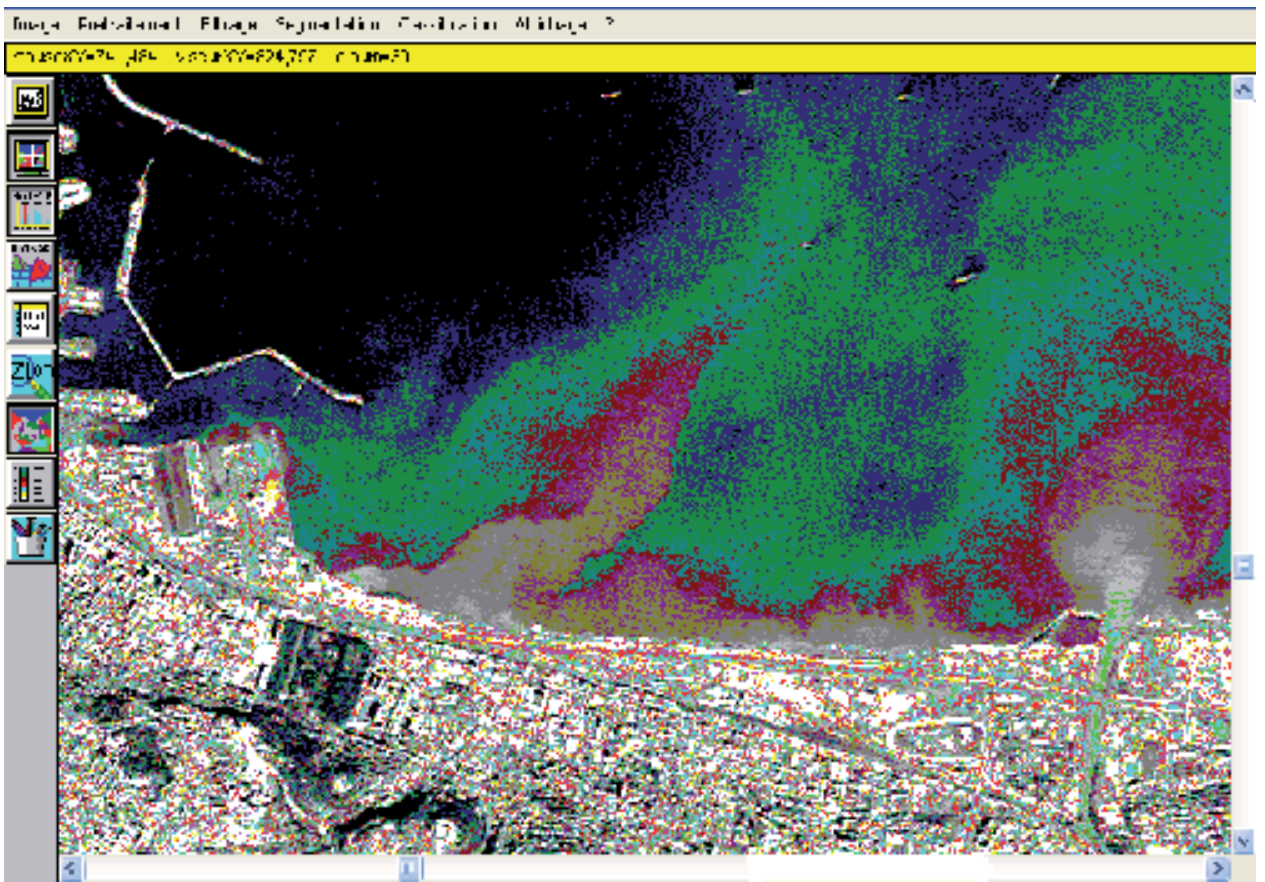

Figure 15. Variation of suspended matter on a SPOTXS satellite image of the Algiers Bay. (10 April 2009)

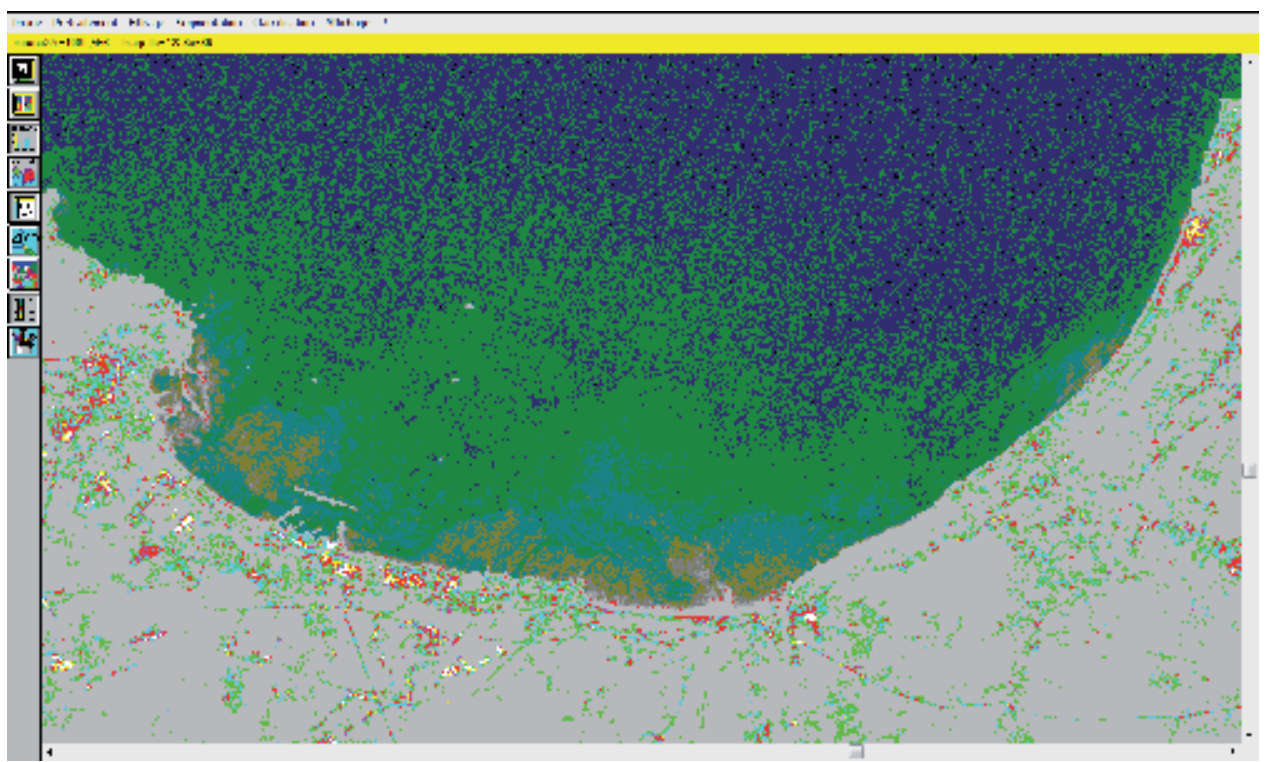

Figure 16. Variation of chlorophyll a on a SPOTXS satellite image of the Algiers Bay. (10 April 2009) Ref(XS1) = $0,17 \cdot \operatorname{Ln}(\mathrm{Ch} / r)+0,692 r^{2}=\mathbf{+ 0 , 8 9 5 3 2}$ 


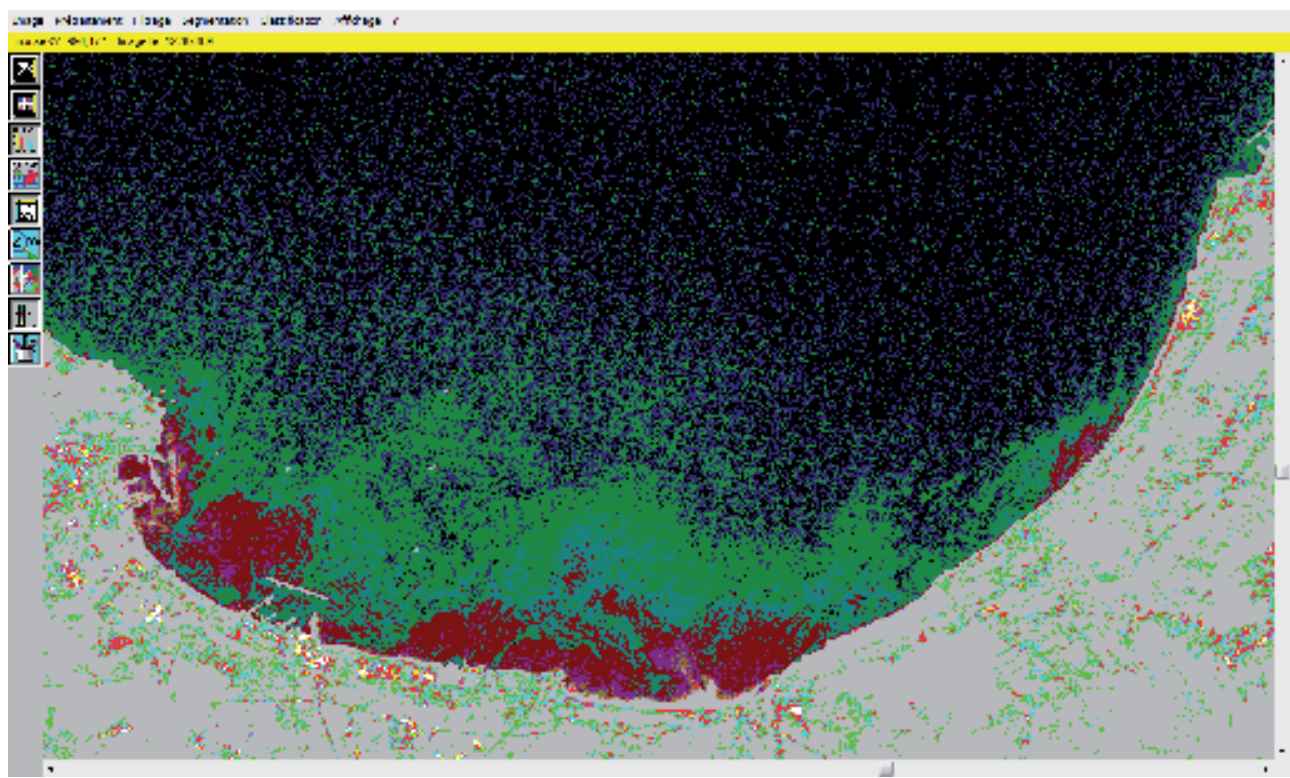

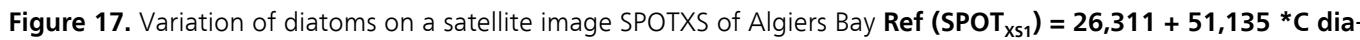
tom ; $r^{2}=0,8920$.

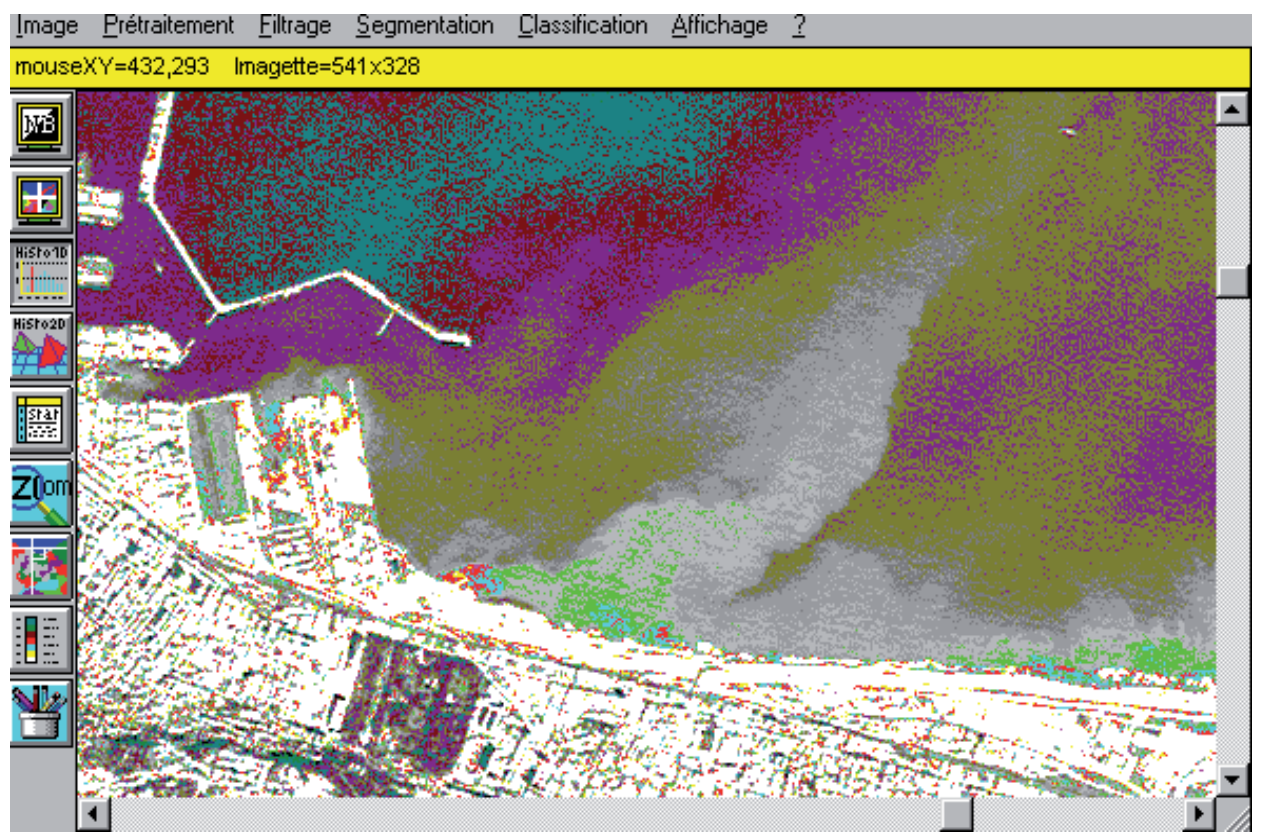

Figure 18. Variation of turbidity on a SPOTXS satellite image of Algiers Bay.( Mars, 2009) Turbidiy(NTU) = 315,9 Ref (XS1) $-1,670 ; r^{2}=+0,88567$ 
A statistical analysis is applied between reflectance measured from satellite image and HPA (polyaromatic hydrocarbons) /HT ( total hydrocarbons). It is found that the linear adjustment gives the best results on the first channels of the satellites. Comparing between the correlation coefficients, we identify adequate field of the electromagnetic spectrum necessary to study or identify a parameter related to the sea water pollution. A strong connection is thus obtained in our case among reflectances in the domain of the visible. However, it seems that the correlation is better for XS1 than XS2, and XS2 than XS3 on the satellite SPOT HRV. Landsat TM gives a strong connection on the first two channels while sensor MSS4 presents only the channel interesting for our application. Spectral bands XS1, TM1, TM2 and MSS1 give the best coefficients of correlation with corresponding reflectances Ref (XS1), Ref (TM1), Ref (TM2) and Ref (MSS1). They are thus best adapted for the follow-up of the quality of water. The lowest values are observed on channels XS3, TM5, TM6, MSS6 and MSS7 what is entirely logical since the absorption of water becomes very significant in this infra-red band, on the other hand the diffusion of the radiation becomes very weak and almost negligible what decreases the information acquired by the sensors.

\begin{tabular}{|c|c|c|}
\hline Functions & $\begin{array}{l}\text { Adjustment Lines } \\
\text { Linear regression }\end{array}$ & $\begin{array}{l}\text { Correlation } \\
\text { coefficient }\end{array}$ \\
\hline Ref. $(X S 1)=F(H P A)$ & Ref. $1=0.031505+0.031$ * HPA & $R=0.75123$ \\
\hline Ref. $(\mathrm{TM} 1)=\mathrm{F}(\mathrm{HPA})$ & Ref. $1=0.08239+0.0352 \mathrm{HPA}$ & $R=0.85845$ \\
\hline Ref. $($ TM2 $)=F(H P A)$ & Ref2 $=0.07104+0.0284 \mathrm{HPA}$ & $R=0.7554$ \\
\hline Ref. $(X S 1)=f(H T)$ & Ref1 $=0.041424+0.06 * \mathrm{HT}$ & $R=0.79704$ \\
\hline Ref. $(T M 1)=f(H T)$ & Ref1 $=0.06313+0.0147 * H T$ & $R=0.87514$ \\
\hline Ref. $(\mathrm{TM} 2)=\mathrm{F}(\mathrm{HT})$ & $\operatorname{Re} 2 f=0.04358+0.0118 * H T$ & $R=0.79823$ \\
\hline Ref. (MSS1) = F (HT) & Ref. $4=0.06948+0.00130 * \mathrm{HT}$ & $R=0.7696$ \\
\hline
\end{tabular}

Table 5. Correlation- reflectance hydrocarbons

\section{Correlative analysis}

\subsection{The punctual measurements}

All the correlations are carried out considering that the parameters are normal at $95 \%$. It is found that the linear adjustment gives the best results on the first channels of the satellites. Comparing between the correlation coefficients, we identify adequate field of the electromagnetic spectrum necessary to study or identify a parameter related to the sea water pollution. A strong connection is thus obtained in our case among reflectances in the domain of the visible. 
However, it seems that the correlation is better for XS1 than XS2, and XS2 than XS3 on the satellite SPOT HRV. Landsat TM gives a strong connection on the first two channels while sensor MSS4 presents only the channel interesting for our application.

Spectral bands XS1, TM1, TM2 and MSS4 give the best coefficients of correlation with corresponding reflectances Ref (XS1), Ref (TM1), Ref (TM2) and Ref (MSS4). They are thus best adapted for the follow-up of the quality of water. The lowest values are observed on channels XS3, TM5, TM6, MSS6 and MSS7 what is entirely logical since the absorption of water becomes very significant in this infra-red band, on the other hand the diffusion of the radiation becomes very weak and almost negligible what decreases the information acquired by the sensors.

\begin{tabular}{|c|c|c|}
\hline Functions & $\begin{array}{l}\text { Adjustment Lines } \\
\text { Linear regression }\end{array}$ & $\begin{array}{l}\text { Correlation } \\
\text { coefficient }\end{array}$ \\
\hline Ref. $(X S 1)=F(H P A)$ & Ref. $1=0.31505+0.0031$ * HPA & $R=0.80123$ \\
\hline Ref. $(\mathrm{TM} 1)=\mathrm{F}(\mathrm{HPA})$ & Ref. $1=0.08239+0.00352 \mathrm{HPA}$ & $R=0.79845$ \\
\hline Ref. $(\mathrm{TM} 2)=\mathrm{F}(\mathrm{HPA})$ & Ref $2=0.07104+0.00284 \mathrm{HPA}$ & $R=0.80254$ \\
\hline Ref. (MSS4) = F (HPA) & Ref4 $=0.07769+0.00313 *$ HPA & $R=0.80129$ \\
\hline $\mathrm{R}$ ef $(\mathrm{XS} 2)=\mathrm{F}(\mathrm{HPA})$ & Ref2 $=0.24882+0.0015 *$ HPA & $R=0.38034$ \\
\hline Ref. $(\mathrm{TM} 4)=\mathrm{F}(\mathrm{HPA})$ & Ref4 $=0.15979+0.0069 *$ HPA & $R=0.39720$ \\
\hline Ref. $($ TM5) $=f(H P A)$ & Ref5 $=0.26010-0.008 * \mathrm{HPA}$ & $R=0.1579$ \\
\hline Ref. $(\mathrm{TM} 3)=\mathrm{F}(\mathrm{HPA})$ & Ref3 $=0.11821+0.0135 *$ HPA & $R=0.38502$ \\
\hline Ref. $(\mathrm{MSS} 6)=\mathrm{f}(\mathrm{HPA})$ & Ref6 $=0.19936+0.0059$ * HPA & $R=0.39132$ \\
\hline Ref. $(X S 1)=f(H T)$ & Ref1 $=0.31424+0.00013 * \mathrm{HT}$ & $R=0.79704$ \\
\hline Ref. $(T M 1)=f(H T)$ & Ref1 $=0.7313+0.00147^{*} \mathrm{HT}$ & $R=0.79514$ \\
\hline Ref. $(\mathrm{TM} 2)=\mathrm{F}(\mathrm{HT})$ & $\operatorname{Re} 2 f=0.06358+0.00118 * H T$ & $R=0.79823$ \\
\hline Ref. (MSS4) = F (HT) & Ref. $4=0.06948+0.00130 * \mathrm{HT}$ & $R=0.79696$ \\
\hline Ref. $(X S 2)=f(H T)$ & Ref2 $=0.24846+0.00006 * \mathrm{HT}$ & $R=0.42552$ \\
\hline Ref. (MSS6) $=\mathrm{f}(\mathrm{HT})$ & Ref6 $=0.19842+0.00018 * \mathrm{HT}$ & $R=0.35870$ \\
\hline Ref. $(\mathrm{TM} 4)=\mathrm{F}(\mathrm{HT})$ & Ref4 $=0.15887+0.00020 * \mathrm{HT}$ & $R=0.33988$ \\
\hline Ref. $(\mathrm{TM} 5)=\mathrm{F}(\mathrm{HT})$ & Ref5 $=0.25454+0.00032 * \mathrm{HT}$ & $R=0.18558$ \\
\hline Ref. (MSS5) = F (HT) & Ref5 $=0.15067+0.00037 * \mathrm{HT}$ & $R=0.42287$ \\
\hline
\end{tabular}

HPA: polyaromatic hydrocarbons; HT: total hydrocarbons

Table 6. Correlation between reflectance and Hydrocarbon contents. 


\section{- Pollution map}

By using software PCSATWIN we have transformed the reflectance image into an image which makes it possible to estimate a certain extent the pollution of the environments by hydrocarbons. Indeed, there is a strong relation between the reflectances and these components content. Actually, the colour of sea water which is one of the obvious organoleptic descriptors, remains always a significant factor of differentiation which informs about the gleam of water, about its quality and which can be useful like an indicator of its transparency.

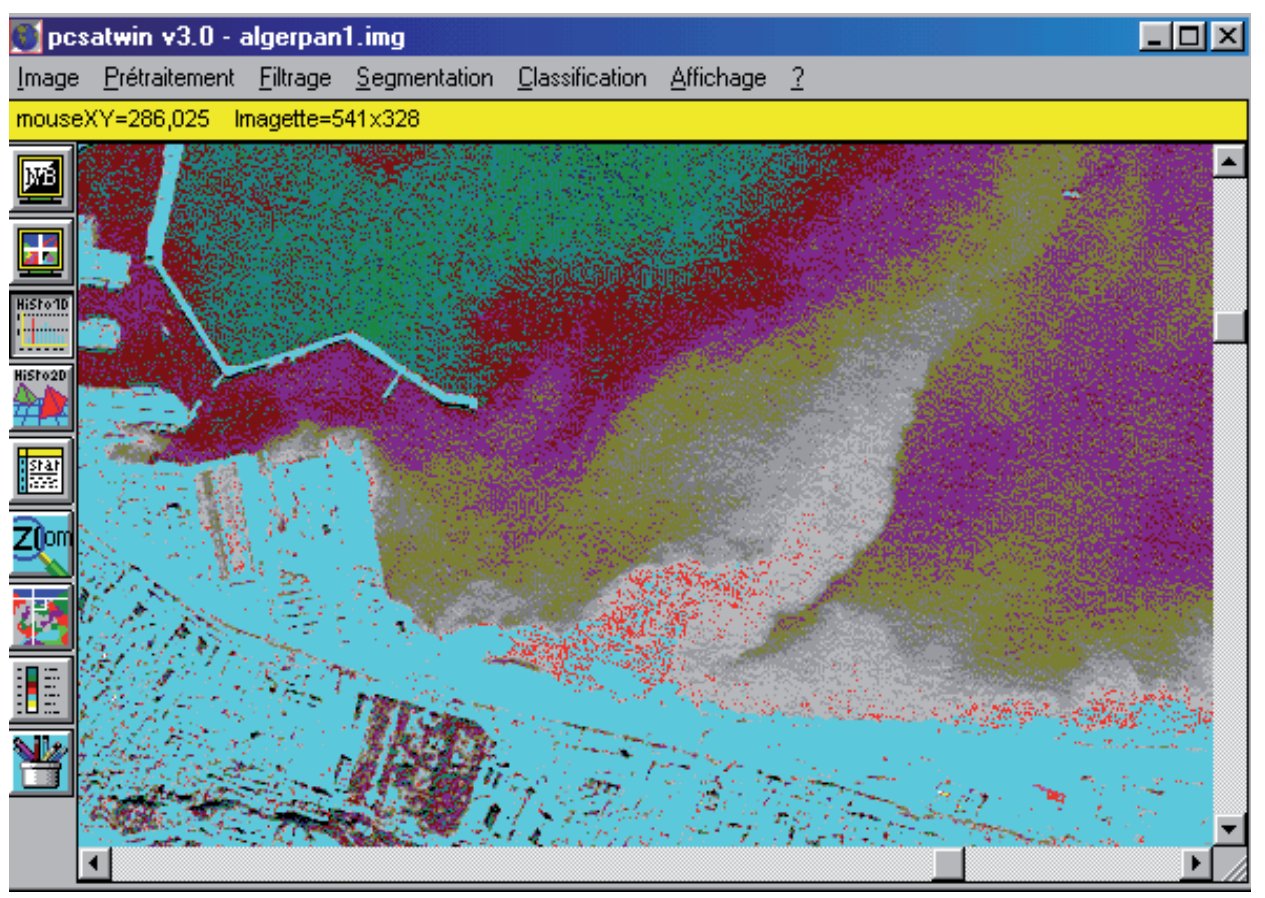

Figure 19. Spatialization of polyaromatic Hydrocarbons. Image SPOT transform starting from the relation: $\mathrm{HPA}(\mu \mathrm{g} / \mathrm{I})=$ $-658.5+2092.8 *$ XS1.

The figures 18, and 19, enable us to clearly classify the zones polluted by the distinction of the colour of each area on the basis of the transformed satellite image, that is to say several classes observed indicating a different degree of pollution. We conclude that the visible channels can thus be well intended for the marine applications. 


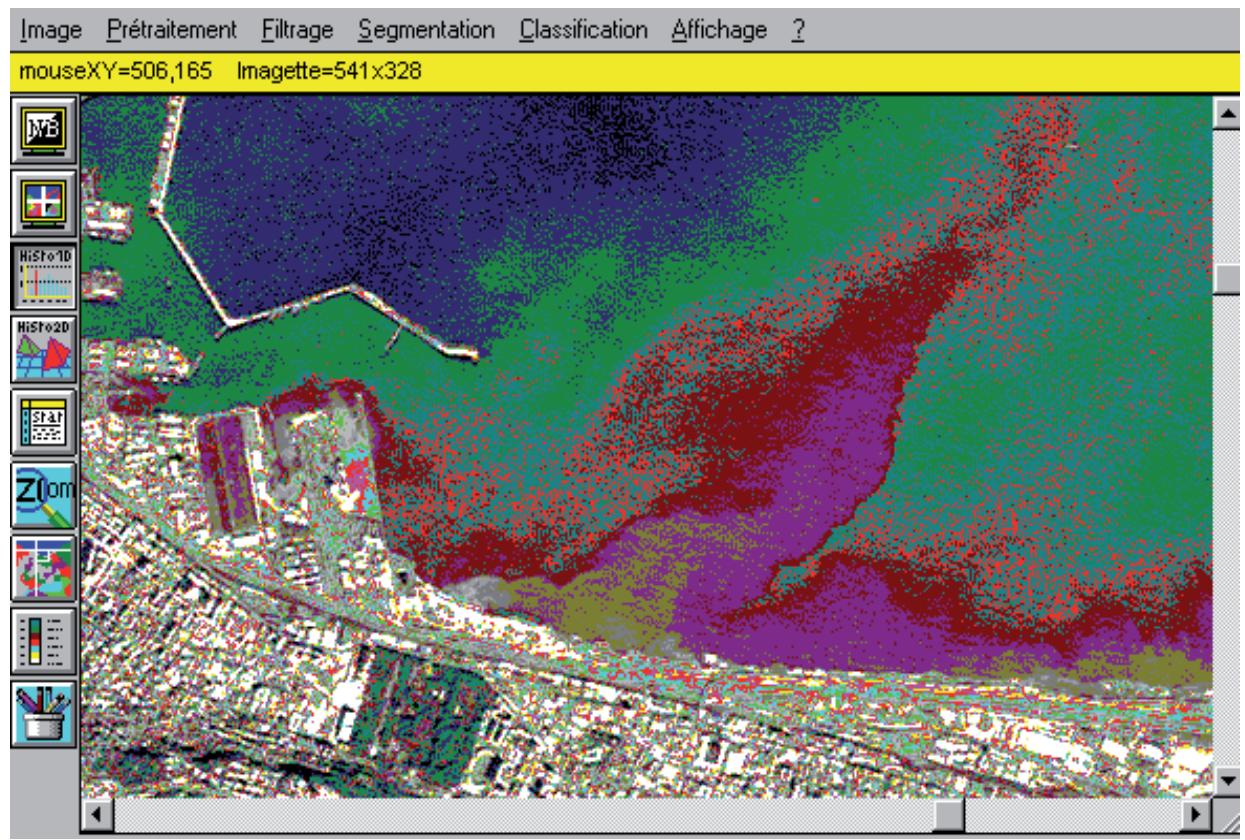

Figure 20. Spatialization of total Hydrocarbons. Image SPOT transform starting from the relation: HT $(\mathrm{mg} / \mathrm{l})=-1559+$ $4975.3 *$ XS1.

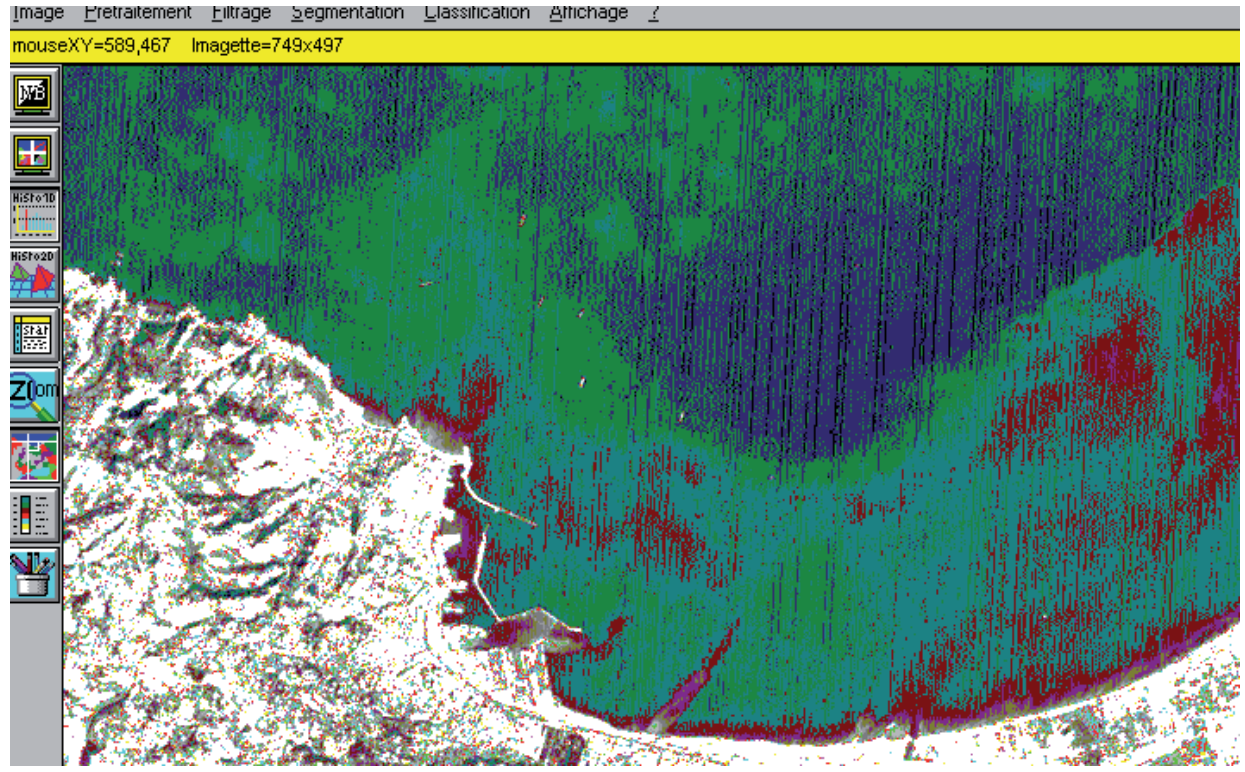

Figure 21. Spatialization of total Hydrocarbons. Image Landsat MSS transform starting from the relation: $\mathrm{HT}(\mathrm{mg} / \mathrm{I})=-$ $29.59+487.83 *$ MSS4 


\section{- Pollution map}

Finally, linear relations are established between physico-chemical parameters and reflectances.The inversion of these relations offers the possibility to estimate for each pixel the degree of water quality. Figures showed clearly different distinct colour subareas in each of the studied area.Each colour indicates a different degree of water quality or pollution. By this technique it is possible to construct a very beautiful and global picture for degree of unknown pollution spread over a wide water surface with relatively rapid evaluation.

By using software PCSATWIN (Bachari, 1994), we have transformed the reflectance image into an image which makes it possible to estimate a certain extent the pollution of the environments. Indeed, there is a strong relation between the reflectances and these components content. Actually, the colour of sea water which is one of the obvious organoleptic descriptors, remains always a significant factor of differentiation which informs about the gleam of water, about its quality and which can be useful like an indicator of its transparency. (Houma and al, 2004)

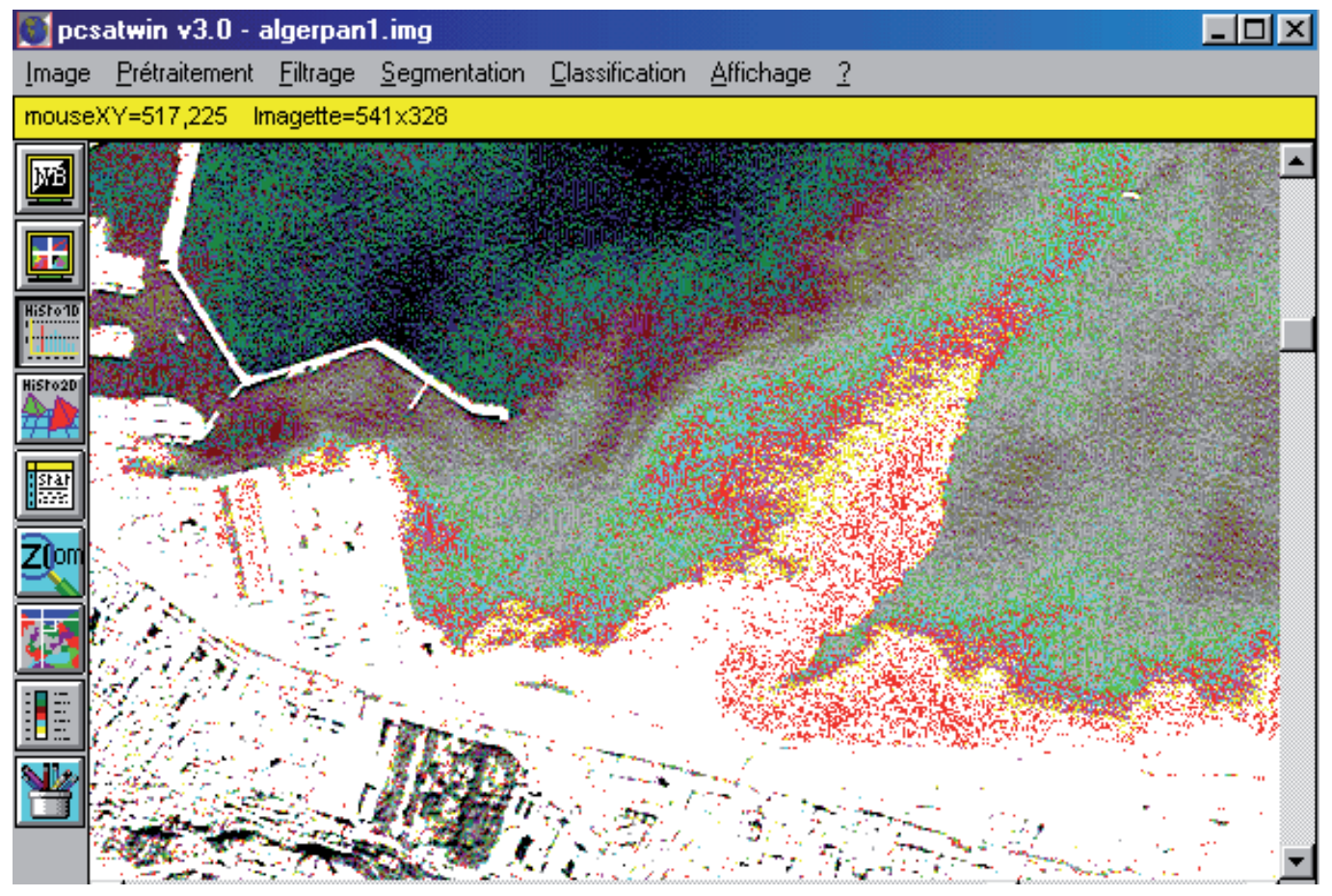

Figure 22. Spatialization of suspended matter. Image SPOT transform starting from the relation: MES $(\mathrm{mg} / \mathrm{I})=-4277+$ $13680 *$ XS1.

The figures20, 21 and 22, enable us to clearly classify the zones polluted by the distinction of the colour of each area on the basis of the transformed satellite image, that is to say several 
classes observed indicating a different degree of pollution. We conclude that the visible channels can thus be well intended for the marine applications.

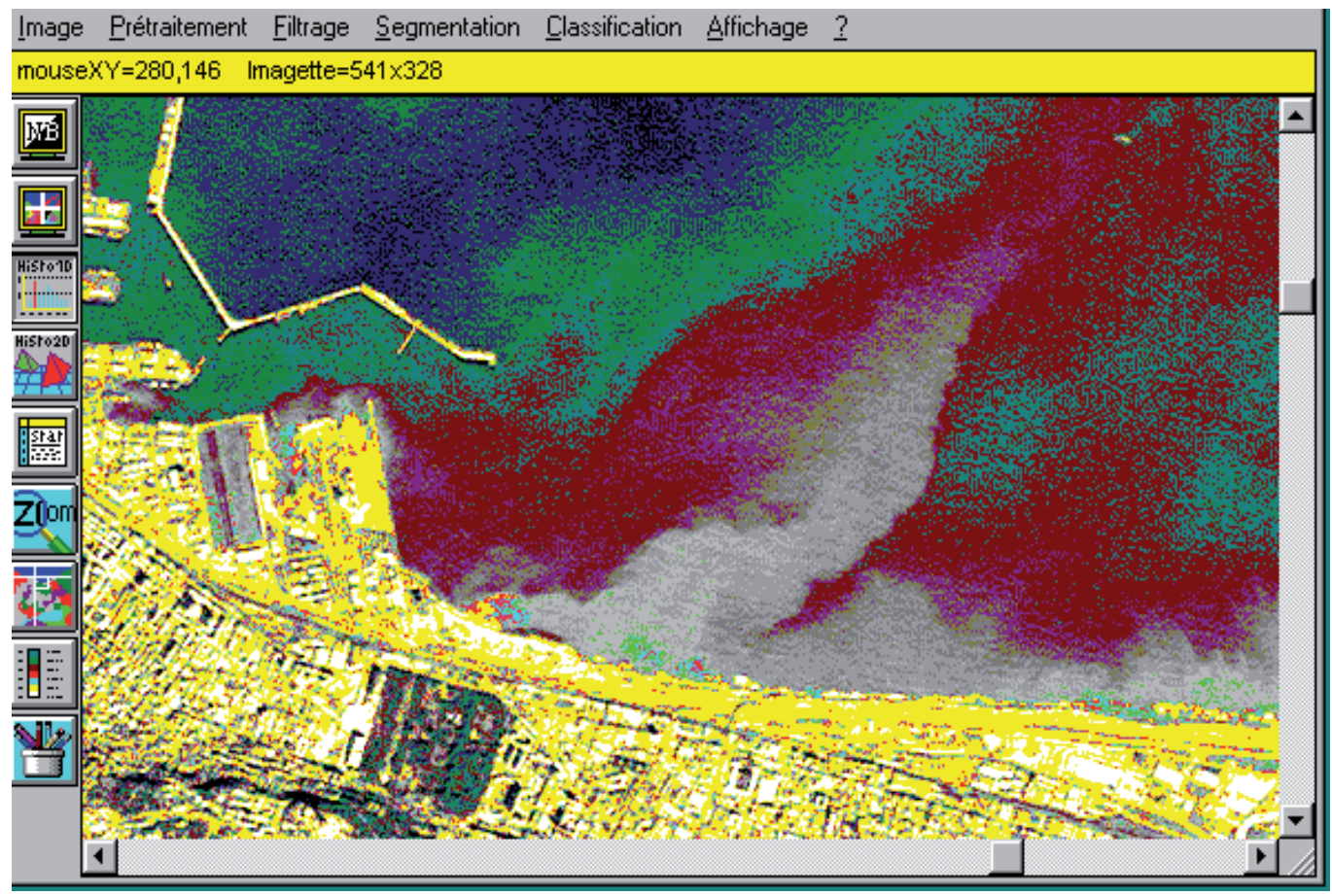

Figure 23. Variation of turbidity on SPOT satellite image XS1 of the Algiers bay Tu (NTU) $=-5149+16421 *$ XS1.
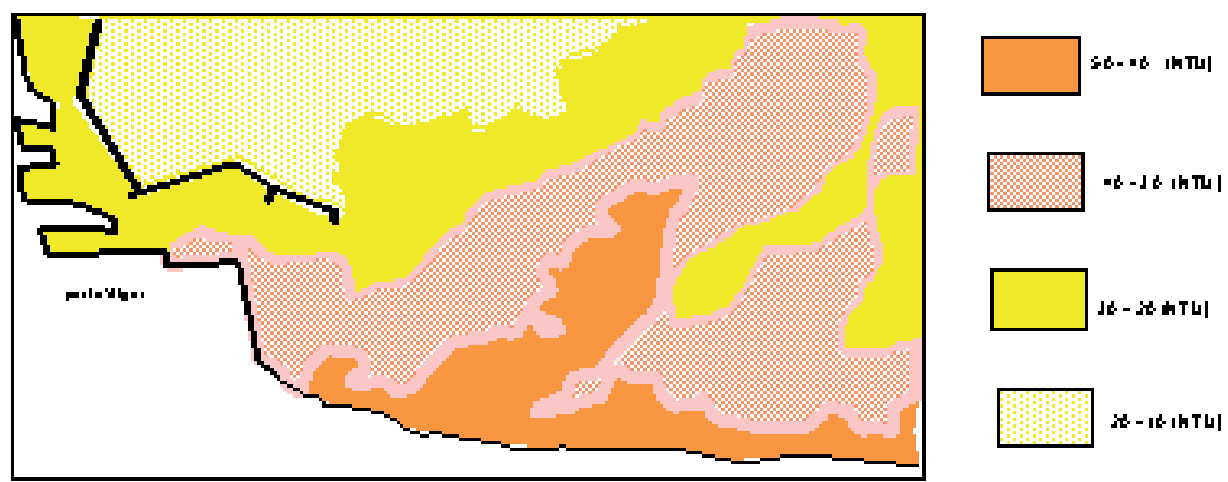

Figure 24. Cartography of the turbidity in Algiers bay. 


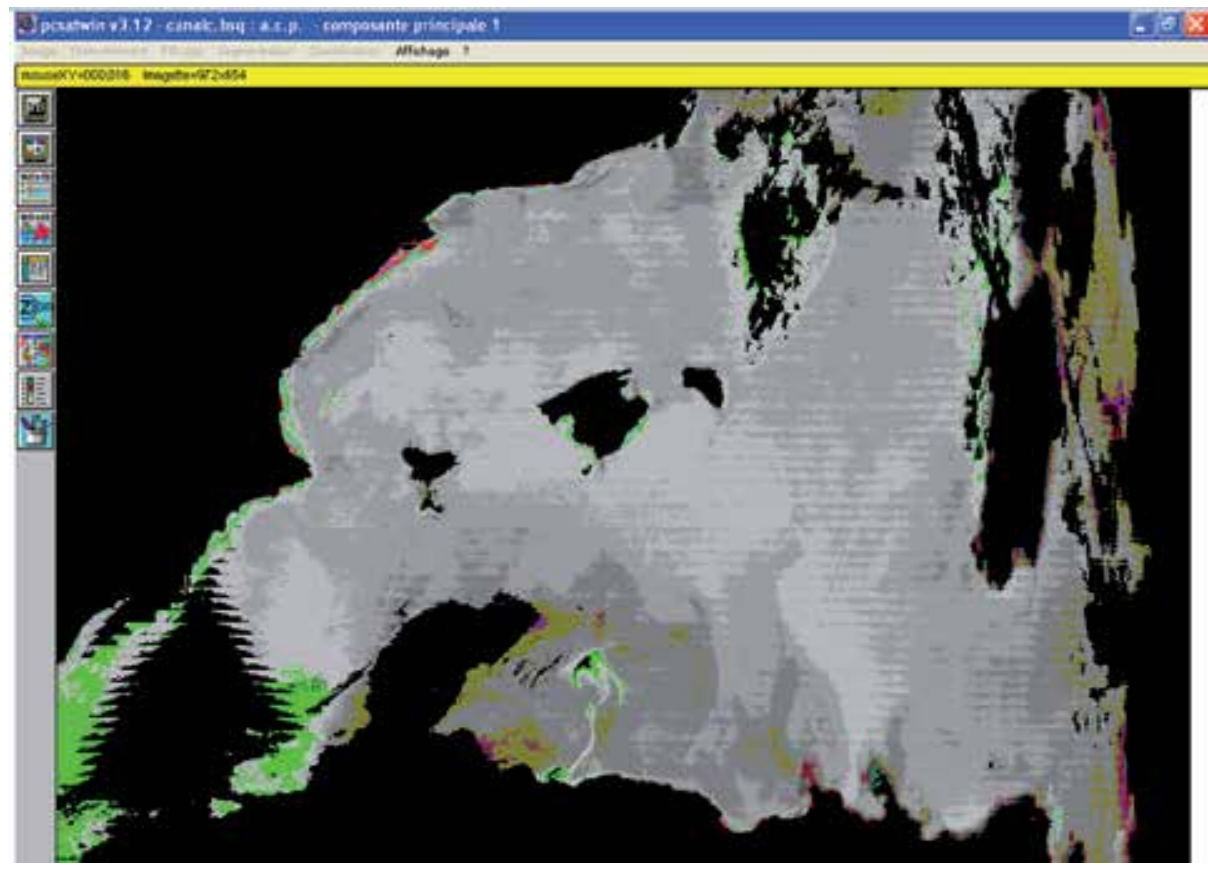

Figure 25. Chlorophyll on Channel 1 SeaWiFS

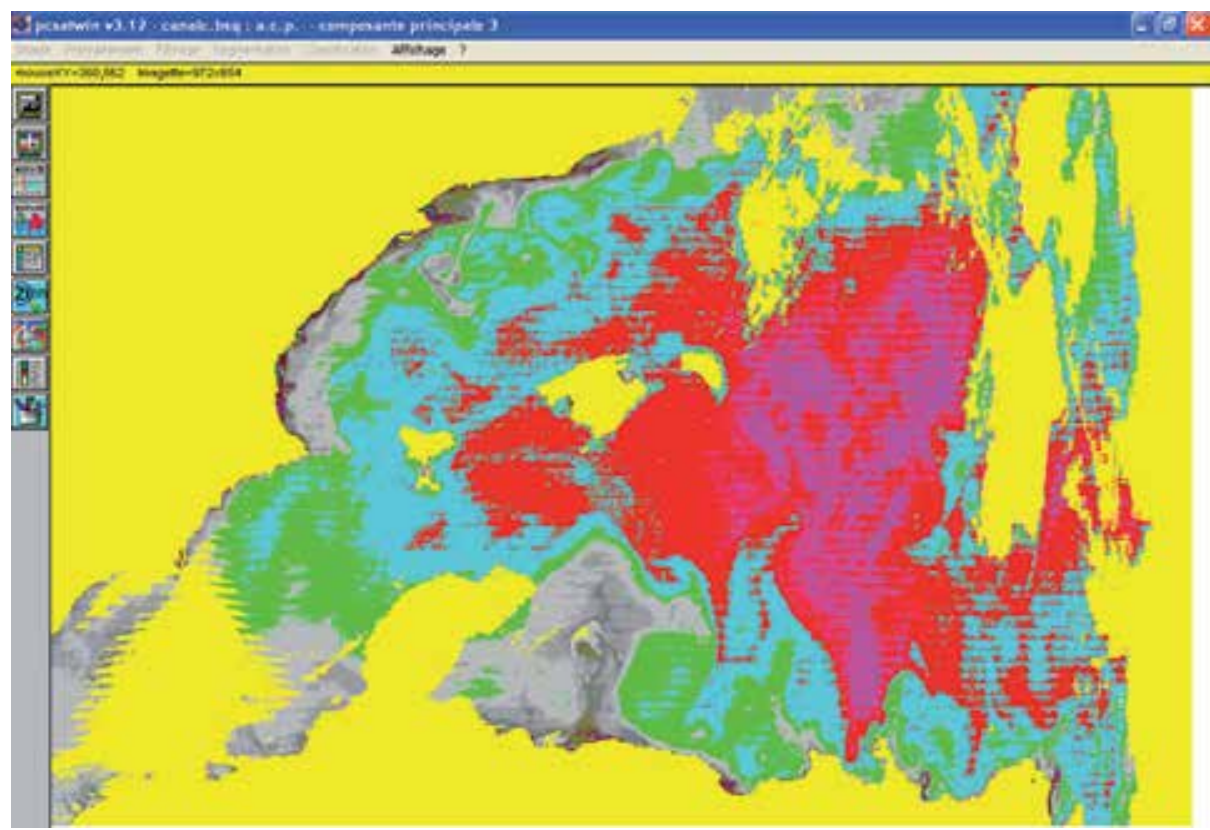

Figure 26. Chlorophyll on Channel 2 SeaWiFS 


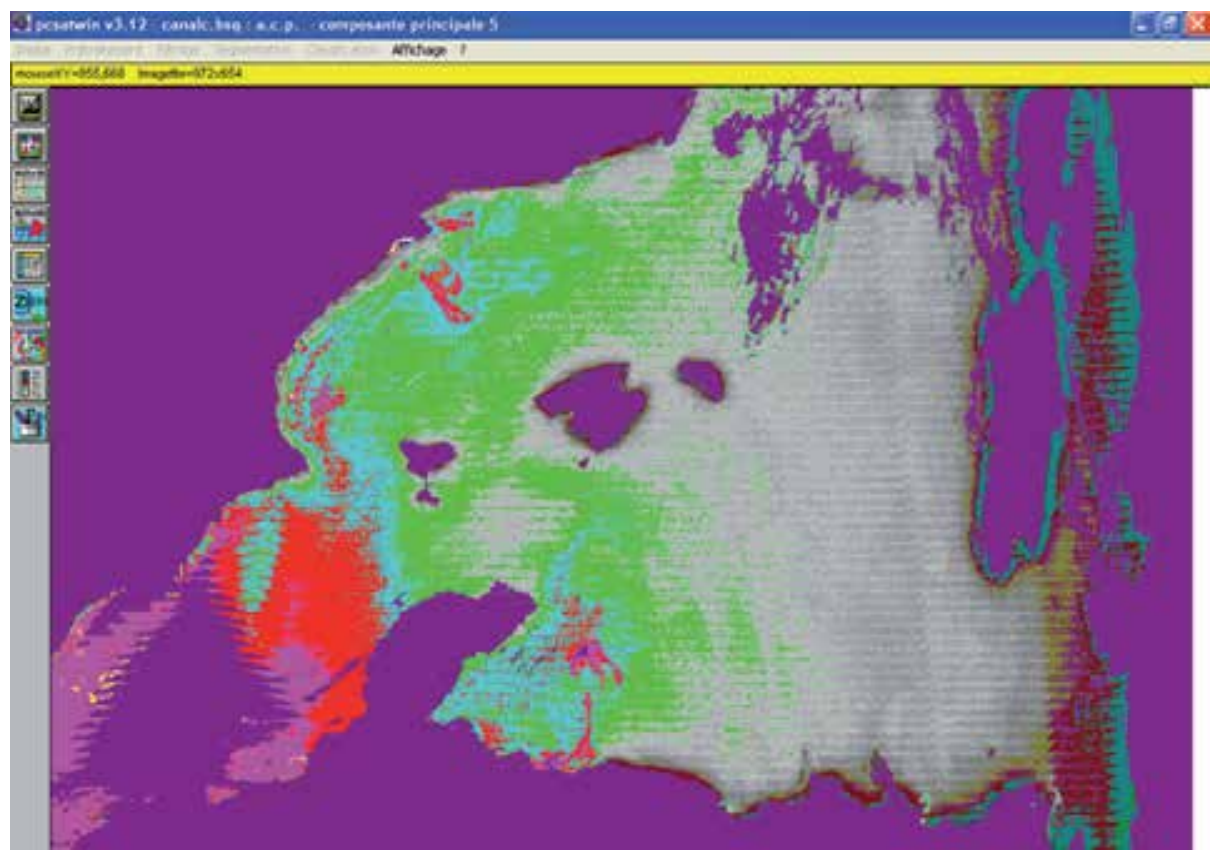

Figure 27. Chlorophyll on the Channels 4 and 5 of SeaWiFS

\section{Conclusion}

The SeaWiFS images (Sea-viewing Wied-Field-of-View) covering the western basin of the Mediterranean (case1 waters) comprising a part of northern Africa and southern European coasts, are treated for spatialization of the chlorophyll. The raw images of the six visible channels have been corrected for atmospheric effects.

The results of the following images correspond at consecutives scenes treated by PCSATWIN software. (Bachari et al., 1997)

The analysis of water sea can be a great importance for the environmental study of a given medium. The physicochemical parameters are revealing of a degree of pollution marine, but their measurements are long and very costly to be used for a continuous survey of the environment. Considering these difficulties the satellite imagery by its spectral wealth and global vision has all potentialities to be an ideal mean for qualitative analysis of the natural medium

The remote sensing is an effective technique for the space-time monitoring of the natural environment. Its use is very promising, it makes it possible to quickly cover a significant surface and at low expenses, by comparison with the traditional methods. This piece of work showed us the possibility of estimating certain pollutants on the basis of the satellite images which can be used to monitor the coastal zones pollution. Indeed, the image reveals a global and 
instantaneous vision of the state of the environment and makes it possible to locate the sample in its environment. The correlative analysis made realizable the determination of the pollution indicators based on the satellites SPOT and Landsat. The spatialization of the values measured on the ground facilitates indeed the environmental monitoring of water quality and the environment interventions. The capacity of visible spectral bands is however very remarkable, they can be used for other thorough studies to establish true pollution maps which can give information on the quality of coastal water by the means of satellites put into orbit.

\section{Author details}

Houma Fouzia ${ }^{1 *}$, Bachouche Samir ${ }^{2}$, Bachari Nour El Islam² and Belkessa Rabah ${ }^{1}$

*Address all correspondence to: houmabachari@yahoo.fr; bachouche.samir@gmail.com; bachari10@yahoo.fr; belkessarabah@yahoo.fr

1 National School of Marine Sciences and Coastal Management (ENSSMAL). University Campus Delly Ibrahim Bois des Cars, Algiers, Algeria

2 Faculty of Biological Sciences, University of Science and Technology Houari Boumediene (USTHB), Algiers, Algeria

\section{References}

[1] Bachari. N and. Belbachir, A.H (1996) Modélisation de l'interaction spectre solaire avec le systéme sol-atmophére pour une mesure satellitaire; Congrés national de la physique et ses applications en Algérie Sétif 4-6 Décembre.

[2] Bachari N, N-Benabadji , A-Abdellaoui ,1997a. Développement du logiciel d'analyse spectrale et temporelle des images satellite type SPOT, LANDSAT and METEOSAT, A.M.S.E, J Volume.38, N 1,2, pp15-34

[3] Bachari N.E.I., Belbachir A.H ., et Benbadji N.,1997 (b). Numerical Methods for Satellite Imagery Analysis, AMSE.,J Volume.38, N¹,2, pp 49-60.

[4] Bachari. N and Benabadji. N, 1994 : Développement du logiciel d'analyse d'images satellite SPOT, LANDSAT et METEOSAT; J.Télédetection AUPELF-UREF, $\mathrm{N}^{\circ} 24$.

[5] Chandler, J.R. (1970) A biological approach to water quality management, J. Water Pollut. Control 69, 415-422.

[6] G.M .Ferrani and S.Tassan. 1992. Evaluation of the influence of yellow substance absorption of the remote sensing of water quality in the golf Naples:a case study. Int.J.Remote Sensing ,1992 , Vol ,13,N 12 ,2177-2189 
[7] Graham, T.R ( 1965) Ann. Rept Lothians River Purif. Borard. Quoted according to Cahandler, 1970.

[8] Fouzia HOUMA, Nour El Islam BACHARI, 2012 Solar Radiation Modeling and Simulation of Multispectral Satellite Data. Atmospheric Models Applications, 296 pages, Publisher: InTech Book Edited by Ismail Yucel, ISBN 978-953-51-0488-9, Hard cover, 296 pages, Publisher: InTech, Published: April 04, 2012 under CC BY 3.0 license, in subject Oceanography and Atmospheric Sciences, DOI: 10.5772/2012

[9] Houma F., Bachari N.E.I., Belkessa R., and Abdellaoui A, 2010. Contribution of Multispectral Satellite Imagery to the Bathymetric Analysis of Coastal sea bottom. Application to Algiers bay, Algeria. Journal Physical Chemical News, volume 53(57-61), PCN, 2010.

[10] Houma Fouzia, Khouider Ali , Bachari Nour El Islam , Derriche Zoubir ,2004 Etude Corrélative des Paramètres Physico-Chimiques et des Données Satellites IRS1C pour Caractériser la Pollution aquatique. Application à la baie d'Oran Algérie. Journal Sciences de l'eau Vol 17 No 4 pp 429-446

[11] Houma F, Belkessa R, Bachari NEI, 2006. Contribution of multispectral satellite imagery to the bathymetric analysis of sea bottom Application to Algiers city, Algeria. Revue des Energies Renouvelables Vol. 9 N³ (2006) 165 - 172.

[12] Jaquet J.M, 1989 Limnologie et télédétection : Situation actuelle et développements futurs. Review Sciences of water, 2: 457- 481.

[13] Rodier.J, (1992) L'analyse de l'eau (eaux naturelles, eaux résiduaires et eaux de mer) 7ème édition DUNOD.

[14] Rothschein, J. (1977) Saprobitat und Wasserchemismus. Ergebn. Lilmnol. 9, 101-102

[15] Sladecek, V. (1973) System of water quality from biological Point of view.Ergebn. Limnol. 7, 1-218.

[16] Sladecek, V. \& Tucek, F. (1975) Relation of the saprobic Index ti BOD5. Water Res. 9,791-794.

[17] Zelinka, M. \& Marvan, P. (1957) Die wichtigsten Erkenntnisse aus der statistischen Verarbeitung der Wasseranalysenresultate der mahrischen flüsse. Voda 36, 152-155. 
Chapter 4

\title{
Ground Water Contamination with Fluoride and Potential Fluoride Removal Technologies for East and Southern Africa
}

\author{
Bernard Thole \\ Additional information is available at the end of the chapter \\ http://dx.doi.org/10.5772/54985
}

\section{Introduction}

Ground water is main source of water supply in most rural communities in Africa. It has good microbiological and biological properties in general as such requires minimal treatment. Unfortunately groundwater is sometimes contaminated with naturally occurring chemicals. One such naturally occurring toxicant is fluoride. In some parts of Africa ground water contains high fluoride levels beyond the recommended World Health Organisation upper limit of 1.5 $\mathrm{mg} / \mathrm{l}$. It is reported that the East African Rift Valley is a high fluoride area. This region extends from Jordan valley down through Sudan, Ethiopia, Uganda, Kenya and Tanzania. High fluoride levels have also been reported in Malawi and The Republic of South Africa. In Kenya high fluoride levels in ground water beyond $5 \mathrm{mg} / \mathrm{l}$ and beyond $8 \mathrm{mg} / \mathrm{l}$ were reported in $20 \%$ and $30 \%$ respectively of 1000 samples taken nationally. A survey of fluoride in ground water in Tanzania showed that $30 \%$ of the waters used for drinking exceeded $1.5 \mathrm{mg} / \mathrm{l}$ fluoride. In Malawi and the Republic of South Africa fluoride levels beyond $1.5 \mathrm{mg} / \mathrm{l}$ and occurrence of dental fluorosis have also been reported. Proxy indicators of high fluoride levels in ground water are high $\mathrm{pH}, \mathrm{pH}$ beyond 7, and high sodium and bicarbonate concentrations in the water. High fluoride waters often have low calcium and magnesium concentrations as such are fairly soft. There are some exceptions of fluoride occurrence that may not adhere to these proxy indicators.

The beneficial effects of ingesting fluoride to human health are limited to fluoride levels approaching $1.0 \mathrm{mg} / \mathrm{l}$ in potable water. It is reported that drinking of water with such levels of fluoride improves skeletal and dental health. Ingestion of water with fluoride levels beyond $1.5 \mathrm{mg} / \mathrm{l}$ has negative health impacts. Amounts in potable water between 1.5 and $3.0 \mathrm{mg} / \mathrm{l}$ will cause browning and mottling of teeth referred to as dental fluorosis. This is the onset of 
fluorosis that makes the teeth very hard and brittle. Concentrations between 4 to $8 \mathrm{mg} / \mathrm{l}$ result in skeletal fluorosis and crippling fluorosis ensues when water of greater than $10 \mathrm{mg} / \mathrm{l}$ fluoride is ingested for a prolonged period of time. Skeletal fluorosis is characterized by bone malformation resulting in movement difficulties while crippling fluorosis is characterized by weakening of the bones, and bone junctions growing together causing immobility. Excessive fluoride ingestion has other health effects reported in literature, among which are muscle fibre degeneration, low haemoglobin levels, red blood cell deformities, excessive thirst, headache, skin rashes, depression, gastrointestinal problems, urinary tract malfunction, nausea, abdominal pains, tingling sensation in fingers and toes, reduced immunity and neurological manifestations similar to pathological changes that occur in Alzheimer's disease patients. These effects have received less attention compared to dental and skeletal fluorosis that are typical in high fluoride areas.

Ingestion of fluoride through food and air is relatively small compared to fluoride ingestion through water. Attention has thus been drawn to controlling fluoride concentrations in water supplied for drinking. The World Health Organisation recommends that in mitigating for fluorosis in endemic areas the approach should be hierarchical in the following order; first to identify alternative source of potable water with low fluoride content, secondly to dilute high fluoride water with low fluoride water to attain a mass balance of within $1.5 \mathrm{mg} / \mathrm{l}$, thirdly to use high calcium, magnesium and vitamin c diets and finally, when all these may not be feasible; to remove fluoride from water to meet the required level of $1.5 \mathrm{mg} / \mathrm{l}$. Water defluoridation, the removal of fluoride from water, has been studied widely in time, space and materials. This is because the other lines of interventions are often not plausible in high fluoride rural areas where natural sources of water are used and income levels are humble. Wide research has resulted in an a lot of data and information on water defluoridation that may be employed in deciding for fluoride removal techniques at household, communal, municipal or regional level. However this information is oftentimes in different source materials and in different formats.

This chapter aims at enhancing progress towards access to safe drinking water through consolidating knowledge in groundwater fluoride occurrence, effects of fluoride on human health, and technologies available for water defluoridation in East and Southern Africa. Specifically the chapter will; provide information on fluoride occurrence in Eastern and Southern Africa and respective health effects to guide choices and decisions in water supply and treatment at municipal, regional and national level; consolidate research findings in water fluoride and defluoridation science for scientists and non-scientists that will assist in choices of water defluoridation technologies at home or local community and; exemplify research in special water treatment technologies through water defluoridation science for students in water resource sciences. To meet these objectives the chapter is outlined as follows;

\section{Fluoride and human health}

The beneficial and harmful effects of fluoride ingestion are separated by a very narrow margin. Fluoride ingestion through potable water with concentrations about $1.0 \mathrm{mg} / \mathrm{l}$ is known to 
strengthen teeth and the skeleton; however water concentrations beyond $1.0 \mathrm{mg} / \mathrm{l}$ are undesirable because prolonged consumption of such water causes fluorosis. Dental fluorosis is caused by prolonged consumption of water with fluoride concentrations between 1.5 and 4.0 $\mathrm{mg} / \mathrm{l}$. This is characterised by browning and mottling of teeth. Prolonged drinking of water with concentrations of fluoride between 4.0 and $10 \mathrm{mg} / \mathrm{l}$ causes skeletal fluorosis and when water of concentrations beyond $10.0 \mathrm{mg} / \mathrm{l}$ is taken for a long time crippling fluorosis may ensue [1]. Skeletal fluorosis is characterised by weakening of bones and malformation of the skeleton. Symptoms of crippling fluorosis are the growing together of bone junctions causing immobility. The science behind the beneficial and harmful effects of fluoride on the skeletal structure is based on the possible ion exchange reactions between hydroxide and fluoride ions in the calcium hydroxy-phosphate, the main skeletal structure compositional material. The replacement of hydroxide ions with fluoride ions, Equation 1, results in a more acid resistant structure, fluoroapatite.

$$
\mathrm{Ca} a_{5}\left(\mathrm{PO}_{4}\right)_{3} \mathrm{OH}+\mathrm{F}^{-} \rightarrow \mathrm{Ca}_{5}\left(\mathrm{PO}_{4}\right)_{3} \mathrm{~F}+\mathrm{OH}^{-}
$$

Fluoroapatite being more resistant to acid attack compared to hydroxyapatite offers a protective layer to the tooth enamel against acids from foods. This prevents dental caries. Excessive fluoride intake however may enhance the reaction to go beyond replacement of hydroxide, Equation 2.

$$
\mathrm{Ca} a_{5}\left(\mathrm{PO}_{4}\right)_{3} \mathrm{~F}+9 \mathrm{~F}^{-} \rightarrow \mathrm{Ca}_{5} \mathrm{~F}_{10}+3 \mathrm{PO}_{4}^{3-}
$$

In Equation 2 ion exchange occurs between phosphate and fluoride ions. The resultant compound, calcium decafluoride, is a very hard and brittle material not appropriately suited for the functions of the skeletal structure [2]. Other complications associated with excessive consumption of fluoride are muscle degeneration, low heamoglobin content, deformities of red blood cells, skin rashes, depression, abdominal pains, urinary tract malfunction, reduced immunity, tingling sensation in fingers and toes, excessive thirst, and, neurological manifestations similar to pathological changes that occur in Alzhemer's disease patients [3]. Dental and skeletal fluorosis has however attracted greater attention as compared to the other effects of fluoride because of its obvious manifestations. In Malawi for instance, high correlation was obtained between levels of fluoride in drinking water with occurrence of dental fluorosis in primary school pupils. High correlation between fluoride levels in groundwater and occurrence of dental fluorosis was also obtained in a number of districts in the country. Significant correlation $\left(r^{2}=0.77\right)$ between levels of fluoride in borehole water and manifestation of dental fluorosis in primary school pupils of Liwonde, a township in Southern Malawi. A similar picture emerges in Nathenje, a township in Central Malawi, where $68.5 \%$ of school going children in high fluoride areas showed signs of dental fluorosis [4,5].

Incidences of fluorosis have been reported in the Republic of South Africa in high fluoride areas. Research has shown that 803 areas are fluorosis endemic in South Africa. These areas 
include locations in Western and Karoo Regions of Cape Province, the North Western, Northern, Eastern and Western areas of Transvaal, Western and Central Free State. A study on dental fluorosis occurrence among children revealed that even at low concentrations of fluoride in potable water dental fluorosis ensues. In sub optimal fluoride areas (0.4 - 0.6 $\mathrm{mg} / \mathrm{l}$ ) dental fluorosis was evidenced in about $19 \%$ of children [3]. Results obtained, illustrate that there may be no universal safe levels of fluoride in drinking water [6]. Significant dental fluorosis incidences were noted in low, medium and high fluoride areas, Table 1.

\begin{tabular}{ccc}
\hline Location & Fluoride concentration in potable water \% with Dean's index score greater than 2. \\
\hline Sanddrif & 0.19 & 47 \\
\hline Kuboes & 0.48 & 50 \\
\hline Leeu Gamka & 3.0 & 95 \\
\hline
\end{tabular}

Table 1. Fluoride and dental fluorosis occurrence in three locations of South Africa; $[3,6]$

Much higher fluoride levels occur in Tanzania and high dental and skeletal fluorosis have been reported in the Kilimanjaro region. Among 119 children aged between 9 and 13 severe dental fluorosis was evident in $87.4 \%$ of the children at Maji ya chai in Meru, Tanzania. These children had lived all their lives within this area and drank water from a river with fluoride levels of $18.6 \mathrm{mg} / \mathrm{l}$. Very high occurrence of dental fluorosis was also reported among adults in Arusha, $83 \%$, and in Moshi, $95 \%$, in Tanzania. Regions most affected in Tanzania are Arusha, Moshi, Singida and Shinyanga. In Arusha skeletal fluorosis has been observed [3, 7].

Dental fluorosis in Kenya has been reported as having a prevalence rate of up to $39.6 \%$ in three racial groups. Table 2 illustrates the distribution of signs of dental fluorosis classified using the extent of affliction;

\begin{tabular}{lllll}
\hline Distribution of dental fluorosis (\%) & Race & & & \\
& & African & Asian & European \\
\hline Sample size & 3,014 & 626 & 922 \\
\hline Normal & 46.4 & 30.4 & 61.3 \\
\hline Questionable & 15.7 & 11.7 & 15.7 \\
\hline Very mild & 17.9 & 17.5 & 13.4 \\
\hline Mild & 10.8 & 28.6 & 6.4 \\
\hline Moderate & 5.5 & 5.7 & 2.3 \\
\hline Severe & 3.7 & 6.1 & 0.9 \\
\hline Prevalence (\%) & 37.9 & 57.9 & 23.0 \\
\hline
\end{tabular}

Table 2. Reported prevalence of dental fluorosis in Kenya; [8] 
Areas most affected in Kenya are the Northern Frontier (Turkana), Northe-West Kenya, Southern Rift Valley, Central and Eastern Regions. Surveys found that $67 \%$ of Asian, $47 \%$ of African and $30 \%$ of European school children showed signs of dental fluorosis of varying degree. The high prevalence in Asian population was speculated to relate to their vegetarian diet [3]. This research carried out in Kenya employed Dean's index that is decribed below.

\begin{tabular}{cc}
\hline Class & Description \\
\hline 1. Normal & A few white flecks to occasional white spots. \\
\hline 2. Questionable & Less than 25 per cent of the tooth surfaces covered by small white opaque areas \\
\hline 3. Very mild & Fifty per cent of the tooth surfaces covered by white opaque areas. \\
\hline 4. Mild & Nearly all the tooth surfaces are involved, with minute pitting and brown or yellowish stains. \\
\hline 6. Severe & Smoky white appearance of all the teeth with hypoplasia, chipping and large brown stains, \\
which vary from chocolate brown to black. There is discreet and confluent pitting, often \\
accompanied by attrition.
\end{tabular}

Table 3. Dean's Index; [9]

There are other indices that are often employed. These are; DDE (Developmental Defects of Enamel) index developed by Federation Dentaire Internationale in 1992; Thylstrup Fejerskov (TF) index by Thylstrup and Fejerskov (1978) and Tooth Surface Index of Fluorosis (TSIF) developed by Horowitz et al., in 1984 [3].

\begin{tabular}{ccccc}
\hline $\begin{array}{c}\text { Annual average of } \\
\text { maximum daily air } \\
\text { temperature }\left({ }^{\circ} \mathrm{C}\right)\end{array}$ & Recommended fluoride concentration (mg/l) & $\begin{array}{c}\text { Maximum allowable fluoride } \\
\text { concentration (mg/l) }\end{array}$ \\
\hline $10-12$ & Lower & Optimum & Upper & \\
\hline $12.1-14.6$ & 0.9 & 1.2 & 1.7 & 2.4 \\
\hline $14.7-17.7$ & 0.8 & 1.1 & 1.5 & 2.2 \\
\hline $17.8-21.4$ & 0.8 & 1.0 & 1.3 & 1.8 \\
\hline $21.5-26.2$ & 0.7 & 0.9 & 1.2 & 1.6 \\
\hline $26.3-32.5$ & 0.7 & 0.8 & 1.0 & 1.4 \\
\hline
\end{tabular}

Table 4. USPHS Fluoride recommendations in drinking water 
Many parts of some countries in Africa are also affected by fluorosis. These include some areas in Sudan, Uganda, Ethiopia, Senegal and Niger. Fluoride ingestion is highly linked to drinking water because the contributions from other sources, such as food and air is minimal. The United States Public Health Service [10] set some guidelines for lower, optimal, upper and maximum allowable fluoride concentrations in drinking water with respect to average air temperature, Table 3:

\section{Fluoride occurrence in the world}

Geogenic occurrence of fluoride is often linked to volcanic activity, fumaric gases and presence of thermal waters. Proxy indicators of high fluoride levels in groundwater are; low levels of calcium and magnesium, high levels of sodium and bicarbonate ions, and high $\mathrm{pH}$ above 7 . Therearehowever someexceptions to thesegeneric conditions [11].Highfluorideground waters are typically of sodium chloride, or sodium chloride bicarbonate type characterised by high $\mathrm{pH}$. Areas with high fluoride in ground water include fluoride beds encompassing parts of Iraq, Iran, Syria, Turkey, Algeria and Morocco, and the East African rift system extending from Jordan valley down through Sudan, Ethiopia, Uganda, Kenya and Tanzania. There are high fluoride areas in other parts of the world, Figures 1 to 6 show high fluoride areas of the world.

Fluoride is found in a wide variety of minerals that include fluorspar ( $\left.\mathrm{CaF}_{2}\right)$, cryolite $\left(\mathrm{Na}_{3} A l F_{6}\right)$, apatite $\left(\mathrm{Ca}_{5}\left(\mathrm{PO}_{4}\right)_{3} \mathrm{~F}\right)$ and hornblende [ $\left.(\mathrm{ca}, \mathrm{Na})_{2}(\mathrm{Mg}, \mathrm{F}, \mathrm{Al})_{5}(\mathrm{Si}, \mathrm{Al})_{8} \mathrm{O}_{22}(\mathrm{OH})_{2}\right]$. The average crustal abundance is known to be about $300 \mathrm{mg} / \mathrm{kg}$ representing between 0.06 to

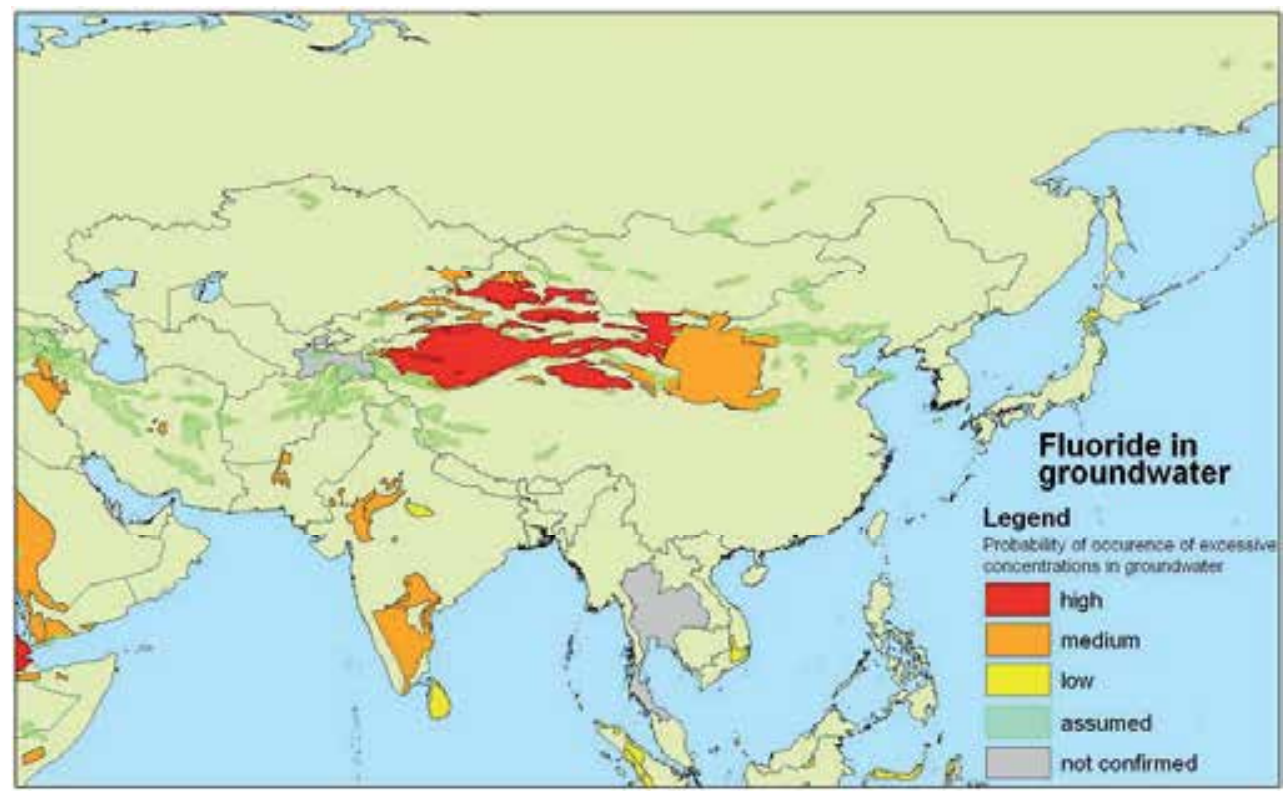

Figure 1. Fluoride occurrence in groundwater in Asia [11] 
$0.09 \%$ by weight of the earth crust. The presence of fluoride in ground water results from dissolution of fluoride bearing minerals where the water is in contact with a fluoritic bed.

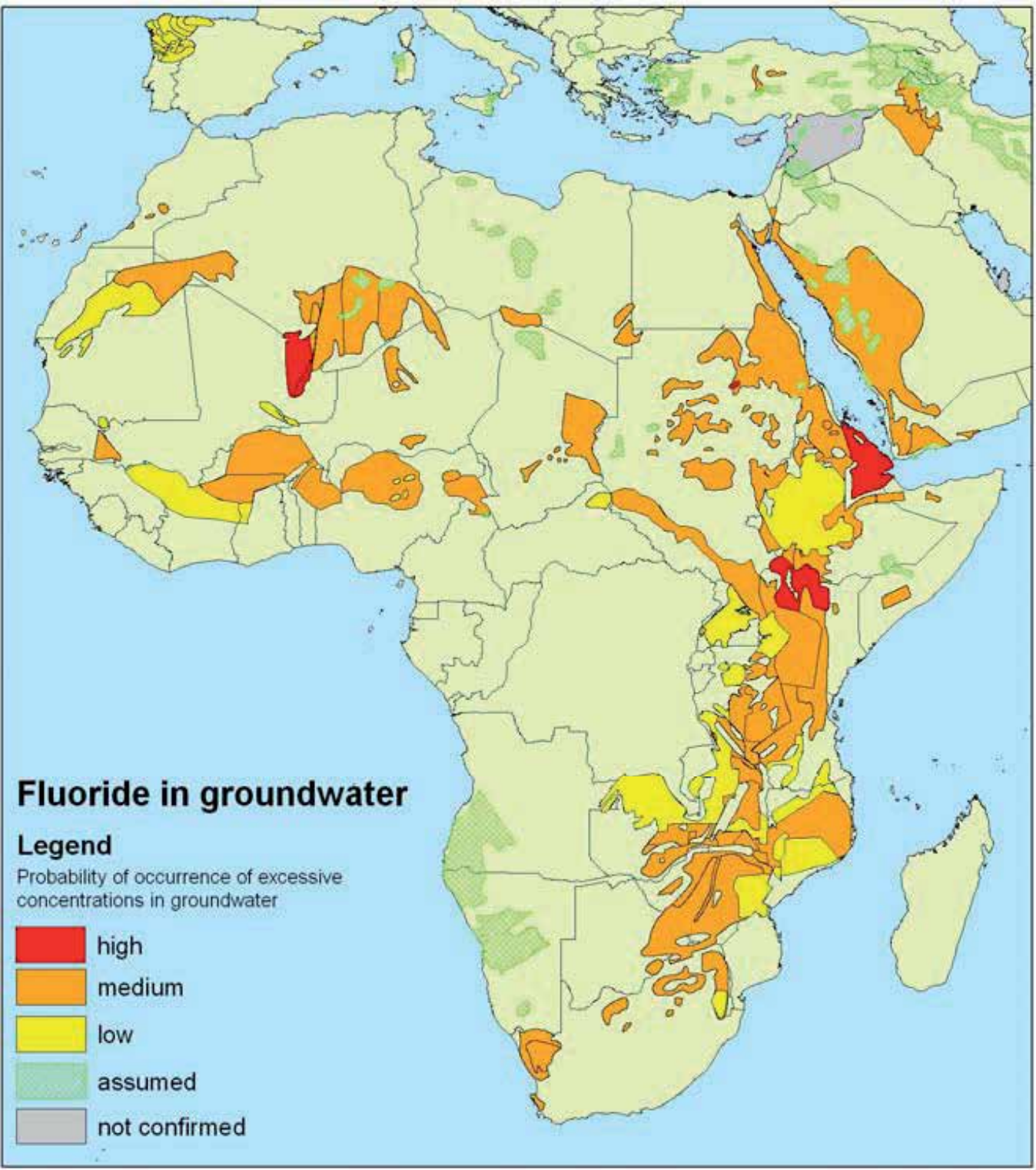

Figure 2. Fluoride occurrence in groundwater in Africa [11] 


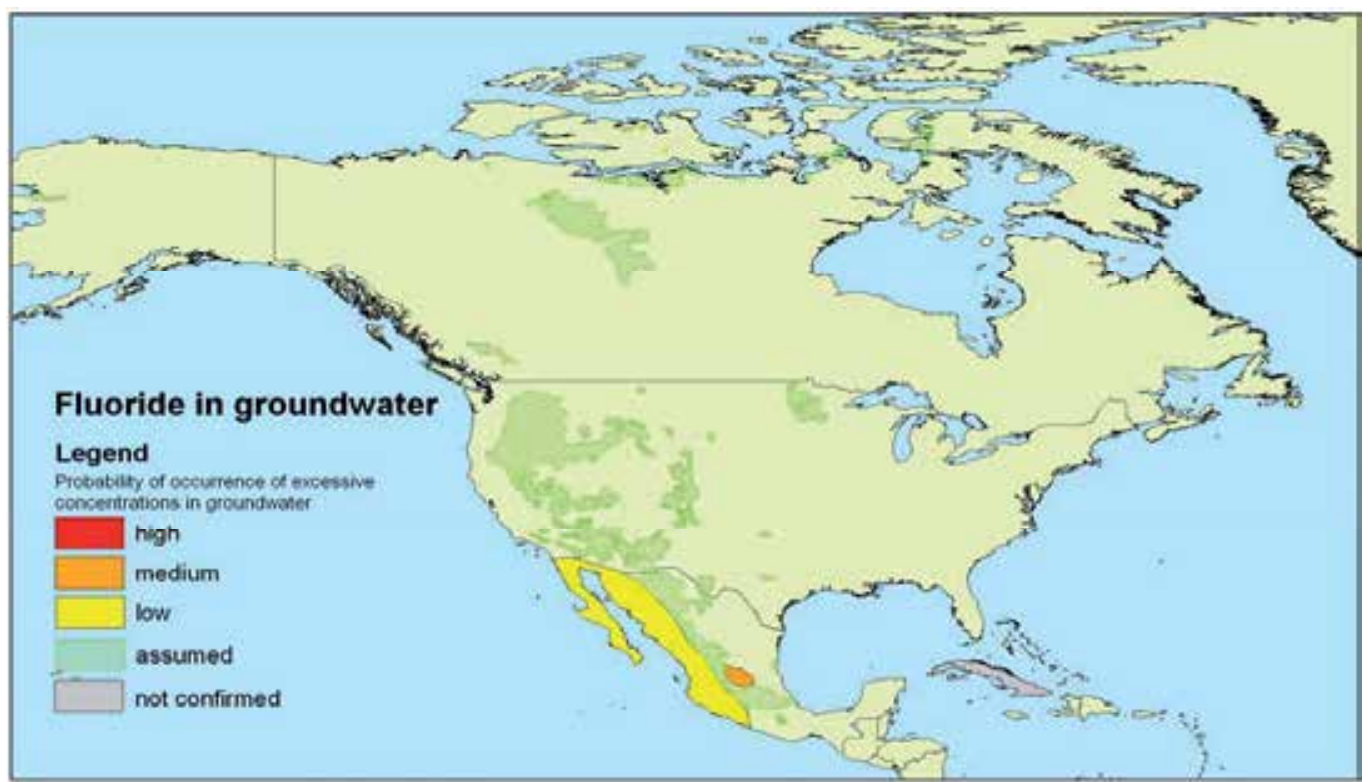

Figure 3. Fluoride occurrence in groundwater in North and Central America [11]

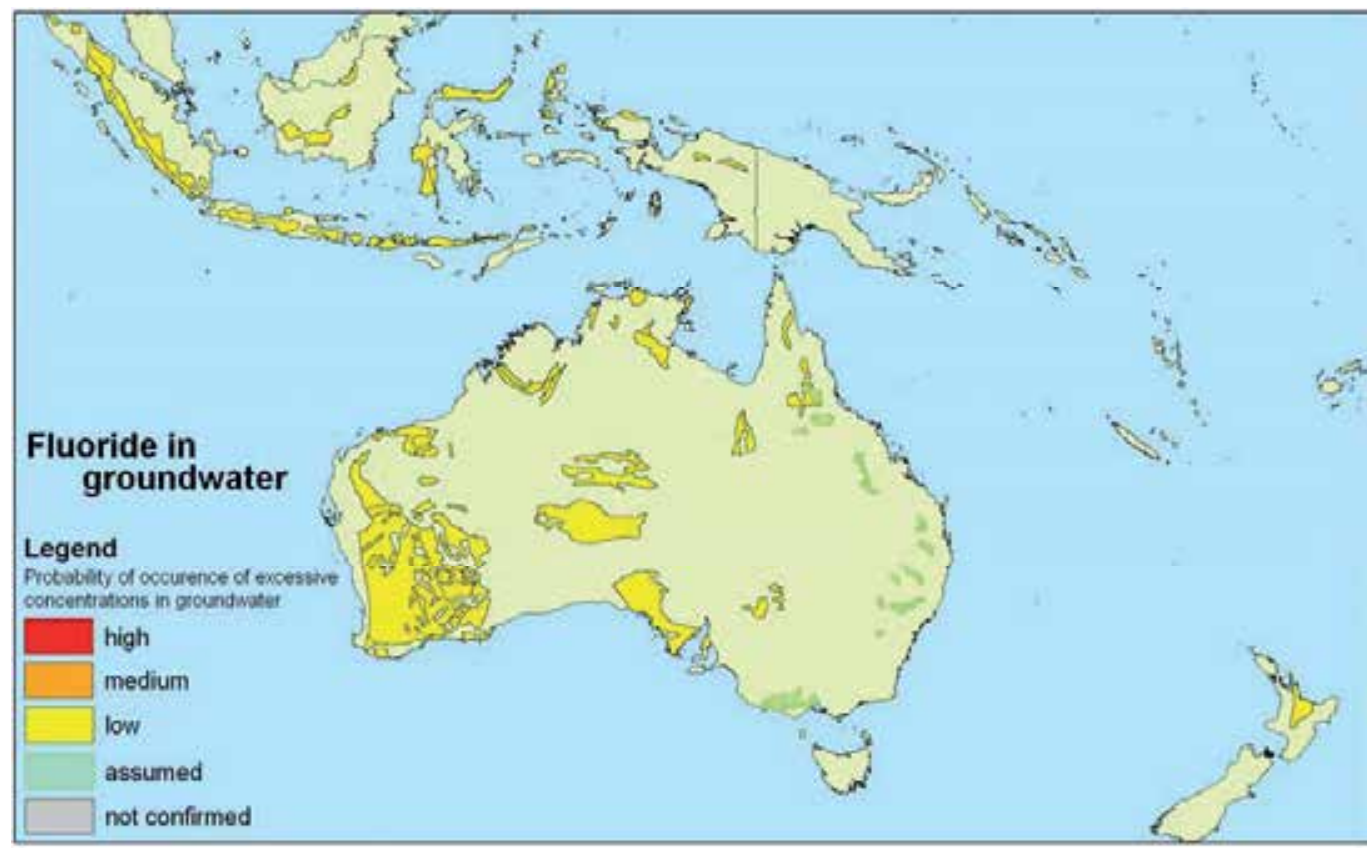

Figure 4. Fluoride occurrence in groundwater in Oceania [11] 


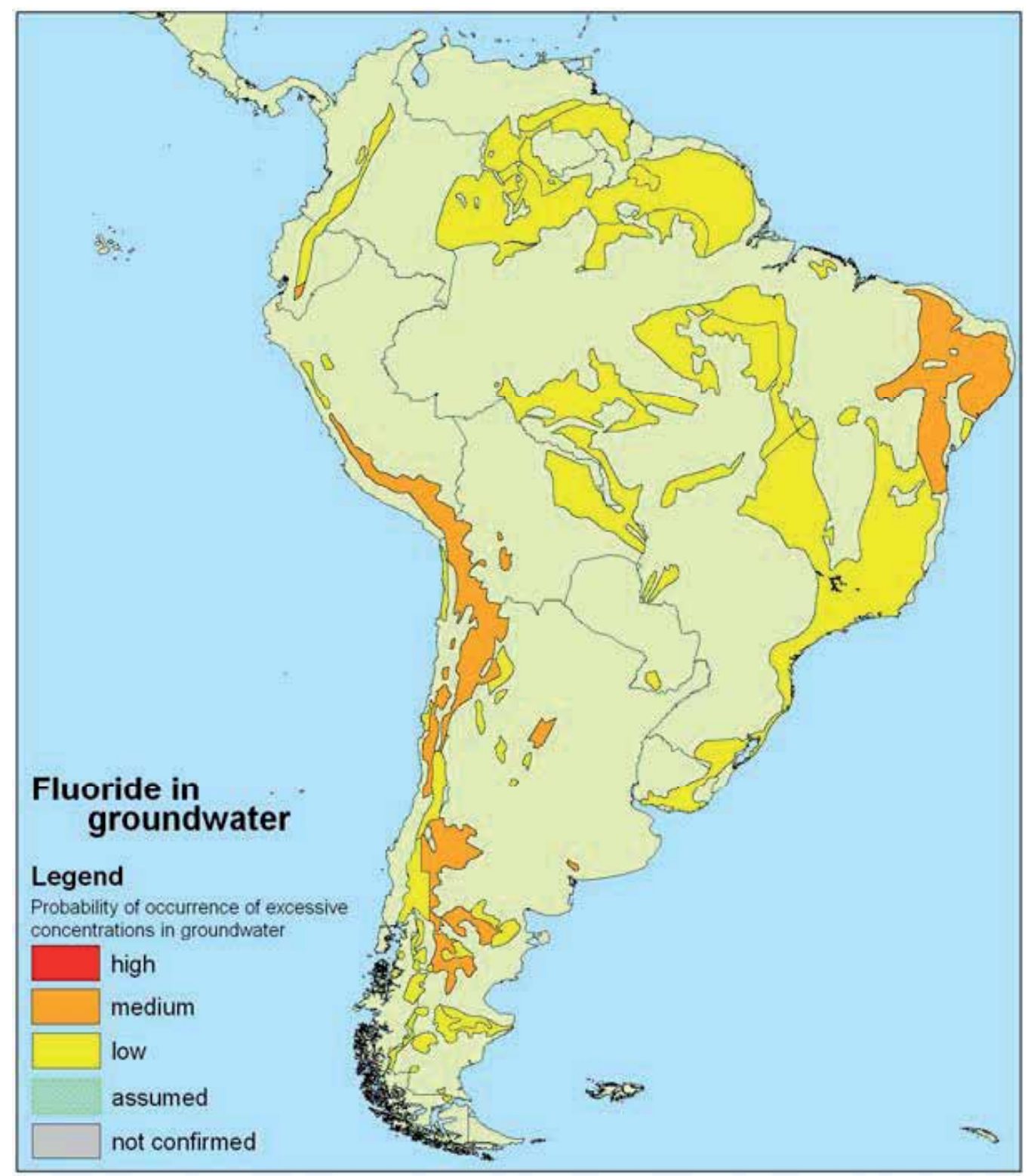

Figure 5. Fluoride occurrence in groundwater in South America [11]

\section{Fluoride occurrence in East and Southern Africa}

High fluoride levels occur in ground waters in some parts of Kenya, Tanzania, Malawi and The Republic of South Africa; however the East African countries have higher levels compared 


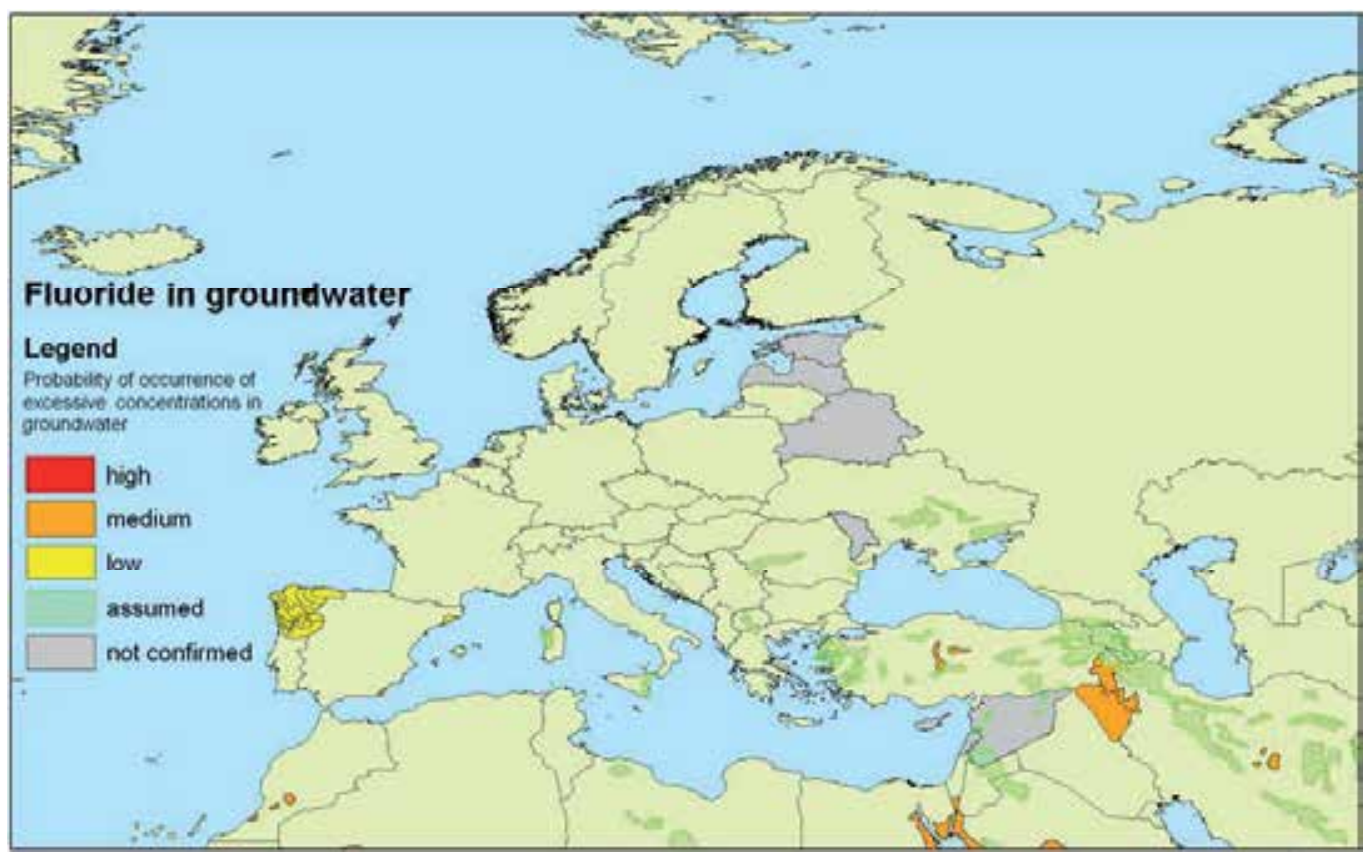

Figure 6. Fluoride occurrence in groundwater in Europe [11]

\begin{tabular}{cc}
\hline Location & Average fluoride level in ground water \\
\hline Arusha Maji ya Chai, Arumeru District & 20.0 \\
\hline Lemongo spring 10.5 & 10.5 \\
\hline Kikati B/H 113/79 11.0 & 11.0 \\
\hline B/H 186/81 - Hanang 46.0 & 32.0 \\
\hline Singida S/W 8/78 - Ngorongoro 11.6 & 46.0 \\
\hline Senene 10.5 & 11.6 \\
\hline Well camp Doromoni 21.3 & 10.5 \\
\hline Hot spring - Manyoni 10.5 & 21.3 \\
\hline Shinyanga S/W Mkokolo 17.0 & 12.5 \\
\hline
\end{tabular}

Sourced from Ngurdoto Defluoridation Research Centre, Tanzania

Table 5. Fluoride concentrations in some ground water sources in Northern Tanzania

to the Southern Countries. In Tanzania for example, fluoride concentrations in ground water of up to $40 \mathrm{mg} / \mathrm{l}$ have been reported, see Table 5. Some lakes in East Africa have extremely high fluoride concentrations, an occurrence not typical in surface waters. Lake Elmentaita and Lake Nakuru of Kenya have fluoride concentrations of 1,640 mg 1-1 and 2,800 mg 1-1 respectively [12]. The Tanzanian Lake Momella is reported to have a fluoride concentration of $690 \mathrm{mg} / \mathrm{l}$ [3]. 
A detailed survey of fluoride concentrations carried out in Kenya revealed that $20 \%$ of the samples had fluoride levels greater than $5 \mathrm{mg} / \mathrm{l}$ and $12 \%$ of the samples exceeded $8 \mathrm{mg} / \mathrm{l}$. A total of 1000 samples were taken from different locations covering the whole country. The highest concentrations were reported in ground waters of the volcanic areas of the Nairobi, Rift Valley and Central Provinces where maximum ground water fluoride concentrations were as high as 30-50 mg/l [12]. In Tanzania concentrations of up to $45 \mathrm{mg} / \mathrm{l}$ have been detected in the rift valley. The most affected areas of Tanzania are Mwanza, Mara, Shinyanga, Arusha, Kilimanjaro and Singida shown in shaded lines in Figure 7.

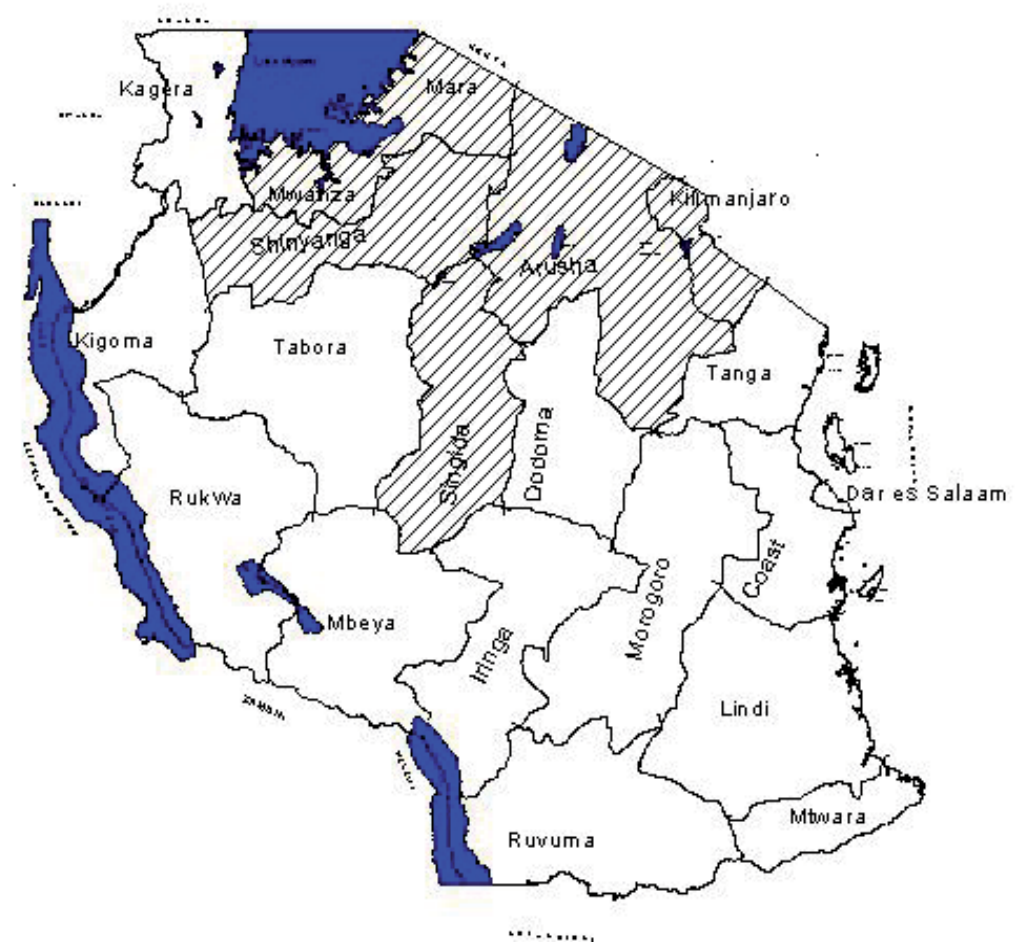

Figure 7. Map of Tanzania showing areas most affceted with fluoride (Sourced from Ngurdoto Defluoridation Research Station)

Fluoride occurrence in groundwater in Malawi has been better surveyed in the southern region $[13,14,15]$. Some data extracted from research is depicted in Table 6.

Research in the Republic of South Africa has shown that underground mine waters may contain high fluoride levels beyond $3 \mathrm{mg} / \mathrm{l}$. In one selected case fluoride levels of about $6 \mathrm{mg} /$ 1 were identified in groundwater of Madibeng Local Municipality, North West Province of South Africa. West province is one of the areas in South Africa where fluorosis is typical. Areas affected include the North-West provinces, the Karoo, Limpopo and the Northern Cape. Cases like these have attracted research in water defluoridation such that evaluation of activated 
alumina as a defluoridating agent was carried out [17 - 19]. The researches demonstrated that the activated alumuna could be employed to treat underground mine water with initial fluoride levels as high as $8 \mathrm{mg} / \mathrm{l}$. Two defluoridation plants were installed each with capacity of 500, 000 litres/day in the early 1980's in the Republic of South Africa.

\begin{tabular}{|c|c|c|c|}
\hline Location & District & $\begin{array}{l}\text { Fluoride level in groundwater } \\
\qquad(\mathrm{mg} / \mathrm{l})\end{array}$ & Reference \\
\hline Bangula market & Nsanje & $4.91 \pm 0.03$ & [13] \\
\hline Nsanje level crossing & Nsanje & $7.25 \pm 0.01$ & [16] \\
\hline Tomali trading centre & Chikwawa & $1.91 \pm 0.00$ & [15] \\
\hline Tomali dip tank & Chikwawa & $1.93 \pm 0.01$ & [15] \\
\hline Mlangalanga Village, Malindi & Mangochi & $2.60 \pm 0.00$ & [13] \\
\hline Mangochi hospital & Mangochi & $2.45 \pm 0.01$ & [13] \\
\hline Nsauya 1 & Mangochi & $3.64 \pm 0.01$ & [13] \\
\hline Mbando village & Zomba & $6.51 \pm 0.01$ & [13] \\
\hline Mtubwi & Machinga & $7.51 \pm 0.00$ & [14] \\
\hline Mliwa village & Machinga & $5.60 \pm 0.00$ & [13] \\
\hline Evangelical Baptist Church & Machinga & $5.08 \pm 0.01$ & [13] \\
\hline Machinga hospital & Machinga & $4.73 \pm 0.01$ & [14] \\
\hline Duwa village & Machinga & $4.88 \pm 0.00$ & [13] \\
\hline Chedweka & Machinga & $6.47 \pm 0.02$ & [13] \\
\hline Mazengera & Lilongwe & $7.00 \pm 0.01$ & {$[5]$} \\
\hline Nkhotakota boma & Nkhotakota & $9.60 \pm 0.02$ & [16] \\
\hline Songwe & Karonga & $8.00 \pm 0.01$ & [16] \\
\hline
\end{tabular}

Table 6. Some locations with high fluoride levels in groundwater reported in literature

\section{Research on fluorosis and water defluoridation}

Research on removal of fluoride from drinking water has employed very many materials world over. The main principles however remain adsorption, ion exchange, precipitation, coagulation, membrane processes, distillation and electrolysis. 


\subsection{Adsorption and ion exchange}

Adsorption involves passage of water through a contact bed where fluoride is removed by ion exchange or surface chemical reaction with the solid bed matrix. After a period of operation, a saturated column must be refilled or regenerated. The different adsorbents used for fluoride removal include activated alumina, carbon, bone charcoal, activated alumina coated silica gel, calcite, activated saw dust, magnesia, serpentine, tricalcium phosphate, activated soil sorbents, carbion, defluoron, and other synthetic ion exchange resins [20 - 24]. Most widely used adsorbents are activated alumina and activated carbon. Activated alumina was first proposed and researched for defluoridation around 1930. It is basically highly porous aluminium oxide with large surface area. The discontinuous cationic lattice of alumina gives it localized areas of positive charge. This renders alumina a good adsorbent for many anionic species, however its greater preference for fluoride compared to other ions has led to its wide use in defluoridation [25]. Defluoridation capacity of activated alumina decreases with increase in hardness. High fluoride concentrations increase the solubility of alumina due to the formation of monomeric aluminium fluoride and aluminium hydroxyl fluoride complexes. It is established that defluoridation with alumina is optimal at $\mathrm{pH} 5-6$. The activated alumina does not shrink, swell, soften nor disintegrate when immersed in water but dissolves at $\mathrm{pH}$ less than 5.0. At $\mathrm{pH}$ greater than 7.0 silicate and hydroxide compete strongly with fluoride for adsorption/exchange sites on alumina resulting in lower fluoride sorption. Chloride does not interfere with sorption of fluoride on activated alumina [23]. The use of activated alumina is highly selective towards fluoride but the $\mathrm{pH}$ specificity, low capacity and low material integrity in acidic medium are some of the limitations of this process [20].

It is common to first treat alumina with hydrochloric acid to make it acidic. However this treatment is often carried out in acidic medium with $\mathrm{pH}$ between 5 and 6 to avoid excessive dissolution of the alumina that occurs below $\mathrm{pH} 5$. The chloride ions on the acidic alumina are replaced by fluorides when the alumina is in contact with fluoride ions. Equations 3 and 4 below illustrate the activation and ion exchange processes respectively.

$$
\begin{gathered}
\mathrm{Al}_{2} \mathrm{O}_{3}{ }^{\Phi} \mathrm{H}_{2} \mathrm{O}+\mathrm{HCl} \rightarrow \mathrm{Al}_{2} \mathrm{O}_{3}{ }^{\Phi} \mathrm{HCl}+\mathrm{H}_{2} \mathrm{O} \\
\mathrm{Al}_{2} \mathrm{O}_{3}{ }^{\Phi} \mathrm{HCl}+\mathrm{NaF} \rightarrow \mathrm{Al}_{2} \mathrm{O}_{3}{ }^{\Phi} \mathrm{HF}+\mathrm{NaCl}
\end{gathered}
$$

\section{$\left(\mathrm{Al}_{2} \mathrm{O}_{3}{ }^{\Phi}\right.$ indicates activated alumina)}

To regenerate the adsorbent a dilute solution of sodium hydroxide is mixed with the adsorbent to get a basic alumina, equation 5, followed by further treatment with acid, equation 6 . 


$$
\begin{gathered}
\mathrm{Al}_{2} \mathrm{O}_{3}{ }^{\Phi} \mathrm{HF}+2 \mathrm{NaOH} \rightarrow \mathrm{Al}_{2} \mathrm{O}_{3}{ }^{\Phi} \mathrm{NaOH}+\mathrm{NaF}+\mathrm{H}_{2} \mathrm{O} \\
\mathrm{Al}_{2} \mathrm{O}_{3}{ }^{\Phi} \mathrm{NaOH}+2 \mathrm{HCl} \rightarrow \mathrm{Al}_{2} \mathrm{O}_{3}{ }^{\Phi} \mathrm{HCl}+\mathrm{NaCl}+\mathrm{H}_{2} \mathrm{O}
\end{gathered}
$$

The regeneration yields sodium fluoride concentrated wastewater that requires disposal, another challenge in the alumina adsorption process. Adsorption with activated carbon is another efficient technique, however, high cost and challenges with the spent carbon limit its large scale application [26]. Granular activated carbon is often employed in adsorption columns because of its non-specific nature of adsorption on its surface [27]. Powdered activated carbon has also been employed successfully in water defluoridation despite that the process is highly $\mathrm{pH}$ dependent with optimum results below $\mathrm{pH} 3$ [28]. This requires $\mathrm{pH}$ reduction during defluoridation and increasing $\mathrm{pH}$ artificially in the water after treatment which is a challenge in the employment of this process. Bone char, which is derived from animal bones charred at $500-600^{\circ} \mathrm{C}$, has a rich surface of heterogeneous components, allowing physisorption, chemisorption or ion exchange to occur. Physisorption, also termed physical adsorption, is adsorption that involves van der Waals forces (intermolecular forces) and there are no significant changes in the electronic orbital patterns of the species involved. Chemisorption, on the other hand, involves valence forces of the same kind as those that result in the formation of chemical compounds. The combination of physisorption, chemisorption and ion exchange processes renders bone char a better sorbent, in terms of ion uptake capacity, among other carbon based adsorbents such as activated carbon and peat [29,30]. Bone charcoal has been widely applied in water defluoridation (Castillo et al., 2007 [7, 31,32]. It is typically a black, granular and porous material with about 57 to 80 percent calcium phosphate [ $\left.\mathrm{Ca}_{3}\left(\mathrm{PO}_{4}\right)_{2}\right], 6$ to 10 percent calcium carbonate $\left(\mathrm{CaCO}_{3}\right)$ and 7 to 10 percent activated carbon. Principal reaction in defluoridation with bone charcoal is hydroxyl-fluoride exchange of apatite, equation 7 [3].

$$
\mathrm{Ca} a_{10}\left(\mathrm{PO}_{4}\right)_{6}(\mathrm{OH})_{2}+2 \mathrm{~F}^{-} \rightarrow \mathrm{Ca}_{10}\left(\mathrm{PO}_{4}\right)_{6} \mathrm{~F}_{2}+2 \mathrm{OH}^{-}
$$

The preparation of bone charcoal is crucial. Unless carried out properly, the bone charring process may result in a product of low defluoridation capacity and/or deterioration in aesthetic water quality. Water treated with poor bone charcoal may taste and smell like rotten meat and is aesthetically unacceptable $[3,7]$.

\subsection{Precipitation - Coagulation}

The Nalgonda technique is a widely known precipitation - coagulation defluoridation method. In this technique aluminium sulfate and lime are added periodically in batch to treat water. These are co-precipitation chemicals that behave as shown, equations 8 - 11, in fluoride removal. 


$$
\begin{gathered}
\mathrm{Al}_{2}\left(\mathrm{SO}_{4}\right)_{3}+6 \mathrm{H}_{2} \mathrm{O} \rightarrow 2 \mathrm{Al}(\mathrm{OH})_{3}+3 \mathrm{SO}_{4}^{2-}+6 \mathrm{H}^{+} \\
\mathrm{Al}(\mathrm{OH})_{3}+\mathrm{F}^{-} \rightarrow \mathrm{Al}-\mathrm{F}_{\text {Complex }}+\text { undefined }_{p p t} \\
\mathrm{CaO}+\mathrm{H}_{2} \mathrm{O} \rightarrow \mathrm{Ca}(\mathrm{OH})_{2} \\
3 \mathrm{Ca}(\mathrm{OH})_{2}+6 \mathrm{H}^{+} \rightarrow 3 \mathrm{Ca}^{2+}+6 \mathrm{H}_{2} \mathrm{O}
\end{gathered}
$$

Other co-precipitation chemicals such as polyaluminium chloride (PAC), lime and similar compounds are also employed and are added daily to raw water in batches. Precipitation techniques produce a certain amount of sludge every day [3].

Calcium and phosphate compounds are an example of contact precipitation chemicals often added to the water upstream of a catalytic filter bed. In contact precipitation there is no sludge and no saturation of the bed, only the accumulation of the precipitate in the bed. Theoretically it is possible to precipitate fluoride as calcium fluoride or fluoroapatite in solutions containing calcium, phosphate and fluoride; however in practice it is kinetically impossible. The reaction kinetics are very slow. Precipitation is easily catalysed in a contact bed that acts as a filter for the precipitate. The reactions involve dissolution of calcium chloride and sodium dihydrogen phosphate, and consequent precipitation of calcium fluoride and fluoroapatite [33]. These are illustrated through equations 12 to 15 .

$$
\begin{gathered}
\mathrm{CaCl}_{2(a q)} \rightarrow \mathrm{Ca}^{2+}{ }_{(a q)}+2 \mathrm{Cl}_{(a q)}^{-} \\
\mathrm{NaH}_{2} \mathrm{PO}_{4(a q)} \rightarrow \mathrm{Na}_{(a q)}^{+}+2 \mathrm{H}_{(a q)}^{+}+\mathrm{PO}_{4}^{2-}(a q) \\
\mathrm{Ca}_{(a q)}^{2+}+2 \mathrm{~F}_{(a q)}^{-} \rightarrow \mathrm{CaF}_{2(s)} \\
10 \mathrm{Ca}_{(a q)}^{2+}+6 \mathrm{PO}_{4}^{2-}{ }_{(a q)}+\mathrm{F}_{(a q)}^{-} \rightarrow \mathrm{Ca}_{10}\left(\mathrm{PO}_{4}\right) F_{2(s)}
\end{gathered}
$$

A small saturated bone char contact bed is employed as a column. This column is supported by coarse grain charcoal or gravel. Figure 8 shows the Ngurdoto configuration [34]. 


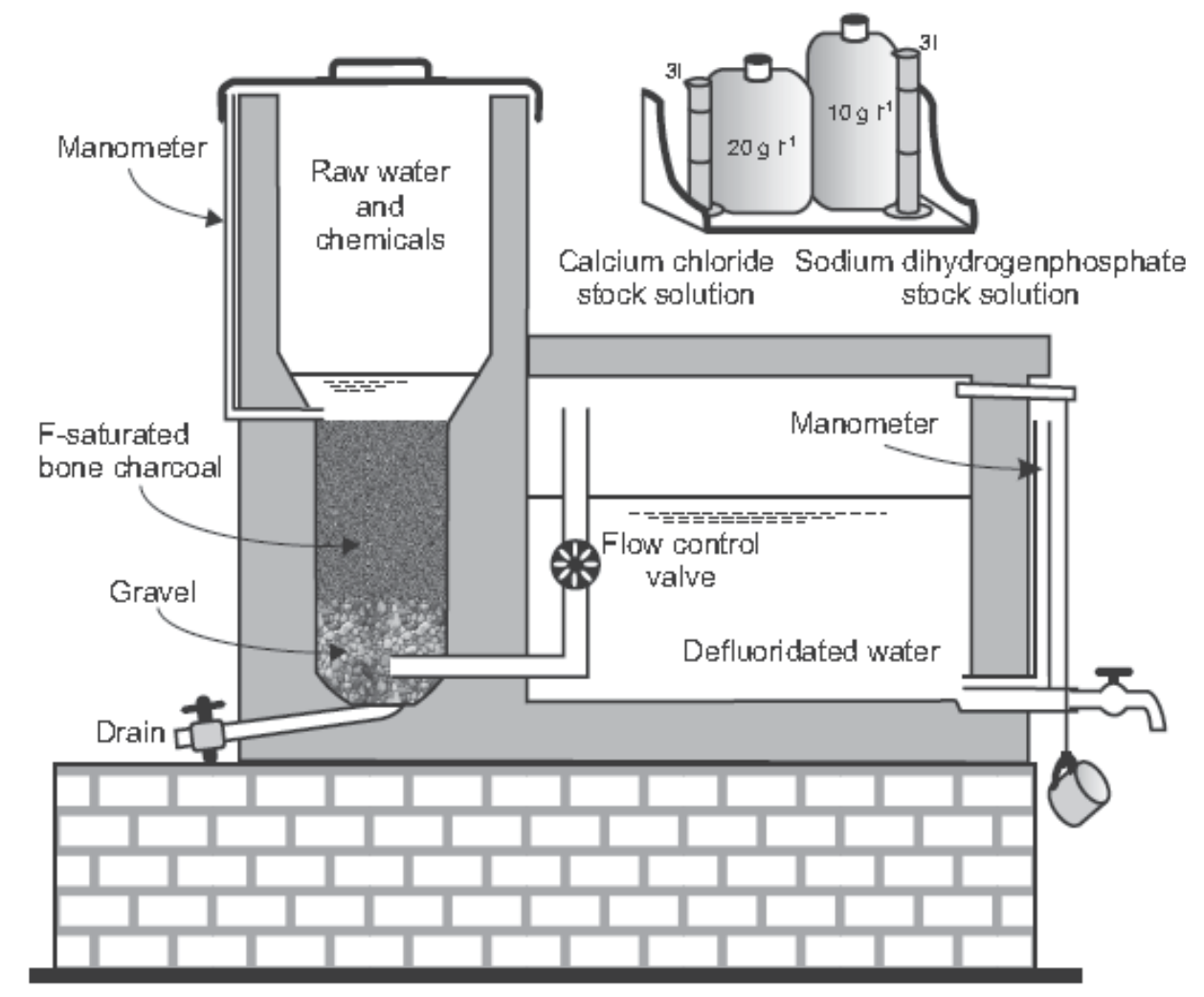

Figure 8. Contact precipitation of fluoride as invented in Ngurdoto

It is recommended to prepare the chemicals monthly as stock solutions and employ them in aliquots. The two stock solutions should not be mixed before treatment in order to avoid the precipitation of calcium phosphate. Two special measuring cups may be used for volumetric portioning of the chemicals. It is advisable to check the bulk density as it may vary for different brands. The stock solutions, stored in Jerry cans, along with the respective chemical bags and the measuring cups and cylinders may be coloured red and green respectively in order to minimize the risk of exchange and so incorrect dosage [3]. The design criteria of the contact precipitation plants is simple however, the theoretical background is fairly complex and largely dependent on the reactions shown in equations 14 and 15 . The extent to which each reaction occurs is not well understood. In calcium fluoride precipitation, the $\mathrm{Ca} / \mathrm{F}$ weight ratio is about 1 , equivalent to a $\mathrm{CC} / \mathrm{F}$ ratio of about 4 . In fluorapatite precipitation, the $\mathrm{Ca} / \mathrm{F}$ ration is 11 and the $\mathrm{PO}_{4} / \mathrm{F}$ ratio is 15 , equivalent to a CC/F ratio of about 39 and a MSP/F ratio of about 23. This implies that the more fluoride precipitated as calcium fluoride, rather than as fluorapatite, the lower is the required dosage of chemicals. Calcium fluoride precipitation is probably more dominant with higher raw water fluoride concentration. Experience from operations of the contact precipitation in Tanzania, where the fluoride concentration averages $10 \mathrm{mg} / \mathrm{l}$, has shown that the process functions effectively when the dosage ratios are 30 and 15 for $\mathrm{CC}$ and 
MSP respectively. This dosage would ensure at least 65 per cent precipitation of fluorapatite and a surplus of calcium for precipitation of the residual fluoride as calcium fluoride [33,34].

\subsection{Membrane filtration}

Membrane filtration processes are among advanced water treatment technologies that have been mainly employed in treatment of pure and ultra pure water. The US EPA, 2003, recommended reverse osmosis, $\mathrm{RO}$, as one of the best available defluoridation technologies [35]. Reverse osmosis and nano-filtration (NF) are the well known membrane technologies that can remove a large spectrum of contaminants from water such as pathogens, turbidity, heavy metals, salinity, natural and synthetic organics, and hardness [36]. The two processes are highly effective in water defluoridation and produce high quality water that includes disinfection during water treatment. NF membranes operate at a lower pressure and have lower capacity as compared to $\mathrm{RO}$ membranes. Another membrane technology is electrodialysis. Use of electrodialysis plants in North Africa is employed in large scale water treatment of high fluoride brackish water for potable water supply [37]. Electrodialysis is similar to Reverse Osmosis, except it uses an applied direct current potential instead of pressure, to separate ionic contaminants from water. Water does not physically pass through the membrane in the electrodialysis process as such particulate matter is not removed. The ED membranes are therefore not technically considered filters. The water quality from electrodialysis treatment is comparable to $\mathrm{RO}$, and may require post-treatment stabilization. The process tends to be most economical for source water with TDS levels in excess of 4,000 mg/L. It is established that $\mathrm{RO}$ and electrodialysis have very high defluoridation capacities $(85-95 \%)$ and function effectively in any $\mathrm{pH}$ range. However the water loss is high (20 - 30\% for electrodialysis, 40 $60 \%$ for RO), have high capital cost and are energy intensive [37]. Membrane technologies often require special equipment, electrical energy and specialized training for operators as such the capital and operation costs are high. Low applicability is therefore envisaged for rural sectors of the developing countries where energy and trained human resource are often deficient.

\subsection{Emerging technologies}

Some emerging technologies employing precipitation, distillation and /or a combination of principles are; The Crystalactor ${ }^{\circledR}$, Memstill ${ }^{\circledR}$ technology, The WaterPyramid ${ }^{\circledR}$ solution and The Solar Dew Collector system. The Crystalactor ${ }^{\circledR}$ was developed by DHV in the Netherlands [38]. It is a pellet reactor employing a fluidized bed. Water defluoridation occurs in the reactor accompanied by formation of calcium fluoride pellets of $1 \mathrm{~mm}$ diameter. The Crystalactor ${ }^{\circledR}$ employs contact precipitation and has the strengths that; the installation is compact, produces usable calcium fluoride pellets with high-purity, and the produced pellets have extremely low water content ( $5 \%$ to $10 \%$ moisture). It is estimated that this technology costs about a quarter of the conventional precipitation techniques. The technology is however suitable for treating high fluoride waters $(>10 \mathrm{mg} / \mathrm{l})$ and to attain concentrations below $1 \mathrm{mg} / \mathrm{l}$ a second treatment is often required. A membrane based distillation concept is also reported as developed by the Netherlands Organisation of Applied Scientific Research (TNO), the Memstill@ technology, 
Figure 11. This technology advances ecology and economy of the existing technologies in brackish and sea water desalination. The technology also removes other anions such as fluoride and arsenic [39]. In the Memstill@ technology cold feed water takes up heat in the condenser channel through condensation of water vapour, then a small amount of (waste) heat is added, and flows counter currently back via the membrane channel. This small added heat evaporates water through the membrane. The water is discharged as cold condensate. The cooled brine is disposed, or extra concentrated in a next module. The Memstill@ technology can produce potable water at a cost well below that of existing technologies like reverse osmosis and distillation. It is expected that the Memstill ${ }^{\circledR}$ technology will also be developed for small scale applications using solar heat [39].

\section{Principle of Memstill-process}

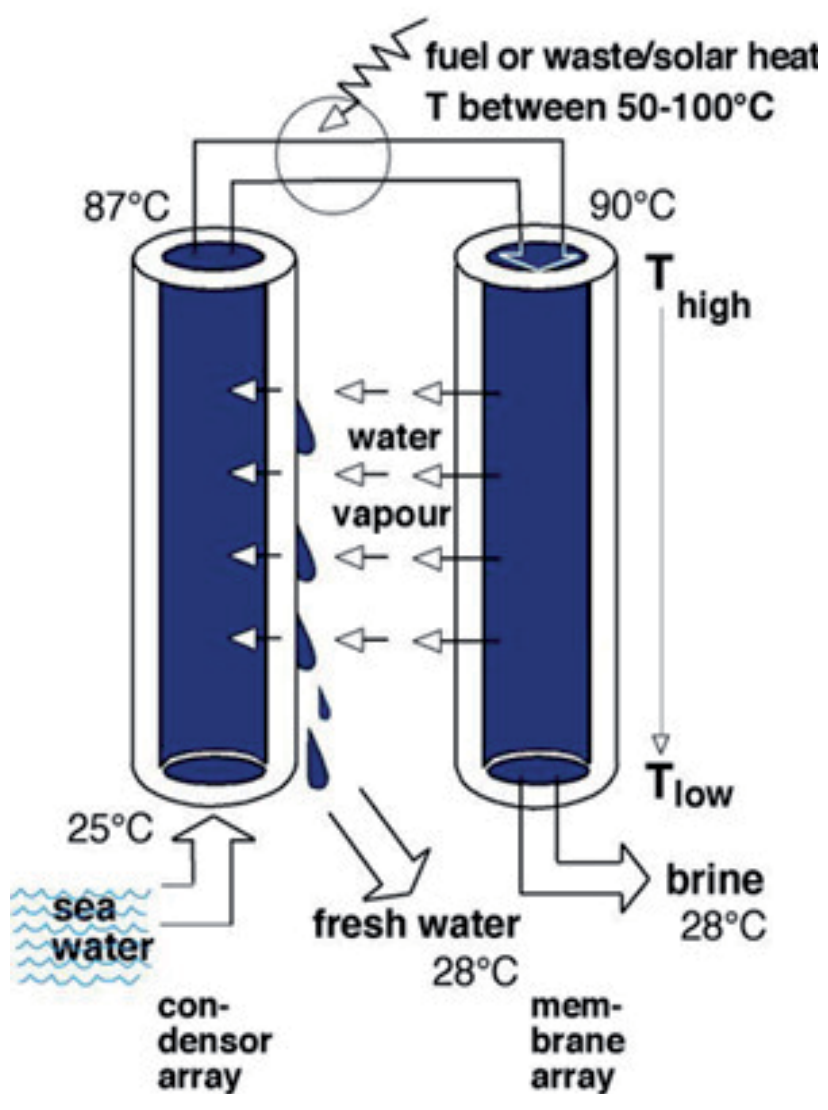

Figure 9. Memstillø technology [39]

The water pyramid, developed for rural tropical areas, employs solar energy to produce potable water from saline, brackish or polluted water, Figure 12 [40]. The technology also removes fluoride. A water pyramid with a total area of $600 \mathrm{~m}^{2}$, placed under favourable tropical 
conditions, can produce about 1250 litres of fresh water a day. The rate of production is however dependent on local atmospheric conditions such as climate, temperature, cloud-cover and wind activity. Solar energy drives the desalination while energy required for pressuring the WaterPyramid ${ }^{\circledR}$ is obtained using solar cells combined with a battery backup system. A small generator may be required to cater for intermittent peak demands in electricity.

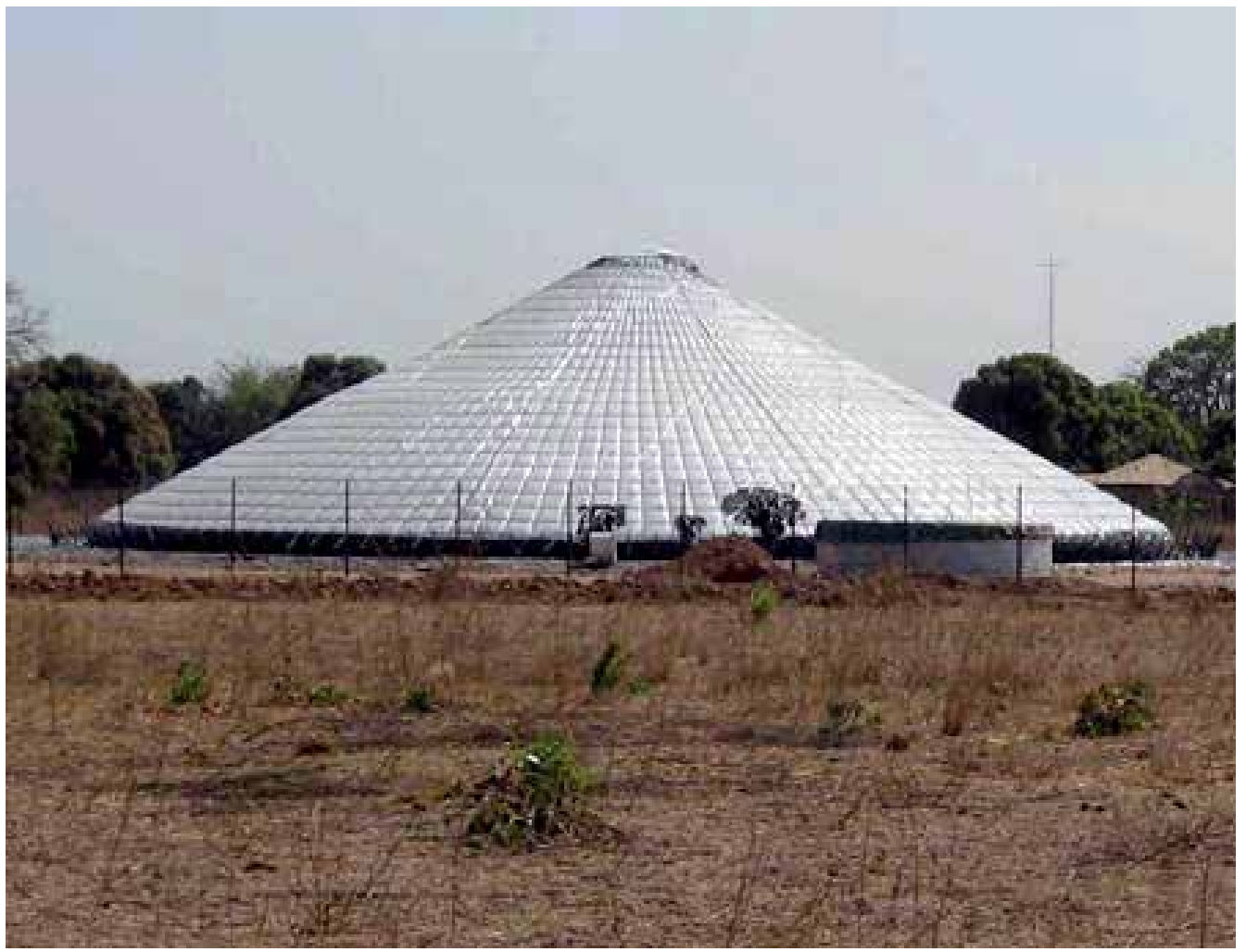

Figure 10. The WaterPyramid ${ }^{\circledR}[40]$

Another technique similar to the WaterPyramid was developed by Solar Dew, Figure 13 [41]. This is a porous membrane that purifies water using solar energy. In this techniques water sweats through a membrane and evaporates on the membrane surface. This increases humidity in the evaporation chamber. As a result of temperature difference pure water condenses on the cooler surface of the system.

Larsen and Pearce, 2002, proposed a defluoridation method in which fluoride containing water is boiled with brushite $\left(\mathrm{CaHPO}_{4} \cdot 2 \mathrm{H}_{2} \mathrm{O}\right)$ and calcite $\left(\mathrm{CaCO}_{3}\right)$. Good results were obtained on laboratory scale. Larsen and Pearce concluded that boiling brushite and calcite in fluoritic water yields fluoroapatite which results in defluoridation [42]. 


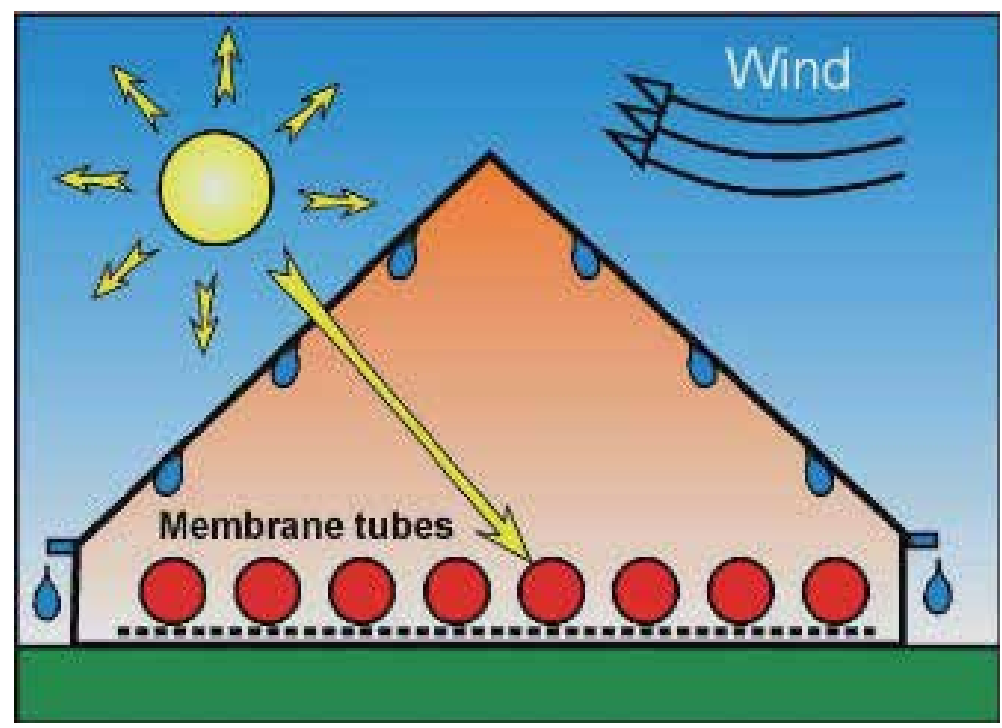

Figure 11. The Solar Dew Collector system [41]

\section{Research on fluorosis and water defluoridation in East and Southern}

\section{Africa}

Research was carried out in Tanzania at Ngurdoto Defluoridation Research Station employing different materials in batch and fixed bed defluoridation configurations. In Malawi Research was carried out at Chancellor College of the University of Malawi. Bone char, bauxite, gypsum, magnesite have been experimented on in defluoridation.

\subsection{Water defluoridation research in Tanzania}

Removal of fluoride from water has been researched on employing a number of materials among which are bauxite, gypsum, magnesite and their composite filters [2,46,47], Calcium chloride $\left(\mathrm{CaCl}_{2}\right)$ and Sodium dihydrogen phosphate $\left(\mathrm{NaH}_{2} \mathrm{PO}_{4}\right)$ as co-precipitation reagents in contact precipitation [33, 34], cow bone char in batch and fixed bed [7, 32], fish bone [43], activated carbon and activated carbon loaded separately with alumina, magnesia and calcium [44], and, magnesite [45].

Research on defluoridation with bauxite, gypsum and magnesite focused on developing a hybrid technology with the three materials to reduce negative impacts on water quality that are encountered when each of the materials i.e. bauxite, gypsum and magnesite, is employed alone. The composites tested were mixtures of bauxite, gypsum and magnesite in respective mass ratios of 1:2:3, and such combinations with the order of the ratio numbers varied, giving a total of six compositions. Different calcine temperatures ranging from 150 to $500{ }^{\circ} \mathrm{C}$ were also tested and performance of batch and fixed bed configurations were compared. The research results in summary showed that the fixed bed configuration of the 3:2:1 (mass ratio of bauxite, 
gypsum, magnesite respectively) obtained water of optimum quality when calcined at $200{ }^{\circ} \mathrm{C}$. The water quality parameters included in this research were $\mathrm{pH}$, alkalinity, apparent colour, concentrations of the ions $\mathrm{F}^{-}, \mathrm{Cl}^{-}, \mathrm{SO}_{4}^{2-}, \mathrm{Ca}^{2+}, \mathrm{Mg}^{2+}, \mathrm{Fe}^{2+}, \mathrm{Al}^{3+}$, and hardness. The World Health Organisation recommended limits were employed as bench marks [48]. Table 7 illustrates the problems that were addressed by this research and potential solutions obtained.

\begin{tabular}{|c|c|c|c|}
\hline Material & Challenge & Result Obtained & Proposed Solution \\
\hline \multirow[t]{3}{*}{ Bauxite } & $\begin{array}{l}\text { High turbidity, above } 1 \\
\text { NTU, in treated water } \\
\text { when used raw }\end{array}$ & $\begin{array}{l}\text { When calcined above } 200{ }^{\circ} \mathrm{C} \text { and employed in } \\
\text { fixed bed turbidity reduced to below } 1 \text { NTU }\end{array}$ & $\begin{array}{c}\text { May use bauxite calcined at } \\
200^{\circ} \mathrm{C} \text { in fixed bed to reduce } \\
\text { turbidity }\end{array}$ \\
\hline & $\begin{array}{l}\text { Residual colour } \\
\text { beyond } 50 \mathrm{TCU}\end{array}$ & $\begin{array}{l}\text { The composite } 3: 2: 1 \text { of bauxite, gypsum and } \\
\text { magnesite calcined at } 200^{\circ} \mathrm{C} \text { obtained colours } \\
\text { below } 50 \mathrm{TCU} \text { in fixed bed. }\end{array}$ & $\begin{array}{l}\text { Combine the materials in this } \\
\text { ratio and calcine at } 200^{\circ} \mathrm{C} \text {, } \\
\text { employ in fixed bed }\end{array}$ \\
\hline & $\begin{array}{l}\text { Residual } \mathrm{Al}^{3+} \text { beyond } \\
0.2 \mathrm{mg} / \mathrm{l}\end{array}$ & $\begin{array}{l}\text { The composite } 3: 2: 1 \text { of bauxite, gypsum and } \\
\text { magnesite calcined at } 200^{\circ} \mathrm{C} \text { obtained } \mathrm{Al}^{3+} \\
\text { concentrations below } 0.2 \mathrm{mg} / \mathrm{l} \text { in fixed bed. }\end{array}$ & As above. \\
\hline \multirow[t]{2}{*}{ Gypsum } & $\begin{array}{l}\text { Residual hardness } \\
\text { above } 500 \mathrm{mg} / \mathrm{l} \text { as } \\
\mathrm{CaCO}_{3}\end{array}$ & $\begin{array}{l}\text { The composite } 3: 2: 1 \text { of bauxite, gypsum and } \\
\text { magnesite calcined at } 200{ }^{\circ} \mathrm{C} \text { obtained hardness } \\
\text { below } 500 \mathrm{mg} / \mathrm{l} \text { as } \mathrm{CaCO}_{3} \text { in fixed bed. }\end{array}$ & As above. \\
\hline & $\begin{array}{l}\text { High residual } \mathrm{SO}_{4}^{2-} \\
\text { beyond } 400 \mathrm{mg} / \mathrm{l}\end{array}$ & $\begin{array}{l}\text { Gypsum calcined at } 400^{\circ} \mathrm{C} \text { obtained residual } \\
\text { sulphates lower than } 100 \mathrm{mg} / \mathrm{l} \text {, composite 3:2:1 } \\
\text { calcined at } 200^{\circ} \mathrm{C} \text { employed in fixed bed } \\
\text { obtained similar results \& higher loading } \\
\text { capacity. }\end{array}$ & $\begin{array}{l}\text { May employ calcined } \\
\text { gypsum but composite has } \\
\text { higher loading capacity } \\
\text { therefore composite is better } \\
\text { choice to gypsum }\end{array}$ \\
\hline Magnesite & Residual pH above 8.5 & $\begin{array}{l}\text { Composite described above obtained pH } \\
\text { between } 6.7 \text { and } 8.0 \text { in fixed bed }\end{array}$ & $\begin{array}{l}\text { Composite may be used } \\
\text { instead of magnesite. }\end{array}$ \\
\hline
\end{tabular}

Table 7. Major findings in defluoridation with bauxite, gypsum and magnesite at Ngurdoto

Bauxite obtained from Kwemashai in Lushotho District of Tanzania when characterised for composition showed that the major components were $\mathrm{Al}_{2} \mathrm{O}_{3}(30.33 \%), \mathrm{SiO}_{2}(15.00 \%)$ and $\mathrm{Fe}_{2} \mathrm{O}_{3}$ $(14.30 \%)$. Fluoride removal with bauxite is known to depend mainly on reactions of the $\mathrm{Al}_{2} \mathrm{O}_{3}$. Oxides of aluminium are amphoteric and will react as base or acid represented in Equations 16 and 17 respectively.

$$
\begin{gathered}
\mathrm{Al}_{2} \mathrm{O}_{3}(s)+6 \mathrm{H}_{3} \mathrm{O}^{+}(a q)+3 \mathrm{H}_{2} \mathrm{O}(l) \rightarrow 2\left[\mathrm{Al}\left(\mathrm{OH}_{2}\right)_{6}\right]^{3+}(a q) \\
\mathrm{Al}_{2} \mathrm{O}_{3}(s)+2 \mathrm{OH}^{-}(a q)+3 \mathrm{H}_{2} \mathrm{O}(l) \rightarrow 2\left[\mathrm{Al}(\mathrm{OH})_{4}\right]^{-}(a q)
\end{gathered}
$$


Defluoridation capacity of bauxite decreased with increase in $\mathrm{pH}$ of the medium, a result attributed to dominance of acidic reaction of $\mathrm{Al}_{2} \mathrm{O}_{3}$ shown in Equation 17 with formation of negatively charged species. The negatively charged species would in effect retard fluoride sorption. Formation of positively charged species as shown in Equation 16 would occur in low $\mathrm{pH}$ medium hence greater adsorption of fluoride, fluoride being an anion [46,47].

Contact precipitation of fluoride was also researched on at Ngurdoto [33,34]. The technique employedCalciumchlorideandSodiumdihydrogenphosphateandhasbeendescribedinsection 2.4.2. Thetechnology bestdemonstrated in Tanzaniaisuse of bonechar athousehold levelinfixed bed. The configuration designed at Ngurdoto Research Station is shown in Figure 12.

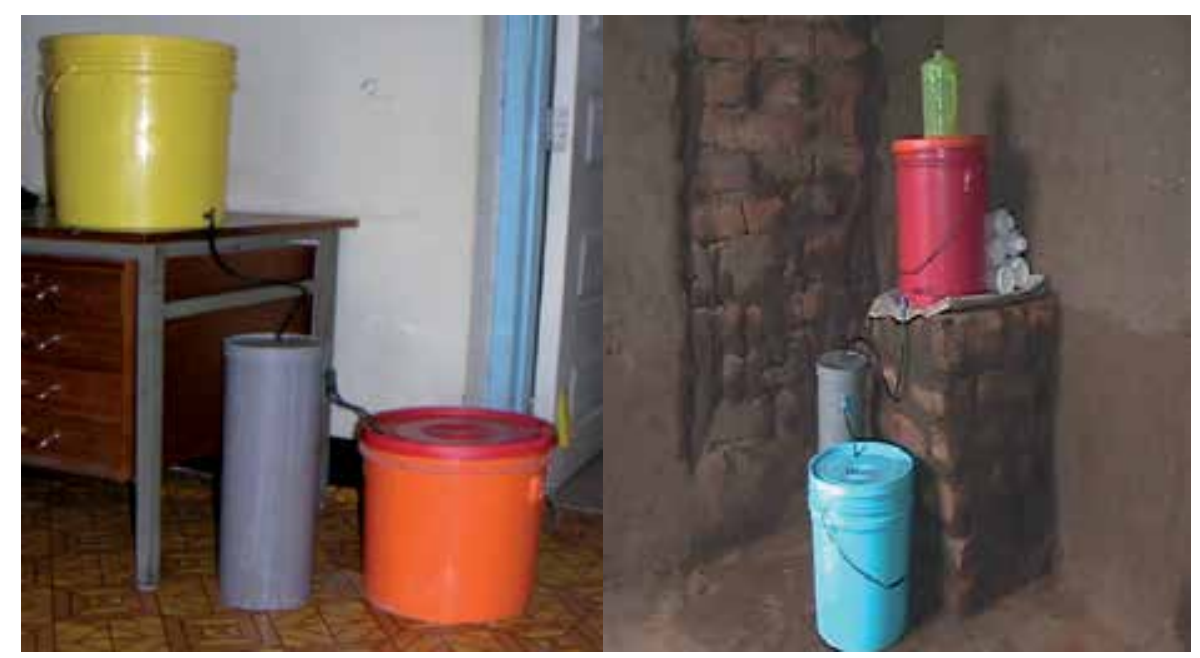

Figure 12. Household defluoridation unit employing bone char developed by Ngurdoto Research Station shown in average and low income household settings

This column for fixed bed defluoridation has also been scaled up particularly in Arusha national park by the Ngurdoto defluoridation station shown in Figure 13.

Clean raw cow bones are collected and charred at $500-550{ }^{\circ} \mathrm{C}$ in specially designed kilns in which air supply is controlled, Figure 14 . The charred bones are pulverized to particle sizes of range 0.5 to $3 \mathrm{~mm}$ in diameter.

The bone char has high sorption capacity initially however the media gets saturated with fluoride with time. The general practice around Arusha is to replace the media when the effluent has a fluoride concentration of $2 \mathrm{mg} / \mathrm{L}$, the maximum permissible limit as per International Reference Centre (IRC) in the Hague, Netherland. Results obtained from a typical bone char household unit are shown in Figure 17. The figure shows that defluoridation of water with initial fluoride of $10 \mathrm{mg} / \mathrm{L}$ up to about 1300 litres of treated water are obtained with fluoride less than $2 \mathrm{mg} / \mathrm{L}$. The mass of bone char used in this investigation was $4 \mathrm{~kg}$. Based on use of 20 litres per family per day of the treated water, the $4 \mathrm{Kg}$ of bone char can be employed 


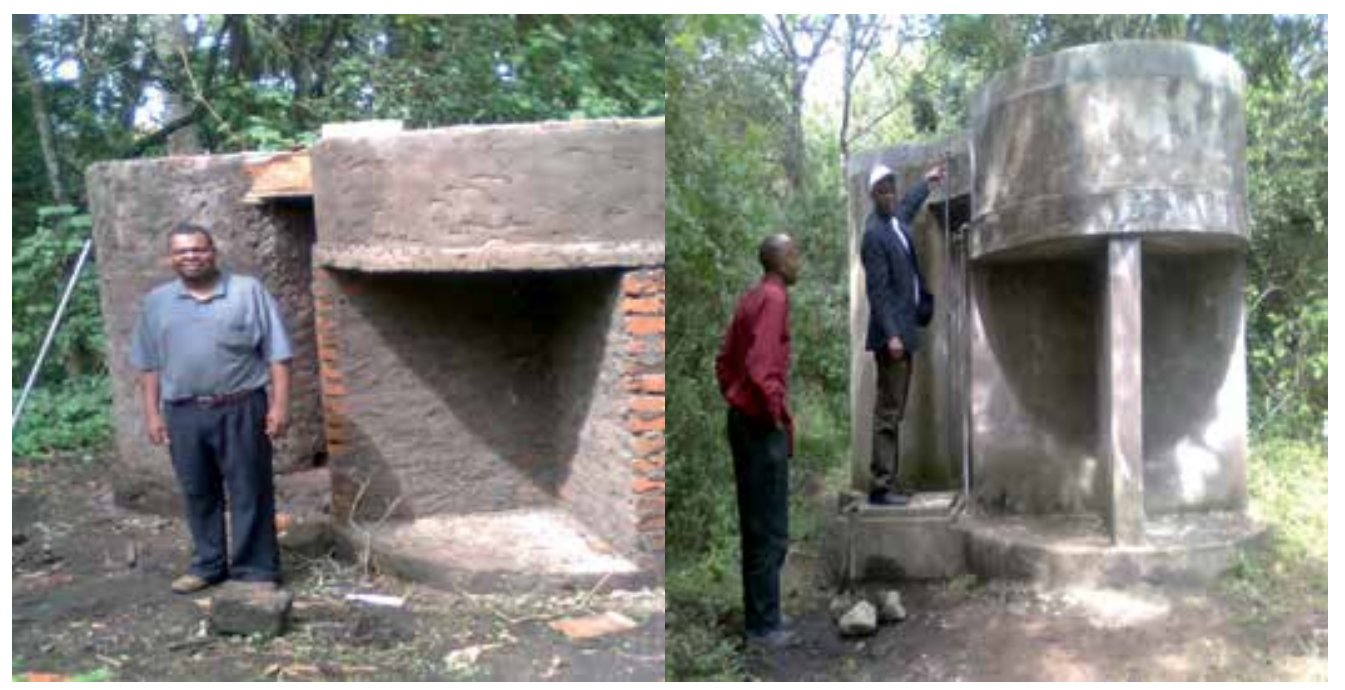

Figure 13. Incomplete and completed community defluoridation unit designed by Ngurdoto Defluoridation research station

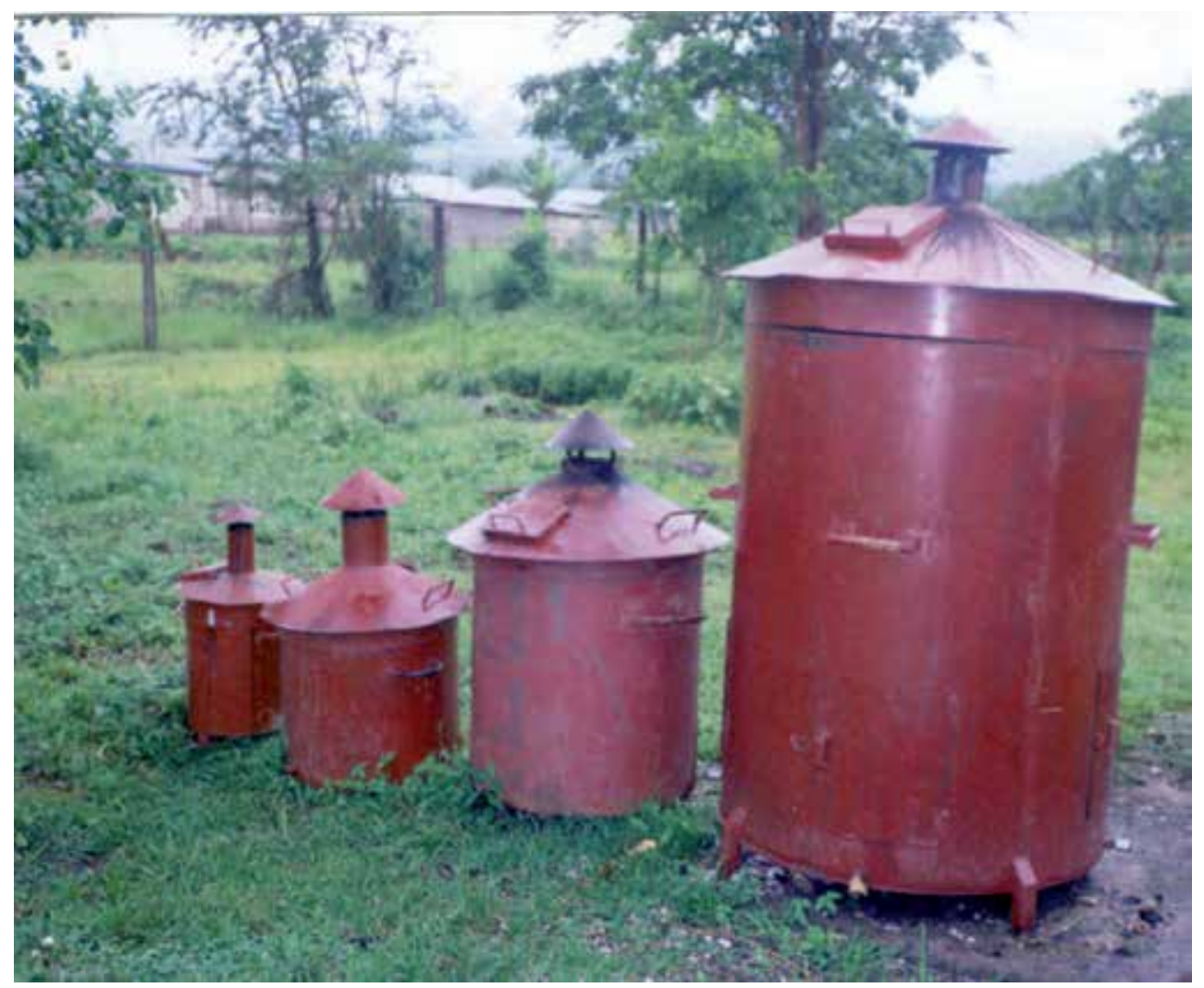

Figure 14. Different sizes of bone charring kilns as developed at the Ngurdoto Defluoridation Research Station 
to treat water for sixty five days family use. This approximates to 20 to $25 \mathrm{~kg}$ of bone char in a year for a family.

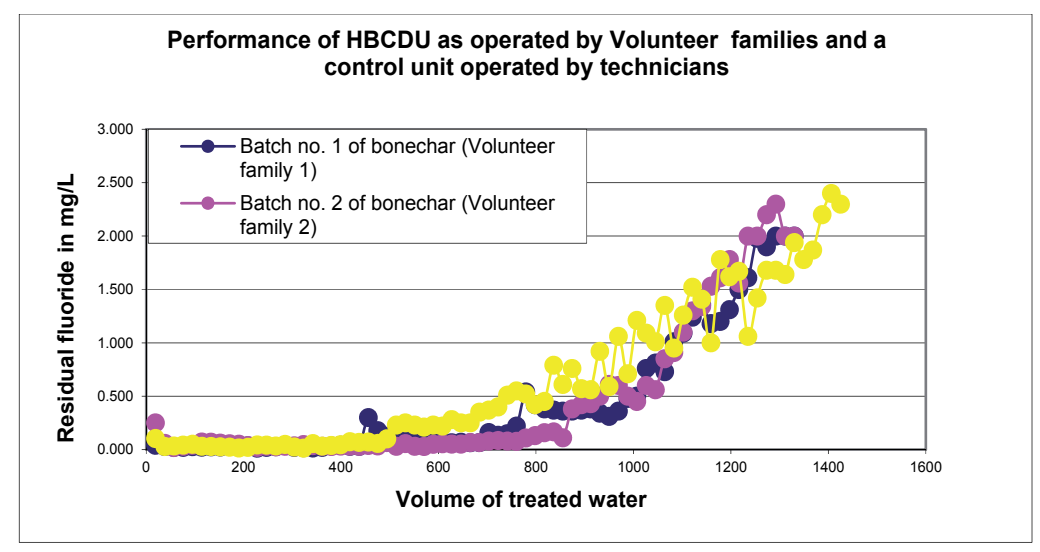

Figure 15. Plot of residual fluoride against volume of treated water for household column units (obtained from Ngurdoto research station development report, 2010)

Investigations have shown that the higher the initial fluoride concentration the higher the bone char exhaustion rate and the smaller amount of bone char the faster the exhausted rate. Fixed bed defluoridation had better performance compared to defluoridation in batch.

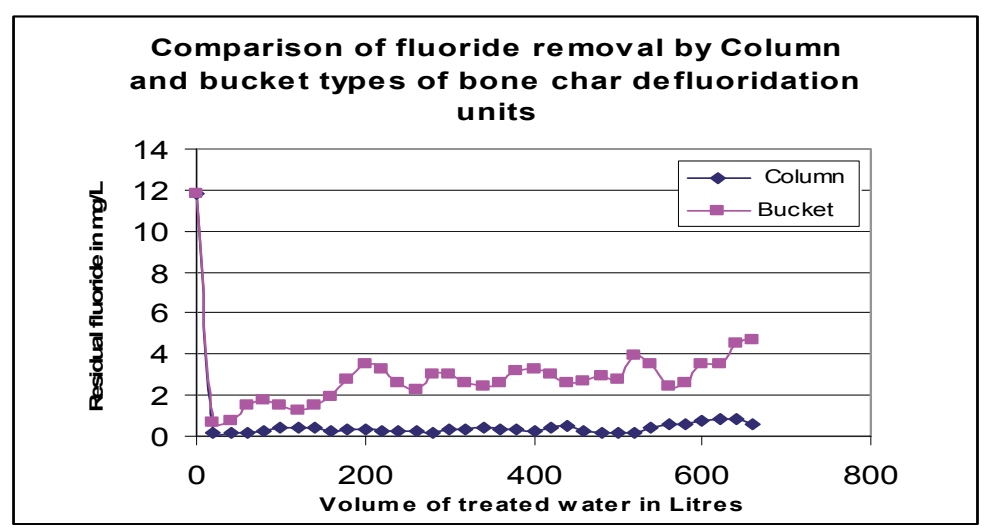

Figure 16. Residual fluoride obtained in column and bucket defluoridation.

\subsection{Water defluoridation research in Malawi}

Water defluoridation research in Malawi has been tested with bauxite, gypsum, clay, synthetic and natural hydroxyapatite (HAP) [5, 13, 14]. Gypsum was obtained from Mponela, in Dowa Diastrict of Malawi. Bauxite was obtained from Mulanje Mountain in Mulanje, Malawi and 
natural hydroxyapatite was obtained from Phalombe District, Malawi. Clay was obtained from Namadzi, Chiradzulu District of Malawi. The materials were calcined at various temperatures, within range 200 to $600{ }^{\circ} \mathrm{C}$, for two hours. Bauxite obtained highest sorption capacity $(3.05 \mathrm{mg} /$ g) when calcined at $200{ }^{\circ} \mathrm{C}$. Gypsum obtained highest capacity, $2.17 \mathrm{mg} / \mathrm{g}$, when calcined at $400{ }^{\circ} \mathrm{C}$. Clay obtained highest capacity, $2.15 \mathrm{mg} / \mathrm{g}$, when calcined at $300{ }^{\circ} \mathrm{C}$. Synthetic hydroxyapatite had a fluoride sorption of $1.70 \mathrm{mg} / \mathrm{g}$. Preparation of synthetic hydroxyapatite involved controlled addition of $98 \% \mathrm{H}_{3} \mathrm{PO}_{4}$ in an aqueous suspension of $\mathrm{CaO}$ with periodic additions of $50 \%$ aqueous ammonia. This was followed with decanting the supernatant and then drying the remaining precipitate at $60^{\circ} \mathrm{C}$ overnight. The product was then sintered at $1100{ }^{\circ} \mathrm{C}$ [49]. The synthetic hydroxyapatite was thus not calcined to various temperatures because its preparation involved high temperature. The natural hydroxyapatite introduced more fluoride in the water with residual fluoride increasing from $8.0 \mathrm{mg} / \mathrm{l}$ to $9.65 \mathrm{mg} / \mathrm{l}$. X-Ray Diffraction (XRD) characterisation showed the material composition were as shown in Table 8.

\begin{tabular}{cc}
\hline Raw material & Major compound composition as per JCPDS [50] \\
\hline Bauxite & $\mathrm{Al}_{2} \mathrm{Si}_{2} \mathrm{O}_{5}(\mathrm{OH})_{4}$ \\
\hline Gypsum & $\mathrm{CaSO}_{4} \cdot 2 \mathrm{H}_{2} \mathrm{O}$ \\
\hline Clay & \\
\hline Synthetic HAP & $\mathrm{Ca}_{5}\left(\mathrm{PO}_{4}\right)_{3} \mathrm{OH}$ \\
\hline Natural HAP & $\mathrm{Ca}_{5}\left(\mathrm{PO}_{4}\right)_{2} \mathrm{CO}_{3}(\mathrm{OH}) \mathrm{F}_{,} \mathrm{Ca}_{5} \mathrm{Al}_{2}(\mathrm{OH})_{4} \mathrm{Si}_{3} \mathrm{O}_{12} \mathrm{Ca}_{5}\left(\mathrm{PO}_{4}\right)_{3} \mathrm{~F}$ \\
\hline
\end{tabular}

Table 8. Major compounds in bauxite, gypsum, clay, synthetic and natural HAP tried in Malawi

The natural HAP contained fluoride that explained why it acted as a fluoridating agent. The research also showed that initial quality of the raw water impacts on the defluoridation capacity of the materials tested. Higher initial concentrations of carbonates and chlorides reduced fluoride sorption whereas high initial concentrations of calcium enhanced the sorption in defluoridation with bauxite. In defluoridation with gypsum the higher the initial concentrations of carbonate, nitrate and chloride ions the lower was the sorption of fluoride. Phosphate and chloride interfered with fluoride sorption in defluoridation with synthetic hydroxyapatite.

\section{Overview of defluoridation technologies}

Table 9 illustrates typical defluoridation outcomes and limitations when different materials are employed. The principals involved in the technologies are briefly outlined in the table to summarise the defluoridation techniques that have been widely demonstrated. 


\begin{tabular}{|c|c|c|c|c|}
\hline $\begin{array}{c}\text { Technology/ } \\
\text { Material }\end{array}$ & $\begin{array}{c}\text { Typical capacities } \\
\text { (mg/g) }\end{array}$ & The science & Strengths & Limitations \\
\hline Activated alumina & $3.5-10.0$ & $\begin{array}{l}\text { Precipitations involving } \\
\mathrm{Al}_{2} \mathrm{O}_{3} \text { and in } \mathrm{F}^{-} \text {ions water }\end{array}$ & $\begin{array}{l}\text { High selectivity for } \\
\text { fluoride }\end{array}$ & $\begin{array}{l}\text { lowers } \mathrm{pH} \text { of water, } \\
\text { residual } A^{3+}\end{array}$ \\
\hline Nalgonda & $0.7-3.7$ & $\begin{array}{c}\text { Reactions of Alum, } \\
\mathrm{Al}_{2}\left(\mathrm{SO}_{4}\right)_{3} \text { and lime }(\mathrm{CaO})\end{array}$ & $\begin{array}{c}\text { Same chemicals used for } \\
\text { ordinary water } \\
\text { treatment }\end{array}$ & $\begin{array}{l}\text { High chemical dose, } \\
\text { high sludge disposal } \\
\text { required }\end{array}$ \\
\hline Bone char & $2.3-4.7$ & $\begin{array}{c}\text { Filtration and ion } \\
\text { exchange in } \mathrm{Ca}_{5}(\mathrm{PO} 4)_{3} \mathrm{OH} \\
\text { structure }\end{array}$ & $\begin{array}{c}\text { Availability of raw } \\
\text { materials }\end{array}$ & $\begin{array}{l}\text { Not universally } \\
\text { acceptable }\end{array}$ \\
\hline Bauxite & $3.0-8.9$ & $\begin{array}{l}\text { Precipitations involving } \\
\mathrm{Al}_{2} \mathrm{O}_{3} \text { and } \mathrm{F}^{-} \text {and other } \\
\text { oxides e.g. } \mathrm{Fe}_{2} \mathrm{O}_{3} \text { ions } \\
\text { water }\end{array}$ & $\begin{array}{c}\text { Available locally in some } \\
\text { areas. High capacity }\end{array}$ & $\begin{array}{l}\text { Residual colour and } \\
\text { turbidity in treated } \\
\text { water if used raw }\end{array}$ \\
\hline Gypsum & $1.1-6.8$ & $\begin{array}{l}\text { lon exchange involving } \\
\mathrm{CaSO}_{4} \text { and } \mathrm{F}^{-} \text {and other } \\
\text { compounds e.g. } \mathrm{Ca}(\mathrm{OH})_{2}\end{array}$ & $\begin{array}{l}\text { Locally available in some } \\
\text { areas }\end{array}$ & $\begin{array}{l}\text { High Residual Calcium } \\
\text { sulphate }\end{array}$ \\
\hline Magnesite & $1.0-3.7$ & $\begin{array}{c}\text { Ion exchange and } \\
\text { precipitation involving } \\
\mathrm{MgOand} F^{-} \text {and other } \\
\text { compounds e.g. } \mathrm{Mg}(\mathrm{OH})_{2}\end{array}$ & $\begin{array}{l}\text { Simple technique, locally } \\
\text { available in some areas }\end{array}$ & $\begin{array}{l}\text { High } \mathrm{pH} \& \text { residual } \\
\text { Mg. }\end{array}$ \\
\hline HAP & $0.5-2.9$ & $\begin{array}{c}\text { Ion exchange and } \\
\text { precipitation involving } \\
\mathrm{Ca}_{5}\left(\mathrm{PO}_{4}\right)_{3} \mathrm{OH} \text { and } F^{-} \text {and } \\
\text { other compounds e.g. } \\
\mathrm{Ca} \mathrm{a}_{5} \mathrm{H}\left(\mathrm{PO}_{4}\right)_{3}(\mathrm{OH})_{2}\end{array}$ & $\begin{array}{c}\text { Naturally available in } \\
\text { some areas }\end{array}$ & Residual Phosphate \\
\hline $\begin{array}{l}\text { Bauxite, gypsum, } \\
\text { magnesite } \\
\text { composite }\end{array}$ & $4.2-11.3$ & $\begin{array}{l}\text { ion exchange and } \\
\text { precipitation in reactions } \\
\text { of } \\
\mathrm{Al}_{2} \mathrm{O}_{3}, \mathrm{CaSO}_{4}, \mathrm{MgCO}_{3}, \mathrm{MgC}\end{array}$ & $\begin{array}{l}\text { Simple and versatile. } \\
\text { Better than use of each } \\
\text { of the materials }\end{array}$ & $\begin{array}{c}\text { Energy intensive, fairly } \\
\text { novel technique. }\end{array}$ \\
\hline Zeolites & $28-41$ & $\begin{array}{l}\text { ion exchange and surface } \\
\text { complexation reactions }\end{array}$ & High capacity & Limited availability \\
\hline $\begin{array}{l}\text { Other advanced } \\
\text { techniques }\end{array}$ & High & $\begin{array}{l}\text { Nano-filtration, Reverse } \\
\text { osmosis, distillation, } \\
\text { precipitation, electrolysis }\end{array}$ & Very high capacities & $\begin{array}{l}\text { High cost. Need for } \\
\text { special training }\end{array}$ \\
\hline
\end{tabular}

Table 9. 


\section{Chapter conclusion}

There is a wide range of defluoridation techniques and materials to employ when fluoride levels in potable water are likely to result in fluorosis. However the decision on limits of fluoride concentrations in potable water for any region must be guided by average annual daily temperatures, dietary habits, nature and levels of activities in the particular area. Choice of technology will depend on appropriateness where factors such as availability of materials, cost, level of defluoridation required and technical complexity need to be considered. In East and Southern Africa naturally occurring materials such as bone, limestone $\left(\mathrm{CaCO}_{3}\right)$, alum $\left(\mathrm{Al}_{2} \mathrm{SO}_{4}\right)$, bauxite, gypsum, magnesite, and such other available materials with fluoride affinity, may be given priority when selecting raw materials for treatment and use in water defluoridation. Adoption and/or adaptation of existing technologies require some research at local level because communities differ in socio, economic, religious and traditional status and norms. A basic level of research is therefore paramount to establish appropriateness of a preselected technology to ascertain sustainability of the intervention.

\section{Acknowledgements}

The author acknowledges the International Programme in Chemical Sciences (IPICS) for supporting his research in Malawi (2002 - 2005), Malawi Government for financing his research in Tanzania (2009 - 2013) The Universities of Malawi and Dar es Salaam, and the Ngurdoto Defluoridation Research Station for guidance, material, technical and moral support rendered.

\section{Author details}

Bernard Thole

Physics and Biochemical Sciences Department, Polytechnic, Blantyre, University of Malawi, Malawi

\section{References}

[1] Ansari M, Kazemipour M, Dehghani M, Kazemipour M. The defluoridation of drinking water using multi-walled carbon nanotubes. Journal of Fluorine Chemistry 2011; DOI: 10.1016/j.jfluchem.2011.05.008.

[2] Thole B. Defluoridation kinetics of $200{ }^{\circ} \mathrm{C}$ calcined bauxite, gypsum, and magnesite and breakthrough characteristics of their composite filter. Journal of Fluorine Chemistry $2011 ; 132,529-535$. 
[3] J. Fawell, K. Bailey, J. Chilton, E. Dahi, L. Fewtrell L, Magara Y., editors. Fluoride in Drinking-water. World Health Organization. London: IWA Publishing; 2006.

[4] Sajidu SM, Masumbu FFF, Fabiano E. Ngongondo C. Drinking water quality and identification of fluoritic areas in Machinga, Malawi. Malawi Journal of Science and Technology 2007; 8, 042- 056.

[5] Msonda KWM, Masamba WRL, Fabiano E. A study of fluoride ground water occurrence in Nathenje, Lilongwe, Malawi. Physics and Chemistry of the Earth, Parts A/B/C 2007; 32 (15 - 18) $1178-1184$.

[6] Grobler SR, Louw AJ, van Kotze TJ. Dental fluorosis and caries experience in relation to three different drinking water fluoride levels in South Africa. International Journal of Paediatric Dentistry 2001; 11 (5) 372-379.

[7] Mjengera H, Mkongo G. Appropriate defluoridation technology for use in fluoritic areas in Tanzania. Physics and Chemistry of the Earth 2003; 28, 1097-1104.

[8] Williamson, MM. Endemic dental fluorosis in Kenya a preliminary report. The East African Medical Journal 1953; 30 (6) 217-233.

[9] Dean HT, Dixon RM, Cohen C. Mottled enamel in Texas. Public Health Reports 1935; 50 (13) 424-442.

[10] United States Public Health Services. PHS Review of Fluoride: Benefits and Risks: Report of Ad Hoc Subcommittee on Fluoride. Committee to Co-ordinate Environmental Health and Related Programs 1991; US Public Health Service.

[11] Brunt R, Vasak L, Griffioen J. Fluoride in groundwater: Probability of occurrence of excessive concentration on global scale. Report SP 2004-2 2004; International Groundwater Resources Assessment Centre (IGRAC).

[12] Nair KR, Manji F. Endemic fluorosis in deciduous dentition - A study of 1276 children in typically high fluoride area (Kiambu) in Kenya. Odonto-Stomatologie Tropicale 1982; 4, 177-184.

[13] Sajidu SMI, Masamba WRL, Thole B, Mwatseteza JF. Ground water fluoride levels in villages of Southern Malawi and removal studies using bauxite. International Journal of Physical Sciences 2008; 3, $001-011$.

[14] Thole B. Water defluoridation with Malawi bauxite, gypsum and synthetic hydroxyapatite, bone and clay: Effects of $\mathrm{pH}$, temperature, sulphate, chloride, phosphate, nitrate, carbonate, sodium, potassium and calcium ions. MSc thesis. University of Malawi; 2005.

[15] Masamba WRL, Sajidu SM, Thole B, Mwatseteza JF. Water defluoridation using Malawi's locally sourced gypsum. Physics and Chemistry of the Earth 2005; 30, 846-849.

[16] ] Carter GS, Bennet JD. The Geology and Mineral Resources of Malawi. Zomba: Government print; 1973. 
[17] Chikte UM, Louw AJ, Stander I. Perceptions of fluorosis in Northern Cape communities. Journal of the South African Dental Association 2001; 56 (11) 528-532.

[18] McCaffrey LP, Willis JP. Distribution and origin of fluoride in rural drinking water supplies in the Western Bushveld Areas of South Africa. In: 4th International Symposium on Environmental Geochemistry 1997, 62; 1997.

[19] Mauguhan-Brown H. Our Land. Is our population satisfactory? The results of inspection of school ages. South African Medical Journal 1935; 9, 822.

[20] Shrivastava KB, Vani A. Comparative Study of Defluoridation Technologies in India. Asian Journal of Experimental Science 2009; 23 (1) 269-274.

[21] Wang Y, Reardon EJ. Activation and regeneration of a soil sorbent for defluoridation of drinking water. Applied Geochemistry 2001; 16, 531-539.

[22] Singh R, Maheshwari RC. Defluoridation of drinking water - a review. Indian Journal Environmental Protection 2001; 21 (11) 983-991.

[23] Raichur AM, Basu MJ. Adsorption of fluoride onto mixed rare earth oxides. Separation and Purification Technology 2001; 24, 121-127.

[24] Bulusu KR, Pathak BN. Discussion on water defluoridation with activated alumina. Journal of Environmental Engineering Division 1980; 106 (2) 466-469.

[25] George S, Pandit P, Gupta AB. Residual aluminium in water defluoridated using activated alumina adsorption-modeling and simulation studies. Water Research 2010; 44, (10) 3055-3064.

[26] Ong ST, Keng PS, Lee SL, Leong MH, Hung YT. Equilibrium studies for the removal of basic dye by sunflower seed husk (Helianthus annuus). International Journal of the Physical Sciences 2010: 5, (8) 1270-1276.

[27] Ko DCK, Lee VCK, John F, Porter JF, McKay G. Improved design and optimization models for the fixed bed adsorption of acid dye and zinc ions from effluents. Journal of Chemical Technology and Biotechnology 2002; 77, 1289-1295.

[28] Meenakshi R, Maheshwari C. Fluoride in drinking water and its removal. Journal of Hazardous Materials 2006; B137, 456 - 463.

[29] Lee VKC, Porter JF, Mckay G. Modified design model for the adsorption of dye onto peat. Institution of Chemical Engineers Part C - Food and Bioproducts Processing 2001; 79 (C1) 21-26.

[30] McKay G, Bino MJ. Adsorption of pollutions onto activated carbon in fixed beds. Water Air Soil Pollution 1990; 51, 33-41.

[31] Castillo NAM, Ramos RL, Perez RO., Garcia de la Cruz RF, Aragon-Piñ a A, Martinez-Rosales JM, Guerrero-Coronado RM, Fuentes-Rubio L. Adsorption of Fluoride 
from Water Solution on Bone Char. Industrial Engineering Chemistry Research 2007; 46, 9205-9212.

[32] Bregnhøj H, Dahi E, Jensen M. Modeling defluoridation of water in bone char columns. In: Proceedings of the First International Workshop on Fluorosis and Defluoridation of Water 18-22 October 1995, Tanzania, The International Society for Fluoride Research, Auckland 1997.

[33] Dahi E. Contact precipitation for defluoridation of water. Paper presented at $22^{\text {nd }}$ WEDC Conference, New Delhi, 9-13 September, WEDC 1996.

[34] Dahi E. Small community plants for low cost defluoridation of water by contact precipitation. In: Proceedings of the 2nd International Workshop on Fluorosis and Defluoridation of Water. Nazareth, 19-22 November 1997, The International Society for Fluoride Research, Auckland 1998.

[35] US EPA. Water Treatment Technology Feasibility Support Document for Chemical contaminants. EPA-815-R-03-004, EPA 2003.

[36] Dysart A. Investigation of Defluoridation Options for Rural and Remote Communities. Research Report No 41, The Cooperative Research Centre for Water Quality and Treatment, Salisbury SA 5108, AUSTRALIA 2008.

[37] Zakia A, Bernard B, Nabil M, Mohamed T, Stephan N, Azzedine E. Fluoride removal from brackish water by electrodialysis. Desalination 2001; 133, 215 - 233.

[38] Giesen A. Fluoride removal at low costs. European Semiconductor 1998; 20 (4) 103-105.

[39] Hanemaaijer JH, van Medevoort J, Jansen A, van Sonsbeek E, Hylkema H, Biemans R., Nelemans B, Stikker A. Memstill Membrane Distillation: A near future technology for sea water desalination, Paper presented at the International Desalination Conference, June 2007, Aruba.

[40] Aqua-Aero WaterSystems WaterPyramid 2007. http://www.waterpyramid.nl (accessed 21 August 2011).

[41] Solar Dew The Solar Dew Collector Sytem 2007. http://www.solardew.com/ index2.html (Accessed 26 July 2011).

[42] Larsen MJ, Pearce EIF. Defluoridation of Drinking Water by Boiling with Brushite and Calcite. Caries Research 2002; 36, 341-346.

[43] Melisa J. Defluoridation of drinking water by adsorption of fishbone. MSc thesis. University of Dar es Salaaam, Tanzania 2001.

[44] Bablia K. Studies of water defluoridation using activated carbons and activated carbons loaded separately with Magnesia, Alumina and Calcium. MSc Thesis. Univesrity of Dar es Salaam, Tanzania 1996. 
[45] Singano JJ. Investigation of the mechanisms of defluoridation of drinking water using locally available magnesite. PhD thesis. University of Dar es Salaam, Tanzania 2000.

[46] Thole B, Mtalo FW, Masamba WRL. Effect of particle size on loading capacity and water quality in water defluoridation with $200^{\circ} \mathrm{C}$ calcined bauxite, gypsum, magnesite and their composite filter. African Journal of Pure and Applied Chemistry 2012; 6 (2) 26-34.

[47] Thole B, Mtalo FW, Masamba WRL. Water Defluoridation with $150-300{ }^{\circ} \mathrm{C}$ Calcined Bauxite-Gypsum-Magnesite Composite (B-G-Mc) filters. Water Resources Management VI, Wit Transactions on Ecology and Environment. 2011; 145, 383 - 393.

[48] WHO. Guidelines for Drinking-water Quality, $4^{\text {th }}$ Ed., World Health Organisation: Geneva; 2011.

[49] Rahman FF, Bonfield W, Cameron RE, Patel MP. Water uptake of polyethylmethacrylate/tetrahydrofuryl metacrylate polymer systems modified with tricalcium phosphate and hydroxyapatite. Royal London School of Medicine and Dentistry, Queen Mary, University of London: London; 1997.

[50] Joint Committee on Powder Diffraction Standards (JCPDS). International Centre for Diffraction Data: Japan; 1997. 

Chapter 5

\title{
Monitoring of Water Quality Parameters in Upper and Lower Reaches of Dudhganga Catchment, India
}

\author{
Mohd lqbal, Haroon Sajjad, F.A. B hat and \\ Imran Ahmad \\ Additional information is available at the end of the chapter \\ http://dx.doi.org/10.5772/52846
}

\section{Introduction}

Water is extremely essential for survival of all living organisms. The quality of water is vital concern for mankind since it is directly linked with human welfare. In India, most of the population is dependent on surface water (damp water) as the only source of drinking water supply. The groundwater is believed to be comparatively much clean and free from pollution than surface water. But prolonged discharge of industrial effluents, domestic sewage and solid waste dump causes the groundwater to become polluted and created health problems [1]. The problems of surface water quality are much more acute in the areas which are densely populated. The rapid growth of urban areas has further affected groundwater quality due to overexploitation of resources and improper waste disposal practices. Hence, there is always a need for and concern over the protection and management of surface water and groundwater quality. [2, 3, 4] Considering the above aspects of water contamination, the present study was undertaken to investigate the possible impact of the surface water quality. In Kashmir, most of the population is dependent on surface water as the only source of drinking water supply Thus, in this paper an attempt has been made to assess the physical and chemical properties of surface water of the Dudhganga stream of Dudhganga watershed, Kashmir valley, India.

Dudhganga watershed of Jammu and Kashmir (Figure 1) is located in the northern part of India between $34^{\circ} 42^{\prime}$ to $34^{\circ} 50^{\prime} \mathrm{N}$ and $74^{\circ} 24^{\prime}$ to $74^{0} 54^{\prime} \mathrm{E}$, covers an area of $660 \mathrm{~km}^{2}$. The area supports a varied topography exhibiting altitudinal extremes of 1610 to $4700 \mathrm{~m}$ above mean sea level. From southwest to northeast, the area consists of the lofty Pir-Panjal, and flat-topped karewas as foothills and plains. The Pir-Panjal mountain range covers the Kashmir valley on the south and southwest, separating it from the Jammu region. The soils in the area 
are generally loamy soil, karewa soil and poorly developed mountain soil [5]. Drainage of the area is quite significant with most of the drainage flowing into river Jhelum. Dudhganga is the important tributaries of river Jhelum which originates near Tatakuti Mountain. The literature survey reveals that no water quality management studies are made in this region so far. Hence the present study was planned and undertaken

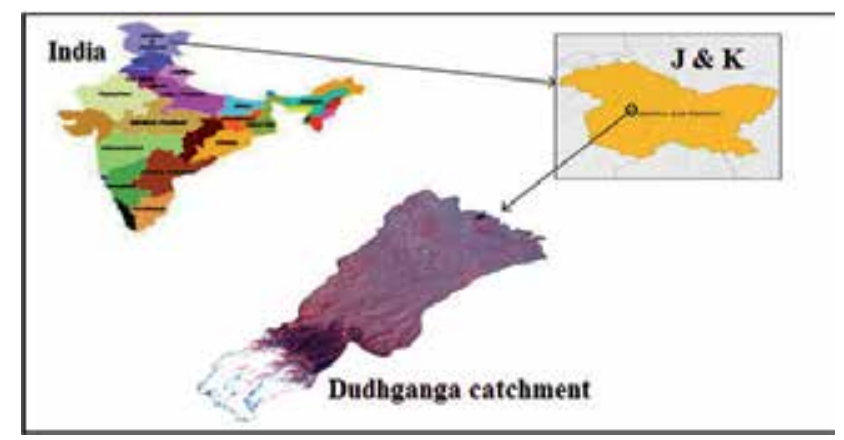

Figure 1. Geographical location of Dudhganga Catchment, India

\section{Method and materials}

The present study was planned and undertaken at following sampling locations.

\begin{tabular}{cccc}
\hline Station No. & Station Name & Latitude and Longitude in degrees & Altitude (meters) \\
\hline S1(Forest Area) & Branware & $33^{\circ} 50^{\prime} 37.3^{\prime \prime} \mathrm{N} 74^{\circ} 39^{\prime} 21.3^{\prime \prime} \mathrm{E}$ & 2278 \\
\hline S2(Urban Centre) & Barzulla Baghat & $34^{\circ} 03^{\prime} 00.0^{\prime \prime} \mathrm{N} 74^{\circ} 48^{\prime} 00.6^{\prime \prime} \mathrm{E}$ & 1605 \\
\hline
\end{tabular}

Table 1. Sampling locations

\subsection{Preparation of water samples}

The sample were collected from all the stations at $09.00 \mathrm{am}$ to $11.00 \mathrm{am}$ for physico-chemical examinations, different methods of collection and handling were adopted based the standard procedures [6]. Water samples were collected carefully in a glass stoppered sterilized container (Volume approx. $1000 \mathrm{ml}$ ) at a depth of $15 \mathrm{~cm}$ without any air bubbles. The instruments were used of accuracy. The $\mathrm{pH}$ of two locations were checked on spot. The instruments used for the $\mathrm{pH}$ was portable $\mathrm{pH}$ meter. Water samples from two sampling sites were collected during May to July months (2011).

\subsection{Physicochemical analysis}

Analysis was carried out for various water quality parameters such as $\mathrm{pH}$, electrical conductivity (EC), dissolved oxygen (DO), free carbon dioxide, total alkalinity (TA), total hardness 
(TH), calcium hardness, calcium content, chloride $\left(\mathrm{Cl}^{-}\right)$, nitrate, nitrite, sulphate, phosphate, Ortho Phosphate Silicates, and TDS and ammonia using standard method [7,8].

\subsection{Statistical analysis}

The simple linear correlation analysis has been carried out to find out correlation between two sampling sites (Branware and Barzulla Baghat) using SPSS.

\section{Results and discussion}

The average results of the physicochemical parameters for water samples are presented in Table 2. and the deterioration of water quality is shown in (figure 2).

\section{1. $\mathrm{pH}$}

$\mathrm{pH}$ is a term used universally to express the intensity of the acid or alkaline condition of a solution. Most of the waters are slightly alkaline due to presence of carbonates and bicarbonates. The $\mathrm{pH}$ values of water samples varied between 7.52 to 7.1 and were found

Within the limit prescribed by WHO.

\begin{tabular}{|c|c|c|c|c|}
\hline Parameters/Sites & $\begin{array}{c}\text { Branware } \\
\text { (Upper Reaches) }\end{array}$ & $\begin{array}{l}\text { Barzulla Baghat } \\
\text { (Lower Reaches) }\end{array}$ & Average & $\begin{array}{l}\text { Standard } \\
\text { Deviation }\end{array}$ \\
\hline $\mathrm{DO}$ mg/L (X1) & 12.25 & 5 & 8.625 & 5.127 \\
\hline $\mathrm{CO} 2 \mathrm{mg} / \mathrm{L}(\mathbf{X} 2)$ & 3.17 & 12.31 & 7.74 & 6.463 \\
\hline Nitrite $\mu \mathrm{g} / \mathrm{L}$ (X3) & 0.05 & 18.73 & 9.3888 & 13.21 \\
\hline Ammonia $\mu \mathrm{g} / \mathrm{L}$ (X4) & 7.0 & 400 & 203.85 & 278.4 \\
\hline Phosphate $\mu \mathrm{g} / \mathrm{L}$ (X5) & 62.37 & 155 & 108.69 & 65.5 \\
\hline $\mathrm{Cl} \cdot \mathrm{mg} / \mathrm{L}(\mathbf{X} 6)$ & 2.73 & 12.56 & 7.6488 & 6.946 \\
\hline $\mathrm{pH}(\mathbf{X 7})$ & 7.52 & 7.1 & 7.31 & 0.297 \\
\hline Total Hardness mg/L (X8) & 85.5 & 280 & 182.75 & 137.5 \\
\hline Ca. Hardness mg/L (X9) & 22.25 & 68.66 & 45.455 & 32.82 \\
\hline Ca. Content mg/L (X10) & 8.64 & 64.53 & 36.585 & 39.52 \\
\hline Alkalinity mg/L (X11) & 55.5 & 83.11 & 69.305 & 19.52 \\
\hline Conductivity ohm.cm (X12) & 37.25 & 300.23 & 168.74 & 186 \\
\hline Nitrate mg/L (X13) & 0.15 & 0.99 & 0.5721 & 0.588 \\
\hline Sulphate mg/L (X14) & 1.62 & 7.56 & 4.5925 & 4.197 \\
\hline Ortho Phosphate $\mu \mathrm{g} / \mathrm{L}$ (X15) & 32.375 & 120.25 & 76.313 & 62.14 \\
\hline Silicates mg/L (X16) & 1.75 & 4.625 & 3.1875 & 2.033 \\
\hline TDS mg/L (X17) & 22.35 & 180.138 & 101.23 & 111.6 \\
\hline
\end{tabular}

Table 2. Average results of the physicochemical parameters 


\subsection{Electrical conductivity}

Electrical conductivity is a measure of water capacity to convey electric current. It signifies the amount of total dissolved salts [9]. EC values were in the range of $37.25 \mathrm{ohm} . / \mathrm{cm}$ to $300.23 \mathrm{ohm} / \mathrm{cm}$ High EC values was observed at sampling station Barzulla Baghat indicating the presence of amount of dissolved inorganic substances in ionized form.

\subsection{Dissolved oxygen}

Dissolved oxygen is important parameter in water quality assessment and reflects the Physical and biological processes prevailing in the water. The DO values indicate the degree of pollution in water bodies. DO values varied from 5 to 12.25. The sampling point Barzulla Baghat showed low DO values indicating heavy contamination by organic matter.

\subsection{Free carbon dioxide}

The origin of free carbon dioxide is from air, algal respiration and organic breakdown. The Free Carbon Dioxide ranged from minimum of $3.17 \mathrm{mg} / \mathrm{L}$ to maximum of $12.31 \mathrm{mg} / \mathrm{L}$ at site1 and site 2 respectively. It indicates the presence of sewage at site 2 in the Dudhganga stream.

\subsection{Total alkalinity}

Alkalinity of water is its capacity to neutralize a strong acid and it is normally due to the presence of bicarbonate, carbonate and hydroxide compound of calcium, sodium and potassium. Total alkalinity values for all the investigated samples were found within the limits prescribed by WHO.

\subsection{Total hardness}

Hardness is the property of water which prevents the lather formation with soap and increases the boiling points of water [10]. Hardness of water mainly depends upon the amount of calcium or magnesium salts or both. The hardness values shown range from $85.5 \mathrm{mg} / \mathrm{L}$ to $280 \mathrm{mg} / \mathrm{L}$. All samples were found within the limits prescribed limits.

\subsection{Calcium hardness and calcium content}

Calcium is directly related to hardness. Calcium hardness ranged between $22.25 \mathrm{mg} / \mathrm{L}$ to $68.86 \mathrm{mg} / \mathrm{L}$ and Calcium content ranged from 8.64 to 64.53 found within permissible limit, prescribed by WHO.

\subsection{Chloride}

The chloride concentration serves as an indicator of pollution by sewage. In the present analysis, chloride concentration was found in the range of $2.73 \mathrm{mg} / \mathrm{L}$ to $12.56 \mathrm{mg} / \mathrm{L}$. The values are within the limits. The length of the river from Branware to Barzulla Baghat is small 
approximately 30 kilometers so an increase of even $5 \mathrm{mg} / \mathrm{l}$ at one station from another station may give rise to suspicions of a sewage discharge [11].

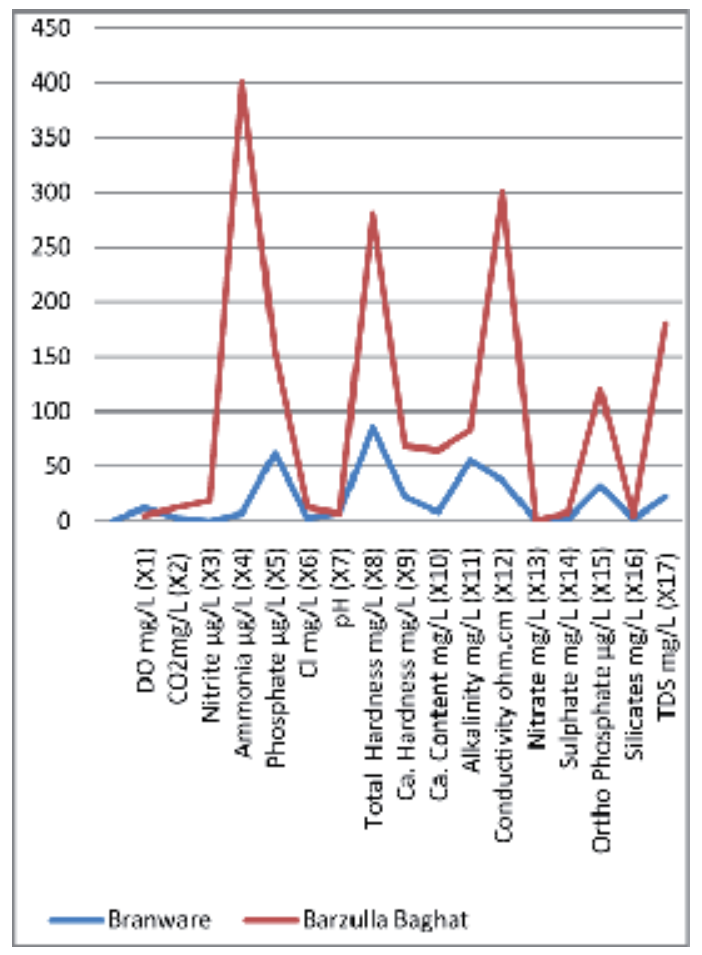

Figure 2. Water quality parameters

\subsection{Nitrite}

Nitrite exists normally in very low concentrations and even in waste treatment plant effluents levels are relatively low, principally because the nitrogen will tend to exist in the more reduced (ammonia; $\mathrm{NH}^{3}$ ) or more oxidized (nitrate; $\mathrm{NO}^{3}$ ) forms. Because nitrite is an intermediate in the oxidization of ammonia to nitrate, because such oxidation can proceed in soil, and because sewage is a rich source of ammonia nitrogen, waters which show any appreciable amounts of nitrite are regarded as being of highly questionable quality. Levels in unpolluted waters are normally low, below $0.03 \mathrm{mg} / \mathrm{l}$ Values greater than this may indicate sewage pollution [11]. In present study it ranges from $0.05 \mu \mathrm{g} / \mathrm{L}$ to $18.73 \mu \mathrm{g} / \mathrm{L}$.

\subsection{Nitrate}

Surface water contains nitrate due to leaching of nitrate with the percolating water. Surface water can also be contaminated by sewage and other wastes rich in nitrates The nitrate content in the study area varied in the range $0.15 \mathrm{mg} / \mathrm{L}$ to $0.99 \mathrm{mg} / \mathrm{L}$ and found within the prescribed limit. 


\subsection{Sulphate}

Sulphate occurs naturally in water as a result of leaching from gypsum and other common minerals [12]. Discharge of industrial wastes and domestic sewage tends to increase its concentration. The sulphate concentration varied between $1.62 \mathrm{mg} / \mathrm{L}$ and $7.56 \mathrm{mg} / \mathrm{L}$. and found within the prescribed limit.

\subsection{Phosphate}

Phosphate may occur in groundwater as a result of domestic sewage, detergents, agricultural effluents with fertilizers and industrial waste water. The phosphate content in the study area was found in the range of $62.37 \mu \mathrm{g} / \mathrm{L}$ to $155 \mu \mathrm{g} / \mathrm{L}$ and found within the prescribed limits.

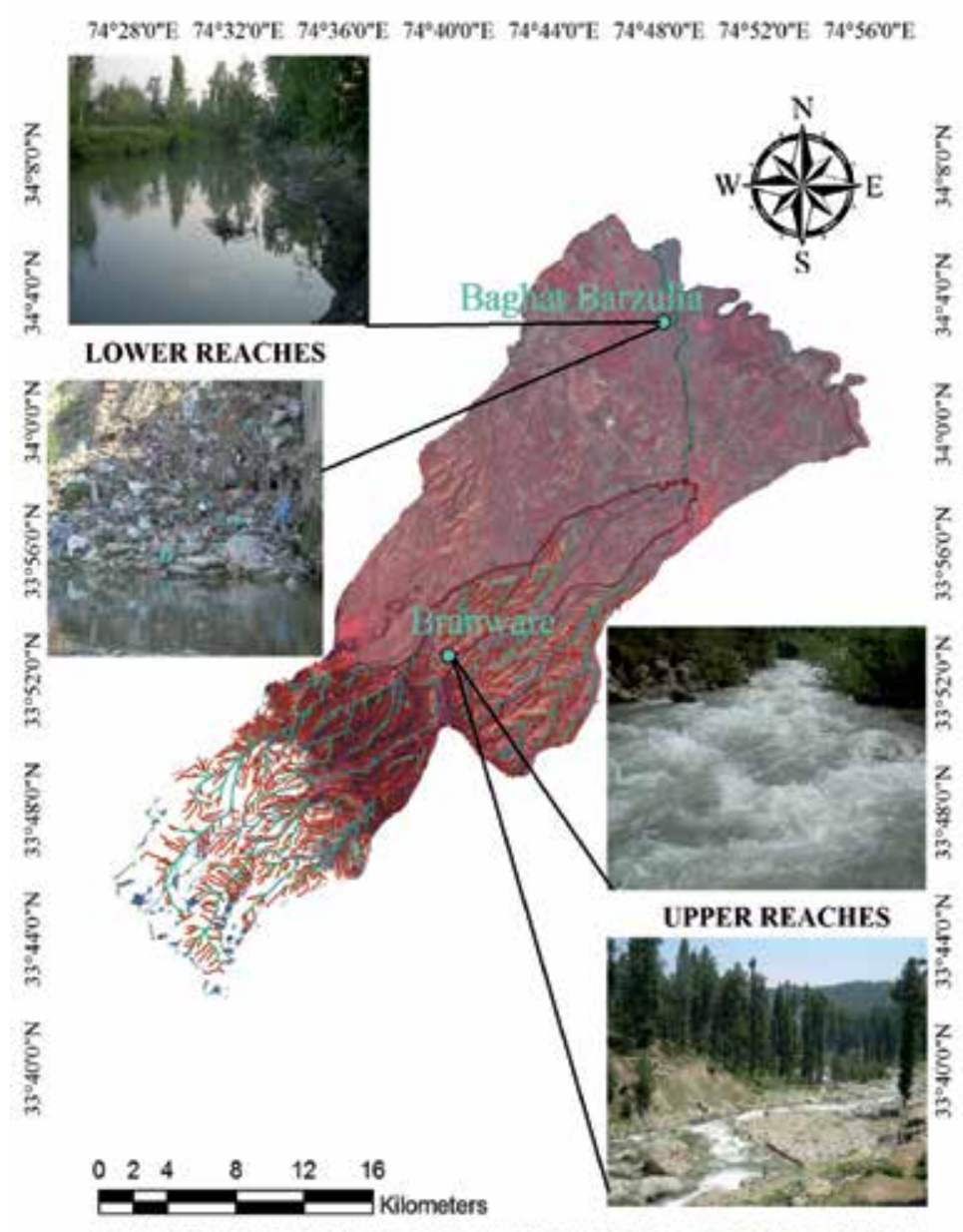

$74^{\circ} 28^{\circ} \mathrm{E} 74^{\circ} 32^{\circ} 0^{\circ \mathrm{E}} 74^{\circ} 36^{\circ} \mathrm{E}$. $74^{\circ} 40^{\circ} \mathrm{E}$. $74^{\circ} 44^{\circ} 0^{\circ \mathrm{E}} 74^{\circ} 480^{\circ} \mathrm{E} 74^{\circ} 52^{\circ} 0^{\circ} \mathrm{E} 74^{\circ} 560^{\circ} \mathrm{E}$

Figure 3. Shows sampling sites in upper and lower reaches of Dudhganga Catchment, India 


\subsection{Ammonia}

Ammonia is generally present in natural waters, though in very small amounts, as a result of microbiological activity which causes the reduction of nitrogen-containing compounds. When present in levels above $0.1 \mathrm{mg} / \mathrm{l} \mathrm{N}$, sewage or industrial contamination may be indicated [11]. In present study ammonia value ranges from $7 \mu \mathrm{g} / \mathrm{L}$ to $400 \mu \mathrm{g} / \mathrm{L}$ at site1 and site 2 respectively.

\subsection{Statistical analysis}

Interrelationship studies between two sampling sites are very helpful tools in promoting research and opening new frontiers of knowledge. The study of correlation reduces the range of uncertainty associated with decision making. The numerical values of correlation coefficient $(\mathrm{r})$ for two sites are tabulated in Table 3.

\begin{tabular}{cccc}
\hline & Correlations & & \\
\hline & & BRANWARE & BARZULLA BAGHAT \\
\hline \multirow{2}{*}{ BRANWARE } & Pearson Correlation & 1 & $.514^{*}$ \\
& Sig. (2-tailed) & 17 & .035 \\
BARZULLA BAGHAT & $\mathrm{N}$ & $.514^{*}$ & 17 \\
& Pearson Correlation & .035 & 17 \\
\hline *. Correlation is significant at the 0.05 level (2-tailed). & 17 & \\
\hline
\end{tabular}

Table 3. Correlation matrix of two sampling stations.

\section{Conclusion}

Dudhganga is fresh water stream of Kashmir valley; it has a length of almost $35 \mathrm{~km}^{2}$. All lotic water bodies have regenerating capacity then lentic water bodies because they are continuously flowing so little deviations in their water quality parameters are of great concern. Deviations were observed in water quality parameters from Site 1 to Site 2. As such no contamination of water is observed at Site S1 (Branware) because this region lies in upper catchment and having mostly forest as land cover. In upper catchment physicochemical parameters are within the water quality standards and the quality of water is good and it is fit for drinking purpose. But at last site S2 (Barzulla Baghat) which lies in the urban centre has the level of DO beyond the permissible limits and water has been contaminated by direct passage of sewage from households and it is unfit for drinking purpose. 


\section{Author details}

Mohd Iqbal $^{1 *}$, Haroon Sajjad ${ }^{1}$, F.A. B hat ${ }^{2}$ and Imran Ahmad ${ }^{3}$

*Address all correspondence to: iqbalbhat901@gmail.com

1 Department of Geography, Faculty of Natural Sciences, Jamia Millia Islamia, New Delhi, India

2 Department of Geology and Geophysics, University of Kashmir, India

3 Department of Industries and Earth Sciences, Tamil University, Thanjavur, India

\section{References}

[1] Raja R E, Lydia Sharmila, Princy Merlin, Chritopher G, Physico-Chemical Analysis of Some Groundwater Samples of Kotputli Town Jaipur, Rajasthan, Indian J Environ Prot., 22(2), 137, (2002).

[2] Patil P R, Badgujar S R. and Warke A. M. Evaluation of Ground Water Quality In Ganesh Colony Area Of Jalgaon City, Oriental J Chem., 17 (2), 283, (2001).

[3] Patil V T. and Patil P R. Physicochemical Analysis of Selected Groundwater Samples of Amalner Town in Jalgaon District, Maharashtra, India, E-Journal of Chem., 7(1), 111-116, (2010).

[4] Murhekar G H. Determination of Physico-Chemical parameters of Surface Water Samples in and around Akot City, Int. J. Res. Chem. Environ., 1(2), 183-187, (2011).

[5] Raza M, Ahmad A, and Mohammad A. (1978). The Valley of Kashmir: A Geographical Interpretation, (New Delhi: Vikas Publishing House, Pvt. Ltd).

[6] Standard Methods for the Examination of Water and Waste Water, 20th Ed., APHA, AWWA, WEF. Washington DC, (1998).

[7] Standard Methods for the examination of water and waste water, American Public Health Association, 17th Ed., Washington, DC, (1989).

[8] Manivaskam N., Physicochemical examination of water sewage and industrial effluent, 5th Ed. Pragati Prakashan Meerut., (2005).

[9] Sudhir Dahiya and Amarjeet Kaur, physic chemical characteristics of underground water in rural areas of Tosham subdivisions, Bhiwani district, Haryana, J. Environ Poll., 6 (4), 281, (1999).

[10] Trivedy R K. and Goel P K. Chemical and Biological methods for water pollution Studies, Environmental Publication, Karad. (1986). 
[11] Environmental Protection Agency, Parameters of Water Quality Interpretation and Standards, Johnstown Castle, Co. Wexford, Ireland. (2001).

[12] Shrinivasa R. B and Venkateswaralu P, Physicochemical Analysis of Selected Groundwater Samples, Indian J Environ Prot., 20 (3), 161, (2000). 


